\title{
HERBICIDAS NO CONTROLE DE PLANTAS INVASORAS EM PLANTIO DE Eucalyptus saligna Smith E NOS TEORES DE N, P, K, Ca E Mg NAS FOLHAS DAS PLANTAS.
}

\section{NELSON VENTORIM}

Prof. Dr. HELLADIO DO AMARAL MELLO ORIENTADOR

Tese apresentada à Escola Superior de Agricultura "Luiz de Queiroz", da Universidade de São Paulo, para obtenção do título de Doutor em Solos e Nutrição de Plantas.

PIRACICABA

Estado de São Paulo - Brasil 
.ii.

A esposa Lêda Aos filhos Régis \& Marcela. 


\section{AGRADECIMENTOS}

0 autor agradece ao professor Helládio do Amaral Mello, pela criteriọsa orientação no desenvolvimento deste trabalho.

Aos Engenheiros Agrônomos Fernando Mendes Pereira e Carlos Alberto Ferreira, pela colaboração na condução do experimento que originou o estudo presente.

Ao Engenheiro Agrônamo Paulo César Lima pela orientação na análise estatística a aos professores Maurício de Souza e Magno Antonio Pat to Ramalho pela ajuda na organização dos dados e revisão dos assuntos des critos.

Ao Professor Antonio Resende Soares pela assunção de todas as responsabilidades da disciplina de silvicultura da ESAL, durante o perío do de ausència do autor.

A Escola Superior de Agricultura de Lavras (ESAL) e ao Minis térió da Educação e Cultura pela licença concedida.

Ao Conselho Nacional de Desenvolvimento Tecnológico e Cientí fico (CNPq) pelo suporte Económico prestado ao autor.

A Escola Superior de Agricultura "Luiz de Queiroz" e à Universidade de São Paulo pelo patrocínio dos estudos de pós-graduação.

A Maria Elisabeth Ferreira de Carvalho, bibliotecária da ESALQ, pela revisão da Bibliografia.

A Sra. Șônia Novaes Rasera, pelo trabalho de datilografia.

A todas as pessoas físicas ou jurídicas que direta ou indire tamente colaboraram para a realização do presente trabalho. 


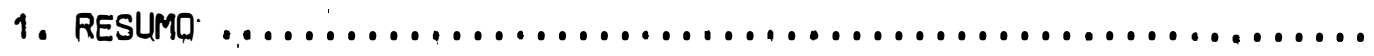

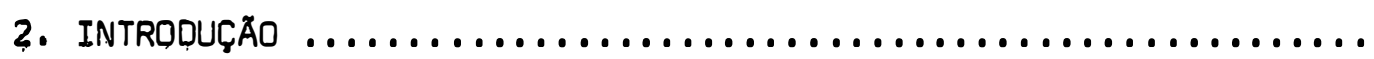

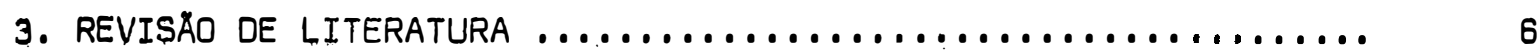

3,1. Plantas invasoras em cultiva florestal ,.............. 6

3.2. Herbicidas em florestas ........................ g

3.2.1. Uso de herbicidas em confferas ................. 11

3.2.2. Uso de herbicidas em fol hosas ................. 13

3.3. Herbicidas em culturas de Eucalyptus sp. ................ 14

3.4. Absorção de nutrientes em função de herbicidas .......... 15

3.5. Características dos herbicidas usados no experimento .... 17

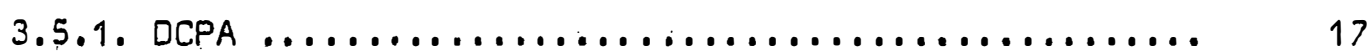

3.5.2. Oryzalin ............................ 18

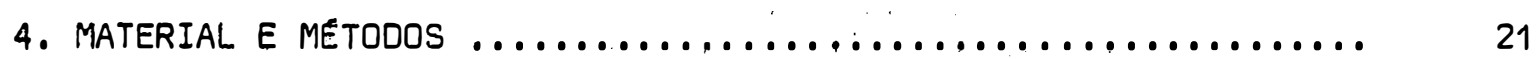

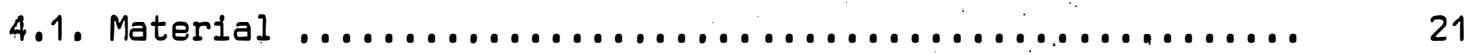

4.1.1. Localização do experimento .................. 21

4.1.2. Solo .................................. 21

4.1.3. Relevo $\ldots \ldots \ldots \ldots \ldots \ldots \ldots \ldots \ldots \ldots \ldots \ldots \ldots \ldots \ldots . . \ldots, 22$

$4.1,4$. Clima $\ldots \ldots \ldots \ldots \ldots \ldots \ldots \ldots \ldots \ldots \ldots \ldots \ldots \ldots \ldots \ldots ., 22$

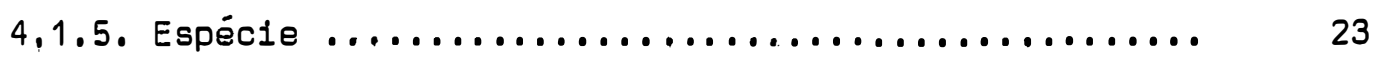

4.1.6. Herbicidas usados ....................... 23

4.1.7. Pulverizador ............................. 24

4.1.8. Condições ambientais na aplicação dos herbicidas . 24

4.2. Método ..................................... 24

4.2.1. Delineamento experimental ................... 24

4.2.2, Tratamentos .............................. 25

4.2.3. Instalação do experimento .................. 26

4.2.4. Avallações ............................. 27

4.2.4.1. Controle de plantas Invasoras .......... 27.

4.2.4.2. Crescimento Inicial do Eucalyptus saligna Smith ............................. 


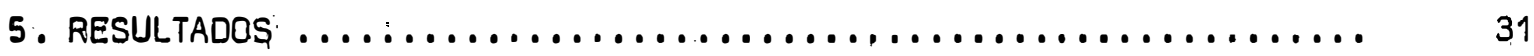

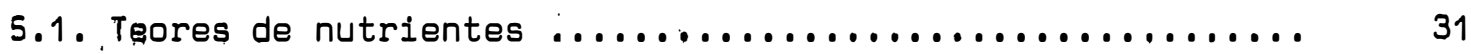

5.1.1. Teores de nutrientes aos 60 dias após plantio .... 31

5.1.2. Teores de nutrientes aos 120 dlas após plantio ... 34

5.1.3. Teores de nutrientes aos 180 dias após plantio ... 34

5.2. Fitotoxidade dos herbicidas ao Eucalyptus saligna Smith . 39

5.3. Plantas Invasoras ............................... 47

5.3.1. Contagem individual de plantas invasoras aos 30

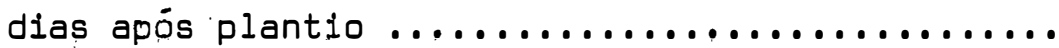

5.3.2. Avaliação visual de plantas invasoras aos 30 dias

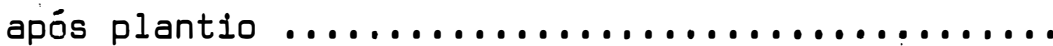

5.3.3. Avalíação visual de plantas invasoras e injúria aos 60 dias após plantio ....................

5.3.4. Reinfestação ...........................

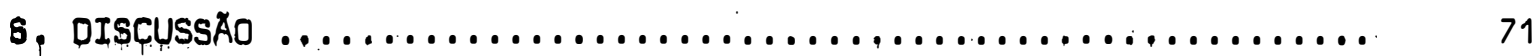

6.1. Teores de nutrientes ........................... 71

0.1.1. Teores de nutrientes aos 60 dias após plantio .... 71

6.1.2. Teores de nutrientes aos 120 dias após plantio ... 72

6.1.3. Teores de nutrientes aos 180 dias após plant1o ... 74

6.2. Fitotoxidade dos herbicidas ...................... 75

6.2.1. Diàmetro de copa e altura de plantas ............ 75

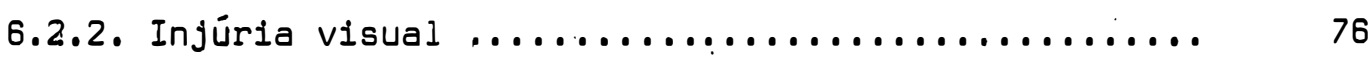

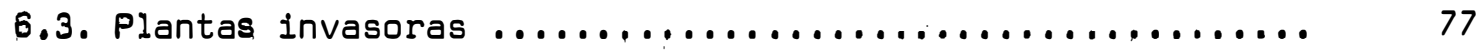

6.3.1. Contagem individual de plantas invasoras aos 30 días após plantio ....................... 77

6.3.2. Avaliação visual de plantas invasoras aos 30 dias

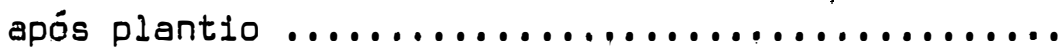

6.3.3. Avaliação visual de plantạ invasoras aos 60 días após plantio ............................ 
. vi.

pāgina

6.3.4. Reinfestação $\ldots \ldots \ldots \ldots \ldots \ldots \ldots \ldots \ldots \ldots \ldots$

7. CONCLUSOES

B. SUMMARY

9. LITERATURA CITADA $\ldots \ldots \ldots \ldots \ldots \ldots \ldots \ldots \ldots \ldots \ldots \ldots \ldots \ldots \ldots$ 
-vii.

\section{LISTA DE TABELAS}

Tabela

pāgina

1. Plantas invasoras encontras em cultura de Eucalyptus salig ua Smith, na área da ESALQ-Piracicaba, segundo VEIGA (1968)

2. Espécíes de plantas invasoras encontradas em ensaio na á-

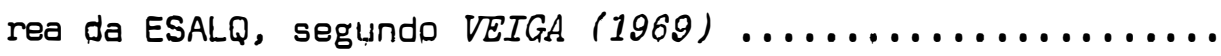

3. Características químicas do solo da área experimental ....

4. Características físicas do solo da área experimental .....

5. Características climáticas correspondentes ao perf́do expe rimental, de novembro a maio de 1975/76. Mogi-Guaçu, SP .

6. Tratamentos utilizados com as respectivas dosagens dos her bicidas usados. Mogi-Guaçu, 1975/76 .................

7. Composição do adubo granulado empregado na adubação de Eucalyptus saligna Smith $\ldots \ldots \ldots \ldots \ldots \ldots \ldots \ldots \ldots \ldots$

8. Escala de avaliação visual no controle de plantas invasoras

9. Escala de avaliação visual de injúría à cultura de Eucalyp

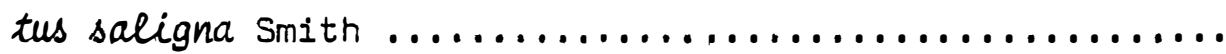

10. Reșumo de análise de variância para teores minerais em foIhas de Eucalyptus saligna Smith, aos 60 dias após plantio.

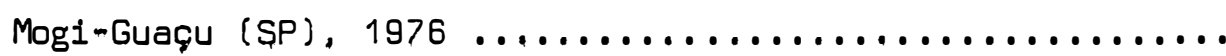

i1. Teores médios em porcentagem de nutrientes em folhas de Eu calyptus saligna Smith, aos 60 dias após plantio para dosa gem de dois herbicidas. Mogi-Guaçu (SP). 1975/76 .......

12. Resumg da anälise de variância para teores minerais em folhas de Eucalyptus saligna Smith, aos 120 dias após o plan

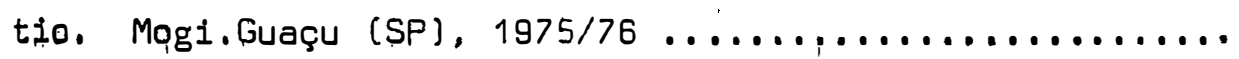


13. Teores médios em porcentagem de nutrientes em folhas de Eu calyptus saligna Smith, aos 120 dias após plantio, para do sagem de dois herbicidas. Mogị-Guaçu (SP), 1975/76 ......

14. Reșumo da anâlise de variância para teores minerais em foIhas de Eucalyptus saligna Smith, aos 180 dias após plan-

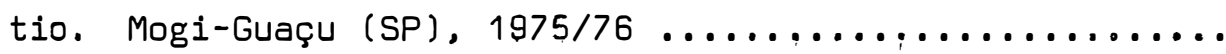

15. Teores médios em porcentagem de nutrientes em folhas de Eu calyptus saligna Smith, aos 180 dias após plantio, para do sagem de dois herbicidas. Mogi-Guaçu (SP) 1975/76 ......

16. Ressumo da análise de variância para altura e diâmetro de E. saligna Sm., aos 180 dias após plantio. Mogi-Guaçu (SP)

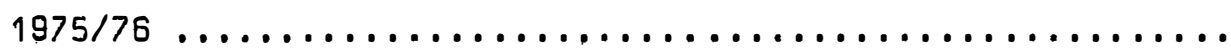

17. Desenvolvimento médio em altura e diâmetro de copa de Euca lyptus saligna $\mathrm{Sm}$. , em função de dosagens de dois herbicidas, aos 180 dias após plantio. Mogi-Guaçu (SP), 1975/76.

18. Espécies invasoras encontradas em cultura de $E$. saligna $\mathrm{Sm}$.,

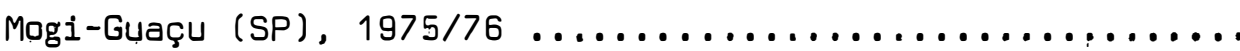

19. Número de plantas invasoras em cultura de $E$. saligna Smith, aos 30 dias após plantio. Mogi-Guaçu (SP) 1975/76 ......

20. Porcentagem de controle de plantas invasoras em cultura de E. saligna Sm., aos 30 dias após plantio, em relação a tes temunha não capinada. Mogi-Guaçu (SP), 1975/76 .........

21. Resumo da análise de variância para plantas invasoras em cultura de $E$. saligna Smith, aos 30 dias após plantio. Da dos transformados em $\sqrt{x+1 / 2}$. Mogi-Guaçu (SP), 1975/76 
22. Valores médios da avaliação visual aos 30 dias apös plan tio para controle de plantas invasoras por dosagens de dois herbicidas. Mogi-Guaçu (SP) $1976 \ldots \ldots \ldots \ldots \ldots \ldots$

23. Resumo da análise de variância para plantas invasoras em cultura de E. saligna Smith, aos 60 dias após plantio. Da dos transformados em $\sqrt{x+1 / 2}$. Mogi-Guaçu (SP) $1975 / 76$.

24. Valores médios da avaliação visual, aos 60 dias após plantio, para controle de plantas invasoras por dosagens de dois herbicidas. Mogi-Guaçu (SP), 1975/76 .............

25. Resumo da análise de variância para reinfestação de plantas invasoras em cultura de $E$. saligna Smith, aos 90 dias após plantio. Dados transformados em $\sqrt{x+1 / 2}$. Mogi-Gua

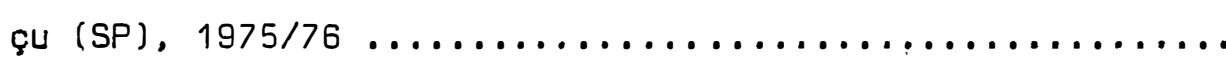

26. Valores médios da reinfestação por plantas de folhas largas e injúria causada por dosagens de dois herbicidas, aos 90 dias após plantio. Mogi-Guaçu (SP), 1975/76 .........

27. Resumo da análise de variância para reinfestação de plantas invasoras em cultura de $E$. saligna Smith, aos 120 dias após plantio. Dạdos transformados em $\sqrt{x+1 / 2}$. Mogi-Gua

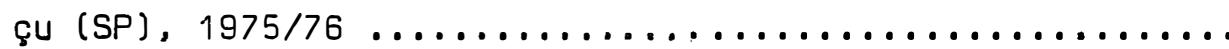

28. Valores médios de reinfestação por plantas de folhas largas e gramíneas, e injúria causada por dosagens de dois herbicidas, aos 120 dias após plantio. Mogi-Guaçu (SP)

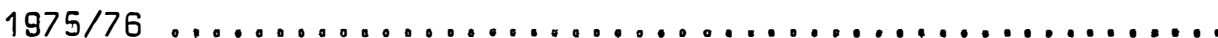


Figura

1. Representação gráfica dos teores de $P$ e Ca em folhas de Eucaliptus saligna Smith, em função de três dosagens (p.a.), do herbicida oryzalin aos 120 dias após plantio ..........

2. Representação gráfica dos teores de $P$ em folhas de Eucalyptus saligna Smith, em função de três dosagens (p.a.) do her

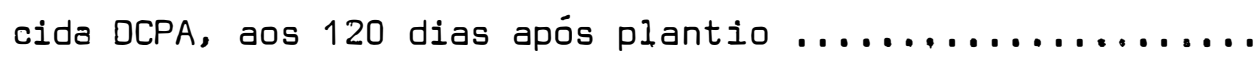

3. Representação gráfica dos teores de $K$ em folhas de Eucalyptus saligna Smith, em função de três dosagens (p.a.) do her bicida DCPA, aos 180 dias após plantio .................

4. Representação gráfica dos teores de Mg em folhas de Eucalyp tus saligna Smith, em função de três dosagens (p.a.) do her bicida oryzalin aos 180 dias após plantio ...............

5. Representação gráfica do desenvolvimento do diāmetro de copa de Eucalyptus saligna $\mathrm{Sm}$., em função de três dosagens (p.a.) do herbicida DCPA aos 180 dias após plantio ........

6. Representação gráfica do controle de gramíneas e folhas lạ gas em função de três dosagens (p.a.) do herbicida DCPA,aos

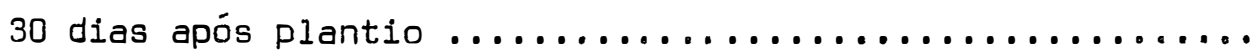

7. Representações gráficas do controle de Sida spp. e Marmodica charantia $L$. em função de três dosagens (p.a.) do herbicida oryzalin, aos 30 dias após plantio ...............

8. Representações gráficas do controle de Sida spp. e Bidens pilosa L., em função de três dosagens (p.a.) do herbicida -

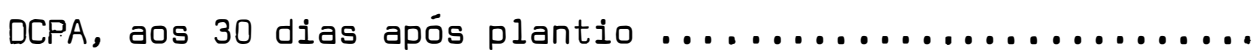

9. Representações gráficas do controle de Cyperus spp. e Marme dica charantia L., em função de três dosagens (p.a.) do her

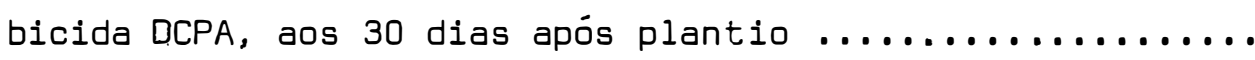


10. Representações gräficas do controle de Cyperus spp. e Sida spp., em função de três dosagens (ì.a.) do herbicida DCPA, aos 60 dias após plantio .....................

11. Representações gráficas do controle de folhas largas e Commelina spp., em função de três dosagens (p.a.) do herbicicida oryzalin, aos 60 dias após plantio .................

12. Representações gräficas do controle de folhas largas e gramíneas em função de três dosagens ( $p . a$.$) do herbicida DCPA,$ aos 60 dias após plantio .......................

13. Representação gráfica do controle de Brachiaria plantaginea (Link) Hitch em função de três dosagens (p.a.) do herbicida DCPA, aos 60 dias após plantio ...................

14. Representações gráficas do controle de gramíneas e injüria, em função de trés dosagens (p.a.) do herbicida DCPA, aos 120 dias apōs plantio ..........................

15. Representação gráfica da injüria em função de trés dosa gens (p.a.) do herbicida oryzalin aos 120 dias após plantio 


\section{RESUMO}

A implantação de florestas cobrindo extensas áreas florestais no Brasil a partir de 1966, com o advento dos incentivos fiscais e do programa nacional de papel e celulose, tem mobilizado elevado contingente de mão-de-obra.

A evasão do homem do campo atraído por melhores salários ofe recidos pelas empresas urbanas, tem criado sérios problemas para a manutenção dos povoamentos implantados.

O uso de herbicidas é uma alternativa válida para substituir a mão-de-obra rural nos trabalhos de limpeza de áreas florestais. Visando solucionar problemas de tratos culturais em áreas de florestas plantadas, foi instalado o presente ensaio, cujos objetivos foram: a. determinar o efeito do DCPA e Oryzalin no teor de N, P, K, Ca e Mg em folhas de Eucalyptus saligna Smith; b. observar a eficiência de níveis de dosagens dos produ tos citados no controle de plantas daninhas da cultura e c. verificar níveis de toxidez de dosagens dos produtos na cultura inicial de Eucalyptus saligna Smith.

0 experimento foi instalado na Fazenda "Santa Teresinha", mu nicípio de Mogi Guaçu, Estado de São Paulo, de propriedade da CHAMPION Papel e Celulose S/A. O experimento obedeceu ao delineamento em blocos casua 
lizados segundo o esquema fatorial de $2 \times 3 \mathrm{com}$ dois tratamentos adicionais (testemunhas) e 4 repetições. Os tratamentos consistiram em 1,50; 3,00 e $4,50 \mathrm{~kg} / \mathrm{ha}$ de oryzalin e 3,75; 7,50 e 11,25 kg/ha de OCPA. Cada parcela con tinha 10 plantas dispostas em linhas. As testemunhas foram uma capinada e outra não capinada. As fontes de oryzalin foram o produto comercial Surflan a $75 \%$ e a fonte do DCPA foi o Dacthal a $75 \%$.

A aplicação de ambos os produtos foi feita em pós-emergència para a cultura e em pré-emergência para as plantas invasoras.

A coleta de folhas de Eucalyptus saligna Sm. para as análises foliares foram realizadas aos 60, 120 e 180 dias após plantio. Foram realizadas avaliações visuais para controle de plantas invasoras e injúria à cultura aos $30,60,90$ e 120 dias. Aos 30 dias foi realizada uma contagem de plantas invasoras.

Nas condições do experimento, concluiu-se que os teores de $\mathrm{N}$, $P$, K, Ca e Mg em folhas de Eucalyptus saligna Smith não foram modificados pelos herbicidas oryzalin e DCPA em comparação com as testemunhas. Entretan to, níveis diferentes de dosagens do herbicida DCPA modificaram os teores de $P$ e niveis diferentes de dosagens de oryzalin alteraram os teores de $P$ e Ca aos 120 dias após plantio. O teor de $K$ aos 180 dias, após plantio, foi também alterado pelas dosagens do herbicida DCPA.

A altura e diâmetro da copa das ärvores de Eucalyptus saligna Smith não foram afetados pelas dosagens médias dos herbicidas Oryzalin e DCPA; mas a dosagem $4,5 \mathrm{~kg} / \mathrm{ha}$ de DCPA provocou redução do diâmetro da copa das plantas.

Avaliações visuais para determinação do grau de injüría demonstraram que aos 30 e 60 dias após plantio não se observou nenhuma injū ria causada pelos herbicidas. Aos 90 e 120 dias, as dosagens de $4,5 \mathrm{~kg} / \mathrm{ha}$ de oryzalin e $11,25 \mathrm{~kg} / \mathrm{ha}$ do DCPA provocaram pequenos graus de injúria a cultura. 
No controle da maioria das plantas invasoras, independente das dosagens, o oryzalin foi mais eficiente que o DCPA, em todas as épocas estudadas; ou seja, aos 30, 60, 90 e 120 dias, após plantio. 


\section{INTRODUÇÃO}

Os produtos químicos que controlam plantas daninhas em cultu ras florestais desempenham papel de relevância mundial (KOSLOWSKI, 1966). Muitos estudos foram realizados com o objetivo de controlar plantas invasoras em cultura de Pinus spp. e outras coníferas.] Para Eucalyptus spp, entratanto, poucos foram realizados.

Os herbicidas vêm sendo largamente aplicados na agricultura brasileira em lugar da capina manual ou mecanizada. No que se refere a Sil vicultura, os trabalhos científicos não atingiram desenvolvimento desejável. A existência, em muitas regiões brasileiras, de bom contingente de mão-de-obra não qualificada que se dispõe a trabalhar no campo, desestimula as empresas a aplicar herbicidas nos empreendimentos florestais.

Com a instituição dos incentivos fiscais e com o desenvolvimento das Indústrias de celulose no Brasil que possibilitaram a implantação de extensas florestas, torna-se imperiosa a aplicação de herbicidas no controle de plantas invasoras.

Os trabalhos mecanizados são alternativas välidas para a manutenção dos povoamentos florestais. Contudo, os altos preços atuais dos combustíveis poderão torná-los antieconômicos. Por outro lado, não há ainda solução satisfatöria para os tratos culturais entre plantas, ao longo das 
linhas. Tais fatores têm levado os empresários s salicitar dos órgãos de pesquisas,soluções que permitem o controle das plantas invasoras às culturas florestais, através de produtos auimicos.] Segundo estudos realizados em diversas partes do mundo, a aplicação de produtos químicos no solo pode afetar a absorção de nitrogênio pelas plantas (FULLERTON, 1971).

A falta de informaçães cientificas acerca das dosagens ideais e das implicações do uso de herbicidas no metabolismo de absorção de nutrientes pelas plantas, tem dificultado a recomendação do emprego destes produtos químicos em culturas de espécies florestais. Na expectativa de oferecer algum subsídio para solução do problema em apreço, instalou-se o presente trabalho com os seguintes objetivos:

a. Determinar o efeito do herbicida DCPA ou Dimetil 2,3,5,6- tetrachloroftalico e do herbicida Oryzalin ou 3,5 dinitro- $N^{4}-N^{4}$-dipropylsulfanilamida, no teor de $N, P, K$, Ca e $\mathrm{Mg}$ nas folhas de Eucalyptus saligna Smith.

b. Observar a eficiência de diferentes dosagens dos herbicidas citados no controle das plantas daninhas na cultura de Eucalyptus saligna Smith.

c. Verificar os graus de toxidez das diferentes dosagens de DCPA e Oryzalin no crescimento inicial do Eucalyptus saligna Smith. 


\section{REVISAOO DE LITERATURA}

\subsection{Plantas invasoras em cultivo florestal}

As plantas invasoras têm causado preocupações constantes aos que se dedicam aos empreendimentos florestais.

Num estudo realizado por VEIGA (1968) na Escola Superior de Agricultura "Luiz de Queiroz" em Piracicaba, foram encontradas as espécies de plantas invasoras constantes da Tabela 1, na cultura de Eucalyptus saligna Smith.

Em outro experimento realizado ainda na Escola Superior de Agricultura "Luiz de Queiroz", VEIGA (1969) encontrou as espécies de plantas invasoras na área do ensaio constantes da Tabela 2.

De acordo com ROBBINS et alii (1955), as plantas invasoras, em geral, possuem grande poder vegetativo e se reproduzem rapidamente. De acordo com MONTOYA (1961), elas são capazes de absorver água e nutrientes com mais eficiência que as ärvores florestais cultivadas. Infere-se portan to que em qualquer estabelecimento de cultura florestal necessita-se reduzir a competição das plantas invasoras (KOSLOWSKI, 1966)。 
Tabela 1. Plantas invasoras em cultura de Eucalyptus saligna Smith, em área da ESALQ - Piracicaba, segundo VEIGA (1968).

Euphorbia geniculata ort.

Cynadon dactileum (L) Pers.

Eleusina indica (L) Gaertu

Leonotis nepetafolia $R$. Ba.

Portulaca oleracea L.

Leonorus sibiricus Lin.

Leontodum tararcacum L.

Phyllanthus corcovadensis

Richardsonia brasiliensis
Grama seda

Pé de Galinha

Gramineae

Cordão de frade

Beldroega

Portulaceae

Rubim

Labiatae

Dente de Leão

Compositae

(L) $M . A r g$.

nuebra Pedra

Eupt

Poaia branca

Rubiaceae 
Tabela 2. Espécies de plantas invasoras encontradas em ensaio na area da ESALQ, segundo VEIGA (1969).

Nomes Científicos

Nomes Comuns

Família

Melinis minutiflora Beauv.

Capim Gordura (*) Gramineae

Tricholaens rosca Mees

Capim Favorita (+) Gramineae

Inchnatus candicans M. ab. E

Capim papouã (+) Gramineae

Cynadon dactileum (L) Pers

Grama seda (+) Gramineae

Bidens pilosus $L$.

Picão

Compositae

Ageratum conyzoides $L$.

Herva de São João Compositae

Meibonia sp.

Beiço de Boi

Leguminosae

Xantium spinossum $L$.

Carrapicho

Compositae

Tagetes minuta L.

Rojão

Compositae

Leonorus sybiricus Lin.

Rubin Labiatae

Phylanthus corcovadensis (L)M.Arg.

Quebra Pedra

Euphorbiaceae

Indigophera sp.

Bananinha

Leguminosae

Solanum nigrum

Maria Preta

Solanaceae

Fecelis retusa

Compositae

Melchia sp.

Sterculiaceae 
Tratos culturais em plantios florestais - para reduzir a com petição de tais plantas invasoras sem desacelerar o ritmo de crescimento dạs espécies - tèm sido feitos através de cultivo manual, pelo fogo controlado, ou peló uso de máquinas agrícolas (SAMPSON e SCHULTZ, 1956; FLINTA, 1960 e WOODFORD e EVANS, 1965).

Segundo AREND e ROE (1961) e KLINGMAN (1961), em regiões tem peradas, o emprego de produtos químicos para controlar plantas invasoras tem mostrado ser mais eficaz e de custo mais baixo que outros métodos.

Para BAGLEY (1966), o controle seletivo das plantas indesejá veis numa plantação florestal, com uso de herbicida, pode ser obtido pela combinação de alguns princípios:

a. A espécie arbórea pode ter tolerância fisiológica e bioquímica ao herbicida aplicado para controlar as ervas daninhas.

b. As características morfológicas das folhas, troncos e raí zes podem reduzir ou evitar a absorção do herbicida pelas ärvores.

c. Dirigir a palicação do herbicida de modo a evitar que par tes sensíveis das árvores sejam atingidas.

\subsection{Herbicidas em florestas}

Poucos são os estudos de herbicidas em plantas florestais no Brasil. Estudo preliminar realizado pelo Instituto de Pesquisas e Estudos Florestais (IPEF), em viveiros, segundo BAZAM e MINAMI (1974), mostrou viabilidade do emprego de Linuron e DCPA em cultura de Pinus e Eucalyptus spp.

Para se aplicar herbicidas em qualquer cultura, torna-se necessário um perfeito conhecimento dos fatores do meio e sua interação com a espécie e herbicidas usados. WILDE et alii (1968), mencionam que a aplicação de herbicidas em cultura de Pinus resinosa Ait com 28 a 32 anos de ida- 
de reduziu sensivelmente a produção da biomassa do sítio. Neste mesmo estu do os autores demonstraram que a produção de madeira e o consumo de água fo ram reduzidos com a aplicação de herbicidas.

A suscetibilidade de uma espécie florestal a um herbicida, varia em função de sua composição química. BAGAEV e ZHUKOV (1974), em expe rimentos de campo e em casa de vegetação, testando resistência das plantas de milho, trigo e outras culturas agrícolas aos herbicidas, concluíram que a toxidade de um herbicida varia em função do estado nutricional da planta.

BURKHALTER e CARTER (1972), testando a resistência de espécies florestais ao 2, 4-D, verificaram que os teores de ácido ribonucleico (RNA) das plantas exerciam influência marcante na resistência das espécies ao herbicida, na seguinte escala:

Liquidambar styraciflua Sensível

Fraxinus pensilvanica

Acer rubrum
Intermediária

Resistente baixo teor de RNA médio teor de RNA alto teor de RNA

O ciclo longo do cultivo florestal traz alguns problemas na aplicação dos herbicidas para controle de plantas invasoras. Um dos mais importantes aspectos a ser encarado, é o da duração ou efeito residual do herbicida no solo. A aplicação repetida de um herbicida poderá onerar a operação a níveis antieconómicos. Contudo, a perda do efeito do herbicida no solo é indiscutível. IYER et alii (1969) observaram que o DCPA aplicado em plantios jovens de Pinus radiata D. Don e Pinus strobus L., teve sua ação reduzida em aproximadamente 50\%, num período de 120 dias.

Segundo WOODFORD e EVANS (1965), há três grupos de plantas invasoras a serem controladas em plantações florestais: as lenhosas, sobre tudo os arbustos, as gramíneas e as plantas de folhas largas anuais. Para as plantas lenhosas e arbustos, PRIMO (1958), AUDUS. (1964) e BACK (1972) men cionam muitos herbicidas com eficiência satisfatória, destacando-se, no entanto, o 2,4-D, o 2,4,5-T e seus derivados.

A experiència tem demonstrado que os herbicidas sob as mesmas condições podem ser mạis tóxicos para plantas de folhas largas do que 
para as de folhas estreitas (BINGHAN e JONES, 1967). Segundo WINGET et alii (7961), um herbicida pode ser tóxico a uma espécie florestal na fase de viveiro, mas não em plantio de campo.

Gramíneas podem ser controladas com o Paraquat, Dalapon, e Bromacil, enquanto que as plantas de folhas largas anuais podem ser controladas por muitos herbicidas encontrados facilmente no comércio como o Piclo ran, 2,4-D e 2,4,5-T (1967); CAMARGO et alii (1971); FORSTER e ALVES (1975).

\subsubsection{Uso de herbicidas em conĩferas}

A maioria dos trabalhos relativos ao uso de herbicidas

em cultura florestal refere-se à aplicação em coníferas, em especial do gênero Pinus spp.. FORSTER (1974), informa que as coniferas, fora do período de ibernação são tolerantes a uma série de herbicidas. As Araucáriaceas, entretanto, são menos tolerantes do que outras coníferas. Os herbicidas mais usados atualmente para controle de plantas daninhas em Pinus spp. são as triazinas e uréias.

Estudos realizados nos Estados Unidos por WINGET et alii (1963), demonstram que a propazina controlou plantas invasoras sem injuriar plantas e Pinus resinosa Ait na dosagem de 0,5 e $1 \mathrm{~kg} / \mathrm{ha}$.

Värios herbicidas, como o EPTC, CDEC, CDAA, 2,4-D e Picloran, aplicados em plantas jovens de Pinus resinosa Ait, afetaram a forma do coti lédone, o alongamento celular e o crescimento da raiz (KOSLOWSKI et alii, 1968 ).

Os trabalhos de GRATKOWSKI (1972), nos Estados Unidos, indicam que o 2,4-D e 2,4,5-T aplicados em emulsões de água e óleo em cultura de Pinus ponderosa Laws, com 1 a 2 anos de idade, mostraram-se tóxicos às plantas quando aplicados em fevereiro. Contudo, tornou-se gradativamente me nos tóxicos, à medida que novos brotos se formaram, tornando-se totalmente inofensivos do fim de agosto até o inverno.

GROVER (1967), testou 17 herbicidas para determinar a tole- 
rância das coníferas aos mesmos, verificando que aproximadamente $60 \%$ do con trole do mato foi indispensável para crescimento satisfatório de Picea glau ca e Picea pungens, enquanto que $40 \%$ do controle foi suficiente para um bom crescimento de Pinus silvestrys L.. Vários herbicidas reduziram o crescimento em altura e diâmetro, bem como o peso fresco de algumas plantas. Os herbicidas que não causaram danos às coníferas foram o neburon, o linuron e o DCPA.

Na Alemanha, SCHMIDT (1973), menciona que ervas daminhas em Pinus silvestrys $L$. foram controladas com misturas de atrazina e prometrina (gesaprim 1798) e atrazina com MCPA mais 2,4; 5-T (Primator D-43).

Os sais do ácido fenoxiacético têm demonstrado ser tóxicos para as coníferas. FITZGERALD e McCOMB (1970), afirmam que a eliminação de folhosa com 2,4-Damino afeta o desenvolvimento de Pinus taeda L.e P. elliot tii Engelm, provocando injüria e morte das plantas. Pinus clausa (Chapm..) Vasey, foi injuriado em menor grau que os demais. Os autores acreditam que a injúria tenha sido ocasionada pela exudação de árvores tratadas com 2,4-D que, eliminadas, foram absorvidas pelas raizeș das árvores de Pinus spp..

O preparo de terreno para plantio de Pinus iumcuia 10. jon. na Nova Zelàndia, segundo relato de CHURCH e BOYERS (1971), tem sido fe1to com cilindros perfurados, de $2 \mathrm{~m}$ de diâmetro, os quais espalham uma mistura de 2,4,5-T com $\mathrm{NaClO}_{3}$ em solução aquosa. Após a secagem de mato, quei ma-se o material morto.

Para outros gêneros e espécies de coníferas, vạrios estudos foram realizados. Entre eles, VAN DORSSER (1969), verificou que o DCPA, nas dosagens recomendadas, mostrou ser ligeiramente tóxico para Cuphessus lusitânica L. e muito tóxico para Pseudotsuga. Para outras coníferas, o DCPA demonstrou ser pouco tóxico, dentro dos limites de doses recomendadas tecnicamente, de acordo com KURT e DORSSER (1969).

ALLEN e REID (1972), trabalhando com Chlorthiamida 75\% (2,6-dichlorothiobenzamida), aplicando dosagens de 2,$4 ; 4,2$ e $5,0 \mathrm{~kg} / \mathrm{ha}$, obtive ram resultados satisfatórios no controle de plantas daninhas em povoamento 
de Picea sitchensis (Bong.) Carr. e Picea abies. A aplicação em anos alter nados mostrou ser mais conveniente e as melhores dosagens foram as duas prí meiras.

Na Inglaterra, BROWN (1.872), verificou que a atrazina, na do sagem de $6 \mathrm{~kg} / \mathrm{ha}$, aplicado em maio, controlou plantas daninhas em várias có níferas, mostrando-se ligeiramente tóxica para Picea abies ( $L$ ) Karst e Tsuga heterophylla. Mistura de 1,6 kg/ha de 2,4-D com 1,2 kg/ha de atrazina, usada ppr KUO e YAO (1973), aplicada em Cuninghamia lancealata, em pré-plan tịo, controlou várias espécies de plantas daninhas, sem apresentar efeito tóxico para a espécies florestal.

Simazina, aplicada em árvores de 4 anos de Picea abies, foi absorvida e distribuida rapidamente por todas as partes da planta (LUND-HOIE, 1969). Foi observada uma estreita relação entre absorção e o vigor das plantas. A atrazina foi degradada pelas raizes, não sendo encontrada nas acículas de Picea abies. Idênticos resultados foram encontrados por DHILLON et alii (1967). Os autores observaram que a Simazina penetrou pelas raizes de Pinus resinosa Ait, movendo-se rapidamente dentro do caule . A quantidade do herbicida encontrada nas acículas foi inferior à encontrada no caule.

\subsubsection{Uso de herbicidas em folhosas}

Trabalhos cientificos concernentes ao emprego de herbicidas em folhosas são mais escassos do que os de aplicação em coníferas.

Herbicidas têm sido amplamente usados como arbusticida, ou seja, para eliminar árvores indesejáveis de foltias largas.

$B A C K$ (1972), determinou que o melhor método de çontrolar bro tações de Eucalyptus spp. era aplicar mistura de picloran + 2,4,5-T (ester), em $5 \%$ de ólẹo diesel em volta do tronco na altura do peito. 
mais eficiente que o picloran no controle de espécies arbustivas de Quercus spp.. Entretanto, para as espécies de sombra, o picloran foi mais eficiente。

Quercus marilandica e outras folhosas foram controladas com - fenuron em doses de 20 a $40 \mathrm{~kg} / \mathrm{ha}$, não causando danos à cultura de Pinus taeda, de acordo com GOEBEL (1972). O efeito tóxico de picloran sobre Acacia hocki Wild foi demonstrado por HARRINGTON (1970). Mistura do produto com 2,4-D na proporção de 4:1 apresentou ótimos resultados nos tocos após o corte da árvore. DAWLER (1970), menciona que o paraquat aplicado em pulverização aérea em Porto Rico e no Texas desfolhou rapidamente florestas natu rais por períodos curtos, para algumas espécies e por maiores períodos para outras. Nenhum herbicida, entretanto, conseguiu manter as árvores sem rebrota após um ano de aplicação-

Herbicidas diversos têm sido testados em outras folhosas com a finalidade de controlar ervas daninhas em áreas florestais. Vários níveis de gramoxone, como menciona NAIR (1973), foram aplicados em cultura de Terminalia tomentosa e outras espécies folhosas, para combater as plantas invasoras. Nas condições do experimento, estudos realizados no Canadá por Van ALTHEN (1970), demonstraram que a taxa de custo-benéfico era maior quan do se aplicava herbicida em plantios florestais para controlar plantas inva soras. A mortalidade de Fraxinus americana L., aumentou com a aplicação de simazina.

3.3. Herbicida em cultura de Eucalyptus spp.

Estudos de aplicação de herbicidas para controlar espécies invasoras em cultura de Eucalyptus spp. são raros, embora sejam, de fundamen tal importância devido a função que os herbicidas poderáo desempenhar na limpeza dos povoamentos florestais recém implantados (LOAIZA, 1967).

Um dos poucos estudos de uso de herbicida em plantio de Euca lyptus spp. foi realizado por KURTH e Van DORSSER (1969), na Nova Zelândia. 
Os autores concluíram que o único herbicida que não injuriou plantas de Eucalyptus delegatensis, mostrando-se eficiente no controle de plantas invaso ras, foi o linuron. BAZAM e MINAMI (1974), testando värios herbicidas em plàntulas de Eucalyptus spp, , concluíram que o DCPA e o lorox não foram tóxicos e não afetaram os mecanismos fisiológicos das plantas em viveiro. Ain da trabalhando em viveiro, VEIGA (1969), na Escola Superior de Agricultura "Luiz de Queiroz", verificou que a simazina, atrazina e varsol injuriaram plântulas de Eucalyptus saligna Smith, enquanto que os melhores resultados foram devidos ao uso de brometo de metila, vapam e shell-DD., antes da semeadura.

LOAIZA (1967), trabalhando com dois herbicidas para limpeza em povoamentos de Eucalyptus saligna Smith, em comparação com limpezas manuais, chegou a conclusão de que aos 5 meses houve diferenças significati vas no crescimento de altura e diāmetro entre os tratamentos herbicida e a limpeza manual. Não houve, contudo, diferenças entre tratamentos com os herbicidas paraquat e aminotriazole. Finalmente, o autor afirma que o para quat (gramoxone) controlou mais eficazmente as ervas daninhas do que o aminotriazole.

Recentemente, BRASIL et alii (1976), trabalhando com värios herbicidas na cultura de Eucalyptus saligna Smith observaram que o Diuron, o Diuron + 2,4-D foram os mais eficientes para controle de plantas invasoras, não apresentando fitotoxidade à cultura.

3.4. Absorção de nutrientes em função de herbicidas

Muitos estudos demonstraram certa relação entre o aumento de produção e uso de herbicida. Entretanto, pouco se conhece sobre o efeito do herbicida na absorção de nutrientes pelas plantas. LUND-HOIE (1969) notou estreita relação entre a absorção e a distribuição de simazina e o vigor das plantas.

O uso do DCPA e nitrogênio, numa série de experimentos foram realizados por BOULANGER et alii (1973), mostrou resultados promissores no 
no crescimento de Hibiscus spp. na Costa do Marfim.

Alguns aspectos como o estado nutricional da planta e sua ca pacidade interna em desdobrar os herbicidas, devem ser considerados. BAGAEV e ZHUKOV (1974), afirmam que as plantas são mais resistentes ao herbicida sob condições nutricionais ótimas, mas podem ser sensíveís quando altas doses de fertilizantes são aplicadas.

Estudos realizados por técnicos da IRLANDA, MINISTRY OF AGRI CULTURE FOR NORTHEN IRELAND (1970), indicaram que a aplicação de herbicidas ao.solo pode aumentar a absorção de elementos minerais pela cultura de Picea sitchensis. A abosrção de nitrato em quantidades excessivas pode tornar-se' tóxico à planta após sua redução a nitrito. Segundo pesquisas realizadas pe la Universidade de Wisconsin, DUAL PURPOSE WEED KILLER TESTED IN. FOREST NURSERIES (1966), O DCPA aplicado em plantas de Pinus spp. em viveiros com dois anọs de idade, porporcionou maior absorção de nitrogênio, fósforo e potássio qụando comparados com plantas não tratadas com o herbicida.

De acordo com FULLERTON (1969), diferenças significativas em várı́s compostos nitrogenados foram encontrados no tecido de plantas tratadas com o DCPA em comparação com plantas não tratadas.

A aplicação de mistura de 2,4-D e $\mathrm{P}^{32}$ em diferentes concentraçöes em raízes destacadas de Hordeum vulgare (cevada), realizada por KOGAN et alii (1973), mostrou um acentuado decréscimo na absorção de $\mathrm{P}^{32}$ pelas raízes na presença de 2,4-D.

Estudos em condições de campo efetuados por RUSS et alii (1974), demonstraram ser possível a combinação de solução de nitrogênio e herbicidas diversos, em cultura de sorgo granífero e milho. Nas condições do experimento, a aplicação da solução de nitrogênio e herbicida foi desejá vel antes do estägio de seis folhas tanto para o milho como para o sorgo Esta operação evitou possíveis injürias às folhas e provomeu em adequado controle herbicida das plantas invasoras. 
3.5. Caracteristicas dos herbicidas usados no experimento

Os herbicidas DCPA ou chlorthal dimetil, comercialmente conhecidos por dacthal e o orizalin, comeroialmente conhecido pelo surflan, são bastante usados na agricultura, mas muito pouco no setor fiorestal.

\subsubsection{DCPA}

E um herbicidas pertencente ao grupo químico dos compostos ftälicos. Segundo DETROUX e GOSTINCHER (1965) e GRAFTS (1967), è também co nhec1do pelo nome de DAC 893 ou DCPA e é comercializado com o nome de Dacthal. Seu nome científico é Dimetil 2,3,5,6 - tetraclorotereftálico. cuja fórmula químiça é derivada do ácido tereftálico, abaixo representada:

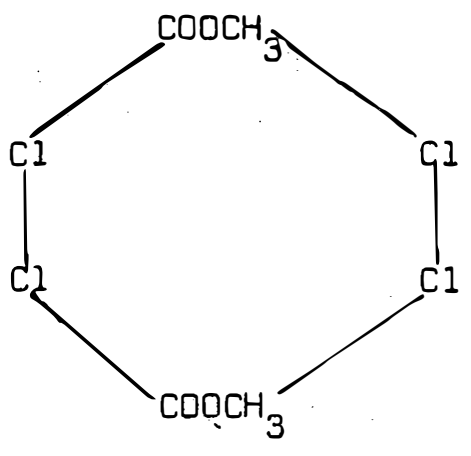

dimetil 2,3,5,6 - tetraclorotereftälico (DCPA)

E uma substancia branca, cristalina, com baixa pressão de vapor e ponto de fusão a $156^{\circ} \mathrm{C}$. Por ser pouco solúvel em solventes orgânicos é formulado em pó molhável a $75 \%$. É pouco tóxico aos animais, possuindo uma dose letal $\left(\mathrm{DL}_{50}\right.$ ) por via oral em ratos, superior a $3.000 \mathrm{mg} / \mathrm{kg}$ de peso vivo do animal. É considerado um herbicida de pré-emergência. Sua ab sorção pelas plantas verifica-se através dos coleoptilos durante a germinaçăo e emissão do eixo hipocotilico.

Há poucas informações sobre o emprego do DCPA em cultura de Eucalyptus spp.. Entretanto, há alguma referência de seu uso em espécies florestais. Van DORSSER (1968), menciona que Cupressus Lusitânica Mill. e 
pouco tolerante e Pseudotsuga é muito injuriado pelo DCPA em condições de viveiro.

GROVER (1967), verificou que a aplicação do DCPA a $10 \mathrm{~kg} / \mathrm{ha}$, não causou prejuízos à cultura de Pinus silvestrys e outras coníferas. Resultados semelhantes foram encontrados por BINGHAN (1968), trabalhando com - produto na cultura de Juniperus spp. e Tuya occidentalis.

Estudos realizados por KURTH e DORSSER (1969), na Nova Zelān dia demonstraram que o DCPA aplicado em doses de $7,5 \mathrm{~kg} / \mathrm{ha}$, foi eficiente no controle de gramíneas anuais como Digitaria sanguinalis, não sendo fitotóxico para coníferas, salvo para o Cupressus lusitânica.

O principal campo do uso do DCPA, tem sido em culturas anuais. WISE et alii (1969), mencionam que o produto foi aplicado em cultura de algodão na dosagem de 6 a $10 \mathrm{~kg} / \mathrm{ha}$, controlando Amaranthus spp. e Sor ghum bicolor, sem reduzir consideravelmente a produção de grãos. DETROUX $e$ GOSTINSCHER (1965) apresentam o DCPA como herbicida para gramíneas anuais e outras espécies de folhas largas como Amaranthus spp.. Cheisopodium album e algumas Euphorbiaceas. Solos arenosos infestados por Amaranthus spp., Digi taria eschaemun e Cenchrus spp., foram tratados com vários herbicidas por SMITH et alii (1973). Entre os melhores resultados destaca-se o DCPA a 6-10 kg/ha, controlando efetivamente as três espécies citadas. Estudos de JOHNSON (1973), em doses de $11,2 \mathrm{~kg} / \mathrm{ha}$ demonstraram que o DCPA, embora tenha controlado espécies de mato como Digitaria sanguinalis, Eleusine indica e Ochothera laciniata, causou retardamento no crescimento inicial de Cynadon spp.

\subsubsection{Oryzal in}

E um herbicida seletivo para controle de gramíneas e certas ervas daninhas de folhas largas anuais usado em superfície do solo, em prëemergência, em várias culturas noṣ Estados Unidos (ELANCO INTERNACIONAL, 1968).

Seu nome científico é 3,5-Dinitro-N $-N^{4}$-dipropylsulfanilami- 
de $a$ nome comum é SURFLAN. Pertence ao grupo químico das dinitroanilinas e sua fórmula química é a seguinte:

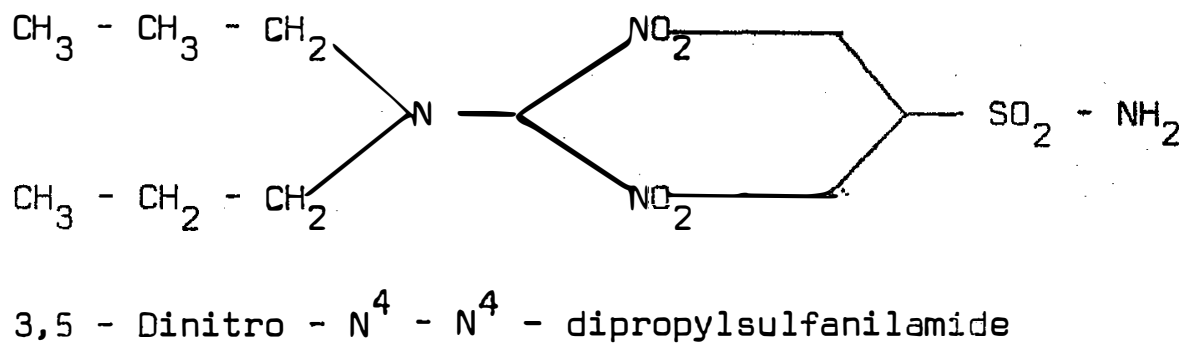

O oryzalin, segundo KLINGMAN et alii (1975), é um produto alaranjado sólido e cristalino. E relativamente estável à luz, podendo ser aplicado à superfície do solo e lixiviado pelas águas de chuva.

Seu $L_{50}$ agudo é superior a $10.000 \mathrm{mg} / \mathrm{kg}$ de peso vivo. O"pro duto sỏ. ou em combinação com outros herbicidas, é usado para soja, fumo, batata, fruteiras, nogueiras e árvores ornamentais, nos Estados Unidos. No Bras11. está sendo recomendado para cebola e café, de acordo com FORSTER e ALVES (1975).

O oryzalin funde-se a $137-138^{\circ} \mathrm{C}$ e é solúvel em ägua a $85 \mathrm{ppm}$ B $25^{\circ} \mathrm{C}$. E rapidamente soluvel em solventes orgânicos como acetona, etanole açetonitrila. sua pressão de vapor é de $1-10^{-7} \mathrm{~mm} \mathrm{Hg}$ a $30^{\circ} \mathrm{C}$, demonstrando ser pouso volátil.

Segundo ELANCO INTERNATIONAL (1968), fatores como decomposiçăo por microrganismos, decomposição química e pela luz, volatilização, tipo de solos, dosagem e método de aplicação podem influenciar à degradação e - bom comportamento do produto no solo.

A ação do produto sobre as plantas, de acordo com

HARVEY (1973), se faz com inibição do sistema radicular dos vegetais. 0 autor tes tou 12 produtos oriundos do grupo Dinitro anilinas, constatando que todos Iniblam o crescimento radicular de Glicine spp., Setaria spp. e Aluntilon app.. Ainda HARVEY (1973), em outro trabalho, demonstrou que o oryzalin cau aou injürlas à aveia. Trabalhos de AHRENS (1975), demonstram que o produto, 
aplicado na dose de $0,75 \mathrm{~kg} / \mathrm{ha}$ foi eficiente no controle de Chrysanthemum morifolium.

No Brasil, o uso de oryzalin ainda se encontra em escala experimental, embora já esteja indicado para algumas culturas. MENEGHEL et alii (1976), trabalhando com o oryzalin e outros herbicidas na cultura de cebola, concluíram que o mesmo, sozinho, controlou muito bem plantas invaso ras de folhas largas e as gramíneas anuais, por período superior a 90 dias nas doses 1,50 e $2,25 \mathrm{~kg} / \mathrm{ha}$ do principio ativo. 


\section{MATERIAL E MÉTODOS}

\subsection{Material}

\subsubsection{Localização do experimento}

O experimento fai localizado na fazenda "Santa Teresinha",de propriedade de Champion Papel e Celulose S/A, no município de Mogi-Guaçu, Estado de São Paulo, situada a $47^{\circ} 07^{\prime}$ de longitude oeste de Greenwich e $22^{\circ}$ 11' de latitude Sul, numa altitude de 580 metros, de acordo com MELLO et alii (1970).

\subsubsection{Solo}

O solo superficial de 0 a $20 \mathrm{~cm}$ de profundidade da ärea expe rimental foi analisado no laboratório de Análise do Instituto de Química "JOHN H. WHEELOCK" do Departamento de Solos da Escola de Agricultura de La vras (ESAL), Minas Gerais. Foram determinadas as características químicase físicas do solo, constantes das Tabelas 3 e 4 . 0 Solo da área experimental é c tipo franco argilo arenoso, profundo, com boa drenagem, de coloração pardo amarelada. 
Tabela 3. Características químicas do solo da área experimental.

\begin{tabular}{ccccc}
\hline $\mathrm{Al}^{+++}$ & $\mathrm{Ca}^{++}+\mathrm{Ma}^{++}$ & $\mathrm{K}^{+}$ & $\mathrm{P}$ & $-\mathrm{pH}-$ \\
$-\mathrm{mE} / 100 \mathrm{~cm}^{3}-$ & $-\mathrm{mc} / 100 \mathrm{~cm}^{3}-$ & $-p p m^{-}$ & $-p p m-$ & \\
\hline 0.2 (baixo) & 1,4 (baixo) & 59 (baixo) & 3 (baixo) & 4,9 (baixo) \\
\hline
\end{tabular}

Tabela 4. Características físicas do solo da área experimental.

\begin{tabular}{llcccc}
$\begin{array}{c}\text { Areias } \\
(\%)\end{array}$ & $\begin{array}{l}\text { Limo } \\
(\%)\end{array}$ & $\begin{array}{c}\text { Argila } \\
(\%)\end{array}$ & $\begin{array}{c}\text { Carbono } \\
(\%)\end{array}$ & $\begin{array}{c}\text { Matéria Orgânica } \\
(\%)\end{array}$ & $\begin{array}{c}\text { Tipo de } \\
\text { solo }\end{array}$ \\
\hline 69.39 & 7,11 & 25,50 & 0,77 & 1,32 & $\begin{array}{c}\text { Franco } A . \\
\text { Arenoso }\end{array}$ \\
\hline
\end{tabular}

Pelos dados contidos nas Tabelas acima, verifica-se que o so lo em estudo contém alto teor de areia, sendo portanto de baixo poder de re tenção de bases e baixa capacidade de troca. Como consequência, verifica - se a baixa fertilidade do solo expressa na Tabela 3.

Segundo dados extraídos de BRASIL (1960), o solo desta área originqu-se do período carbonífero superior, grupo Tubarão constituído por sedimentos arenosos glaciais, intemperizados.

\subsubsection{Relevo}

A área experimental está situada em relevo quase plano com declividade em torno de $2 \%$.

\subsubsection{Clima}

Segundo GODOY e ORTOLANI (s.d.), o clima da área do experimento do tipo Cwa do sistema de Köppen, com inverno seco. A temperatura 
médía do mês mais frio é de $18^{\circ} \mathrm{C}$ e a do mês mais quente em torno de $22^{\circ} \mathrm{C}$. $\mathrm{C}$ períado chuvoso compreende os meses de novembro a março e o período mais se co entre os meses de maio a agosto. O total de precipitação de chuvas do mês mais seco é inferior a $30 \mathrm{~mm}$.

Os dados climáticos correspondentes ao período do experimento, estão expressos na Tabela abaixa:

Tabela 5. Características climáticas correspondentes ao período experimental de novembro a maio de 1975/76 - Mogi-Guaçu, SP.

\begin{tabular}{|c|c|c|c|c|c|c|c|c|c|}
\hline \multirow[t]{2}{*}{ Meses } & \multicolumn{3}{|c|}{$\begin{array}{l}\text { Pluviosidade } \\
(\mathrm{mm})\end{array}$} & \multicolumn{3}{|c|}{$\begin{array}{c}\text { Temperatura } \\
\left({ }^{\circ} \text { ) }\right.\end{array}$} & \multicolumn{3}{|c|}{$\begin{array}{c}\text { Umidade relativa } \\
(\%)\end{array}$} \\
\hline & $\max$ & $\min$. & média & $\max$. & min. & média & $\max$. & $\min$. & média \\
\hline novembro & 93,5 & 2,0 & 23,2 & 33 & 11 & 22 & 91 & 41 & 73 \\
\hline dezembro & 26,0 & 8,0 & 15,6 & 34 & 12 & 23 & 91 & 50 & 76 \\
\hline janeiro & 20,0 & 3,0 & 11,0 & 34 & 16 & 24 & 90 & 41 & 73 \\
\hline fevereiro & 61,0 & 8,0 & 2,2 & 31 & 14 & 23 & 89 & 21 & 78 \\
\hline março & 18,0 & 8,0 & 13,0 & 32 & 12 & 23 & 89 & 28 & 79 \\
\hline abril & 19,0 & 8,0 & 12,0 & 31 & 8 & 21 & 89 & 42 & 65 \\
\hline maio & 26,3 & 8,0 & 15,8 & 29 & 12 & 22 & 92 & 38 & 68 \\
\hline
\end{tabular}

\subsubsection{Espëcie}

A espécies utilizada no experimento foi Eucalyptus saligna Smith. As mudas foram produzidas no "Horto Santa Teresinha", provenientes de sementes semelcionads pelo Instituto de Pesquisas e Estudos Florestais (IPEF) de Piracicaba, São Paulo. Na época do plantio, as mudas apresentavam aproximadamente $20 \mathrm{~cm}$ de altura.

\subsubsection{Herbicidas usados}

Foram usados os herbicidas Dimetil 2,3,4,6 - Tetrachlorote reftalico, conhecido pelos nomes comuns de DCPA ou Chlorthaldymetil e comer 
clalmente pelo nome de Dacthal; e o 3,5-0initro- $N^{4}, N^{4}$-dipropylsulfanilamide, conhecido pelo nome técnico de Oryzalin e comercialmente pelo nome de Surflan.

0 Oryzalin é um pó molhävel, com $75 \%$ de ingrediente ativo. 0 Dacthal é também um pó molhável com 75\% de ingrediente ativo; Dimethyl es ter do ácido tetrachlorotereftalico de acordo com COELHO e VIANA (1968).

\subsubsection{Puiverizador}

O pulverizador usado foi um tipo manual de pressão constante a gäs, provido de bico Teejet 110-H. A distạncia entre bicos era de $50 \mathrm{~cm}$ e a distància dos bicos ao solo também de $50 \mathrm{~cm}$.

\subsubsection{Condições ambientais na aplicação dos herbicidas}

A aplicaçāo dos herbicidas foi realizada entre as 16:30 e 17: 30 horas do dia 17 de novembro do ano de 1975. Minutos antes da aplicaçäo foram registradas as seguintes temperaturas: superfície do solo - $29^{\circ} \mathrm{C}$; a $5 \mathrm{~cm}$ de profundidade $-32^{\circ} \mathrm{C}$ e temperatura do ar $-27^{\circ} \mathrm{C}$.

0 céu apresentava-se parcialmente nublado e a velocidade do vento sra praticamente nula.

A superfície do solo apresentava-se com pequenos torrōes de 1 a $3 \mathrm{~cm}$ de diàmetro e em estado seco a $3 \mathrm{~cm}$ de profundidade.

Adicionaram-se 10 litros de água por cova empregando-se rega dor manual, antes do plantio das mudas.

\subsection{Métodos}

\subsubsection{Delineamento experimental}

0 experimento foi conduzido em blocos casualizados, segundo 
- esquema fatorial de $2 \times 3$ com dois tratamentos adicionais (testemunhas) e com 4 repetiçöes. Os tratamentos foram constituídos de dois herbicidas e très dosagens e mais duas testemunhas.

Cada parcela foi composta por 10 plantas, dispostas em linha. o total de plantas utilizadas no experimento foi de 320. Não foram usadas plantas nas bordaduras.

\subsubsection{Tratamentos}

Os oito tratamentos utilizados no experimento estão descritos na Tabela 6.

Tabela 6 . Tratamentos utilizados com as respectivas dosagens dos herbicidas. Mogi-Guaçu-SP, $1976 / 77$.

Tratamentos

Ingrediente ativo

$\mathrm{kg} / \mathrm{ha}$

1,50

3,00

4,50

3,75

7,50

11,25

DCPA

Testemunha capinada

Testemunha não capinada

Oryzalin

DCPA
Produto formulado

$\mathrm{kg} / \mathrm{ha}$

$$
\begin{array}{r}
2,0 \\
4,0 \\
6,0 \\
5,0 \\
10,0 \\
15,0
\end{array}
$$

\section{.}

cada

\section{2,3. Instalação do experimento}

Para o plantio das mudas no campo, o solo foi preparado com trator de esteira e lâmina buldozer. Em seguida efetuou-se uma gradagem do terreno e posteriormente procedeu-se à abertura dos sulcos no espaçamento de 3 metros entre linhas e 1 metro entre plantas da mesma linha, com profun 
cidade de $20 \mathrm{~cm}$. Tal espaçamento foi julgado adequado para a curta duração do experimento.

Após a abertura dos sulcos, foram distribuídas $130 \mathrm{~g} / \mathrm{cova}$ de fertilizante granulado com fórmula 4-16-8 + micronutrientes, contendo a com posição contida na Tabela 7 .

Tabela 7. Composição do adubo granulado empregado na adubação de Eucalyptus saligna Smith.

\begin{tabular}{|c|c|c|c|c|}
\hline Elementos & - Teores em \% & Elementos & & Teores em \% \\
\hline$N$ & 4 & $\mathrm{~B}$ & $=$ & 0,04 \\
\hline$P$ & 16 & $\mathrm{Cl}$ & $=$ & 0,4 \\
\hline$K$ & 8 & $\mathrm{Fe}$ & $=$ & 0,06 \\
\hline $\mathrm{CaC}$ & 17 & $M n$ & $=$ & 0,3 \\
\hline $\mathrm{MgO}$ & $=$ & $\mathrm{Zn}$ & $=$ & 0,04 \\
\hline $\mathrm{S}$ & $=$ & & & . \\
\hline
\end{tabular}

Tal adubação básica foi usada com o objetivo de permitir cres cimento vigoroso das plantas e assegurar o fornecimento de elementos minerais para anälise foliar.

Os herbicidas foram aplicados em pós-emergência em relação à cultura e em pré-emergência em relação às plantas invasoras.

A aplicação dos herbicidas foi realizada imediatamente após - plantio, em faixas de dois metros sobre as linhas de plantio.

Não foi tratada a área compreendida entre as linhas do eucalipto onde é possível a capina mecanizada.

Aos trinta dias de idade efetuou-se a primeira limpeza das testemunhas. Aos sessenta dias, considerando que as testemunhas e alguns tratamentos se encontravam visualmente dominados pelas plantas invasoras, fez-se uma capina geral com o abjetivo de manter a uniformidade do experi- 
mento e permitir o crescimento das plantas de eucalipto, possibilitando a amostragem de folhas para as determinações.

\subsubsection{Avaliações}

Todos os dados experimentais utilizados no presente trabalho. foram tomados no período compreendido entre 17 de novembro e 17 de maio de 1976.

\subsubsection{Controle das plantas invasoras}

A eficiẹncia dos herbicidas testados no controle das plantas invasoras foi determinada pela sua contagem individual aos 30 dias de idade. usando um quadrado de arame de área conhecida, segundo ALVES (1974) e AZZI e FERNANDES (1966), em duas amostragem de $0,25 \mathrm{~m}^{2}$ em cada parcela.

Aos 30 e 60 dias após a instalação do experimento, foram rea lizadas "avaliações visuais" das plantas invasoras, segundo o sistema proposto pelo Comitê de Métodos do Conselho Europeu de Pesquisas sobre plantas daninhas (European Weed Research Counc1l), citado por ALVES (1974). Tal sis tema, denominado. EWRC, se basefa na escala proporcional de diferenças com a testemunha, expressa por notas 0 a 10, conforme a Tabela 8.

Após a capina total do experimento foram realizadas novas "avaliaçāes visuaịs", para estimar o controle de plantas invasoras, usando o mesmo critério anteriormente citado, aos 90 e 120 dias.

As anālises dos dados obtidos pelas "avaliaçōes visuais" foram realizadas em parte nos Estados Unidos da América do Norte, pelo computador de uma empresa multinacional que opera com herbicidas no Brasil.

Para a realização da análise de variāncia, as notas originais relativas à avaliação visual as plantas invasoras aos 30, 60, 90 e 120 dias de idade foram transformadas em $\sqrt{x+1 / 2}$, conforme recomenda STEEL e TORRIE (1960), para possibilitar uma distribuição normal dos dados. 
Tabela 8. Escala de avaliação visual no controle de plantas invasoras.

\begin{tabular}{ll}
\hline Indice & Controle de ervas \\
\hline 0 & nenhum \\
1 & pobre \\
2 & pobre \\
3 & pobre \\
4 & pobre \\
5 & pobre \\
6 & pobre \\
7 & pobre \\
7,4 & pobre \\
$7,5-8,4$ & regular \\
$8,5-9,4$ & bom \\
$9,5-10,0$ & excelente \\
\hline
\end{tabular}

Os dados obtidos pela contagem individual de plantas aos 30

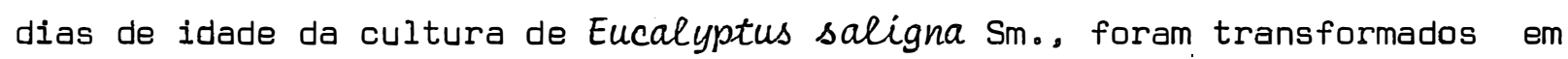
porcentagem de controle em relação a testemunha e colocados em quadro resumido para melhor compreensão.

4.2.4.2. Crescimento inicial do Eucalyptus saligna Smith

0 efeito dos herbicidas no desenvolvimento inicial de plantas de eucalipto foi avaliado pela análise dos parâmetros: grau de injúria, altura das plantas e diâmetro das copas.

O grau de injüria foi determinado pela observação visual, ba seando-se em sintomas típicos e atribuindo-se notas variáveis com intensida de de injúria, de acordo com a tabela de ALVES (1974), apresentada a seguir. 
Tabela 9. Escala de avaliação visual de injüria à cultura de Eucalyptus saligna Smith.

\begin{tabular}{cll}
\hline Indice & Grau de injüria & Sintomas \\
\hline 0 & Ausente & \\
1 & Leve & \\
2 & Leve & Folhas com clorose e manchas ne- \\
3 & Leve & crosadas. \\
4 & Moderado & \\
5 & Moderado & Folhas com clorose, manchas necro \\
6 & Moderado & sadas e queda das folhas. \\
8 & Severo & Folhas com clorose, manchas necro \\
9 & Severo & sadas, quedas das folhas, morte \\
10 & Severo & dos ramos. \\
\hline
\end{tabular}

A altura das plantas foi tomada aos 180 dias de idade, desde o nível do solo até o broto terminal. A medição foi realizada com uma vara graduada com aproximação de centímetro.

Aos 180 dias de idade foram medidos os diāmetrọ das : copas das plantas tomadas mo meio das árvores. A medição foi realizada com régua graduada com aproximação de centímetro.

\subsubsection{Determinação dos macronutrientes}

Para se determinar o conteüdọ de nitrogênio, fọ́sforo, potàssio, cälcio a magnésio existentes nas folhas dos diversos tratamentos foram coletadas amostras aos 60, 120 e 180 dias de idade após plantio do eucalipto, ou seja, no dia 17 de janeiro, 17 de março e 17 de maio de 1976.

As folhas foram colhidas no terço médio das copas e em torno Je todas as plantas de cada parcela. 
0 material assim coletado foi colocado em sacos de papel e secado em estufa até peso constante. Em seguida, foi moído e recolhido em vidraria especial para análise química posterior.

A análise foi realizada no laboratório de Análise Foliar da ESAL, Minas Gerais, sendo utilizados os seguintes métodos para cada macronu triente, de acordo com JOHNSON e ULRICH (1959).

Para o nitrogênio usou-se o método de Kjeldahl, com microdes tilador.

Para o fósforo, usou-se o processo colorimétrico.

Para o potássio, usou-se o método de fotometria de chamas.

Para o cálcio e magnésio, usou-se o processo de espectometria de absorção atômicà.

\subsubsection{Anālises estatîsticas}

Os dados obtidos pela média das alturas e diâmetro de copa foram analisados através da análise de variância.

Foi também realizada análise de variância para detectar dife renças de teores de nutrientes em folhas de Eucalyptus saligna Smith, aos 60,120 e 180 dias da instalação do experimento.

A análise de variância foi ainda usada para verificar diferenças de infestação entre os herbicidas usados nas diversas épocas do expe rimento, ou seja, aos $30,60,90$ e 120 dias após o plantio. 
5. RESULTADOS

\subsection{Teores de nutrientes}

\subsubsection{Teores de nutrientes aos 60 dias paōs plantio}

A Tabela 10 mostra o resumo da análise de variância e os coe ficientes de variação para todos os elementos estudados. A análise destes dados permitiram observar que não houve diferenças entre os teores de minerais encontrados em folhas de Eucalyptus saligna Smith, para todos os nutrientes, quando se comparou dosagens dos herbicidas oryzalin e DCPA com as testemunhas capinadas e não capinadas.

A Tabela 11 mostra os teores médios de cada elemento e das testemunhas bem como DMS a $5 \%$ de probabilidade correspondentes para compara ção,

Os coeficlentes de variação foram diferentes de um elemento para outro, conforme indica a Tabela 11. Segundo PIMENTEL GOMES (1970), coe ficientes de variação entre 0 e 10 é considerado baixo; entre 10 e 20 médio e acima de 20 alto. 
Tabela 10. Resumo da anpalise de variância para teores minerais em folhas de Eucalyptus saligna $\mathrm{Sm} .$, aos 60 dias após plantio. Mogi-Guaçu (SP), 1976.

F.V.

Quadrado Médio

N $\quad P \quad$ K

Ca

$\mathrm{Mg}$

Herbicida 1

$0,040837 \quad 0,001441$

0,009599

0,037604

0,000016

Dosagem/ $/ H_{1} 2$

0,128659

0,001659

0,001600

0,008809

0,001173

R.L

0,238050

0,000050

0,003200

0,013613

0,001540

$R \cdot Q$

0,019267

0,003267

0,000000

0,004004

0,000805

Dosagem/ $/ H_{2} 2$

0,189634

0,000848

0,033100

0,028659

0,003745

R.L

0,110450

0,000300

0,048050

0,001250

0,000105

R.Q

0,268817

0,001395

0,018150

0,056067

0,007385

(Fatorial)

(5)

0,135484

0,001291

0,015800

0,022507

0,001961

Fat. vs. Test. 1

0,060503

0,000162

0,003384

0,034884

0,000429

Cap. vs. s/cap. 1

0,004049

0,002415

0,019012

0,048049

0,001485

\begin{tabular}{lccllll} 
(Tratamentos) & $(7)$ & 0,105996 & 0,001290 & 0,014485 & 0,027924 & 0,001674 \\
Blocos & 3 & 0,041478 & 0,000131 & 0,056228 & 0,008411 & 0,001354 \\
Residuo & 21 & 0,068480 & 0,002031 & 0,019406 & 0,041806 & 0,002147 \\
\hline C.V. & 7,56 & 20,14 & 8,92 & 24,84 & 22,06 \\
\hline
\end{tabular}

$H_{1}=$ Oryzalin

$\mathrm{H}_{2}=\mathrm{DCPA}$ 


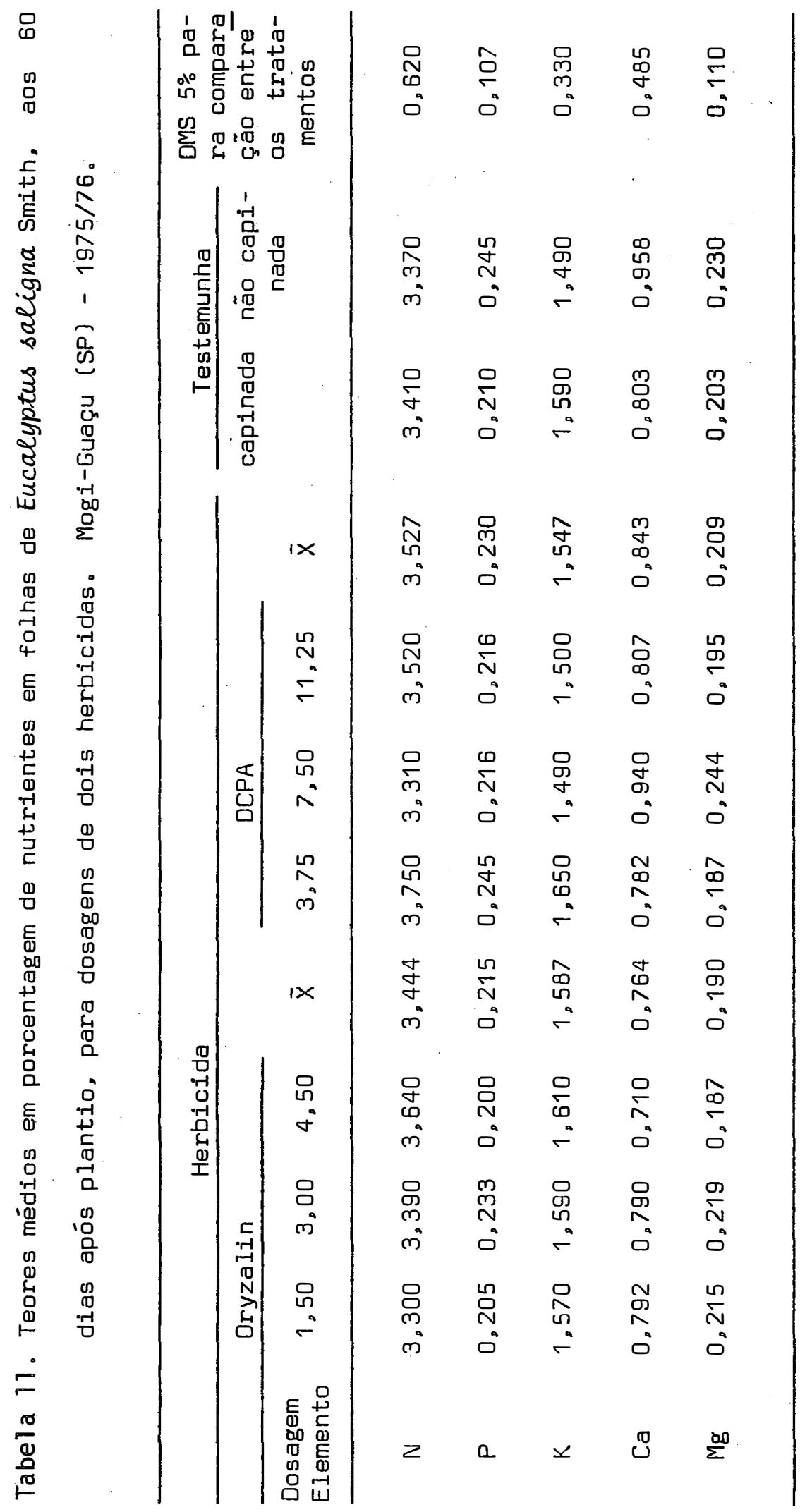




\subsubsection{Teores de nutrientes aos 120 dias apōs plantio}

Na Tabela 12 são encontradas as informações estatísticas relativas a análise de variância. O desdobramento dos graus de liberdade para as dosagens dos dois herbicidas, mostrou significância para $P$ com relação aos herbicidas oryzalin e DCPA e para Ca somente com relação ao oryza lin. São mostrados ainda na Tabela 12, os coeficientes de variação para to dos os tratamentos.

A Tabela 13 mostra as médias de todos os tratamentos compara dos entre si pelo teste de Tuckey.

A Figura 1 mostra as alterações nos teores de $P$ e Ca presentes na matéria seca das folhas de Eucalyptus saligna Smith, com os níveis de oryzalin utilizados. As respectivas equações e os coeficientes de determinação estão contidos na Figura 1. Observa-se que o máximo de $P$ foi obtido com aproximadamente $2,41 \mathrm{~kg} / \mathrm{ha}$ de oryzalin ao passo que para o $\mathrm{Ca} O$ ponto máximo foi de $3,0 \mathrm{~kg} / \mathrm{ha}$.

A Figura 2 mostra as modificações nos teores de $P$ em folhas de $E$. saligna $\mathrm{Sm}$. em função dos níveis de DCPA. As equações e coeficientes de determinação correspondentes estão contidos na figura mencionada. 0 pon to máximo de $P$ foi obtido com cerca de $7,5 \mathrm{~kg} / \mathrm{ha}$ de DCPA, aos 120 dias após o plantio.

\subsubsection{Teores de nutrientes aos 180 dias apōs plantio.}

A Tabela 14 apresenta o resumo da análise de variância para teores minerais aos 180 dias após plantio em folhas de Eucalyptus saligna Sm. e os coeficientes de variação para cada elemento analisado. O desdobra mento dos graus de liberdade para dosagens dentro dos herbicidas mostram significância a $5 \%$ de probabilidade para regressão linear dentro do herbici da oryzalin e a $1 \%$ de probabilidade para regressão linear dentro do DCPA. 
Tabela 12. Resumo da análise de variância para teores minerais em folhas de Eucalyptus saligna Sm., aos 120 dias após plantio. Mogi-Guaçu, SP $-1975 / 76$.

F.V.

Quadrados Médios

\begin{tabular}{lllll}
\hline & $P$ & $\mathrm{Ca}$ & $\mathrm{Mg}$ \\
\hline
\end{tabular}

Herbicida

0,077966*

0,000308

0,074816

0,014016

0,000384

Dosagem/ $H_{1}$

0,007809

$0,001077 * *$

0,025900

$0,024359 *$

0,001603

R.L

0,000113

$0,001405 * *$

0.051200

0,022050

0,000190

$R \cdot Q$

0,015504

$0,000748 *$

0,000600

0,026667 *

0,003015

Dosagem $/ \mathrm{H}_{2}$

0,029734

0,000654 *

0,008034

0,006359

0,001573

R.L

0,007200

0,000001

0,000050

0,000113

0,000242

$R \cdot Q$

0,052267

$0,001306 * * \quad 0,016017$

0,012604

0,002904

(Fatorial) (5)

0,030430

$0,000754 * * \quad 0,28536$

0,015090*

0,001358

Fat. vs. test. 10,004539

0,000002

0,000126

0,000600

0,002320

Cap. vs. s/cap.1 0,011250

0,000561 *

0,005512

0,000050

0,001770

(Tratamentos

(7) 0,023991

0,000619

0,021188

0,010871

0,001554

Blocos

30,003271

$0,000028 * *$

$0,078769 *$

0,019433 *

0,000685

Resíduo

$21 \quad 0,015301$

0,000124

0.017788

0,005457

0,000785

C.V.

4,18

6,60

11,74

9,09

13,65

* Efeito significativo ao nível de 5\% de probabilidade

** Efeito significativo ao nível de $1 \%$ de probabilidade

$H_{1}=$ Oryzalin

$\mathrm{H}_{2}=\mathrm{DCPA}$ 


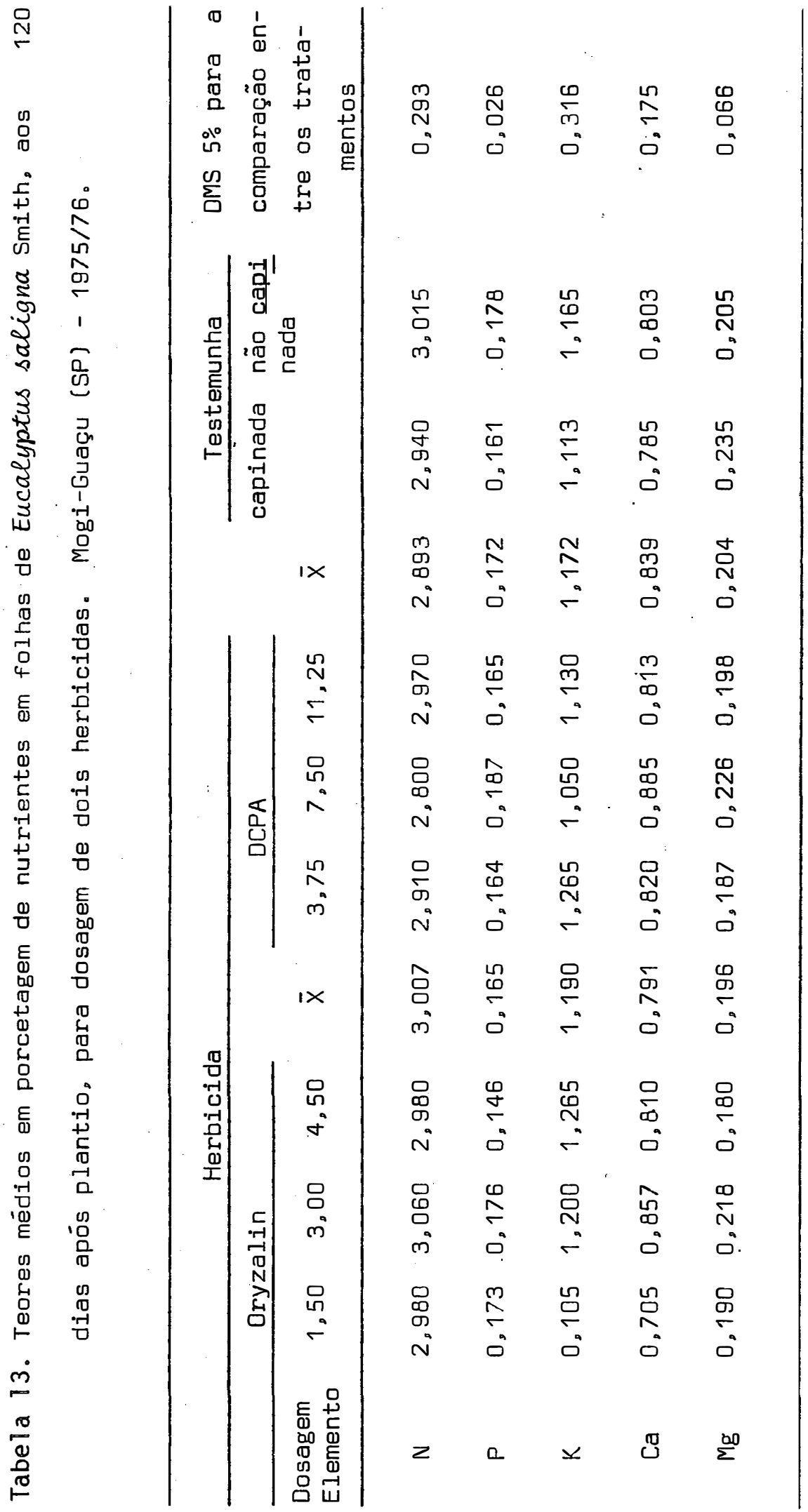



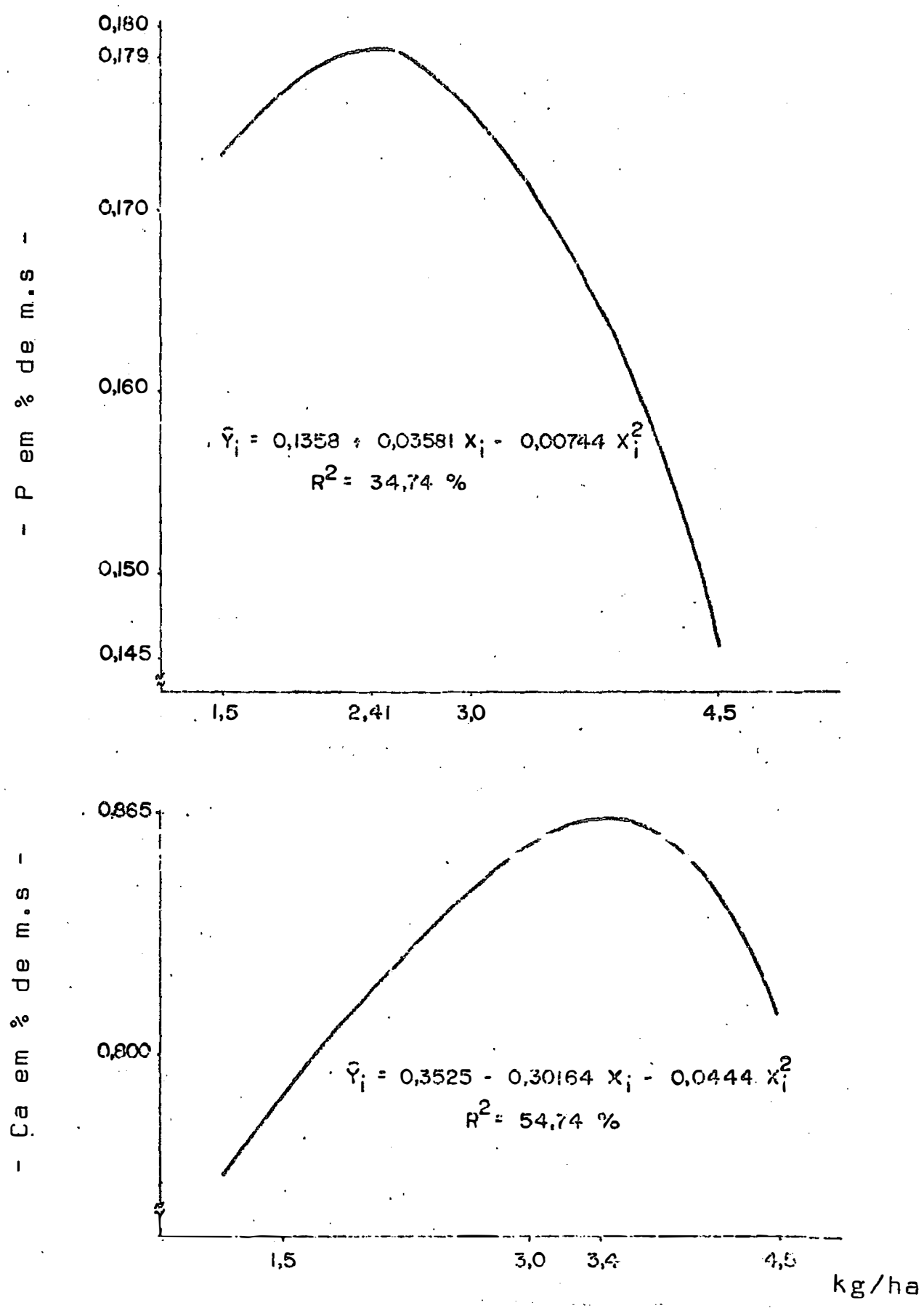

Figura 1. Representação gráfica dos teores de $P$ e Ca em folhas de: Eucalyptus saligna $S m_{0}$, em função de três dosagens $\left(p_{\circ} a_{\circ}\right)$, do 'herbicida oryzalin aos 120 dias após plantio. 


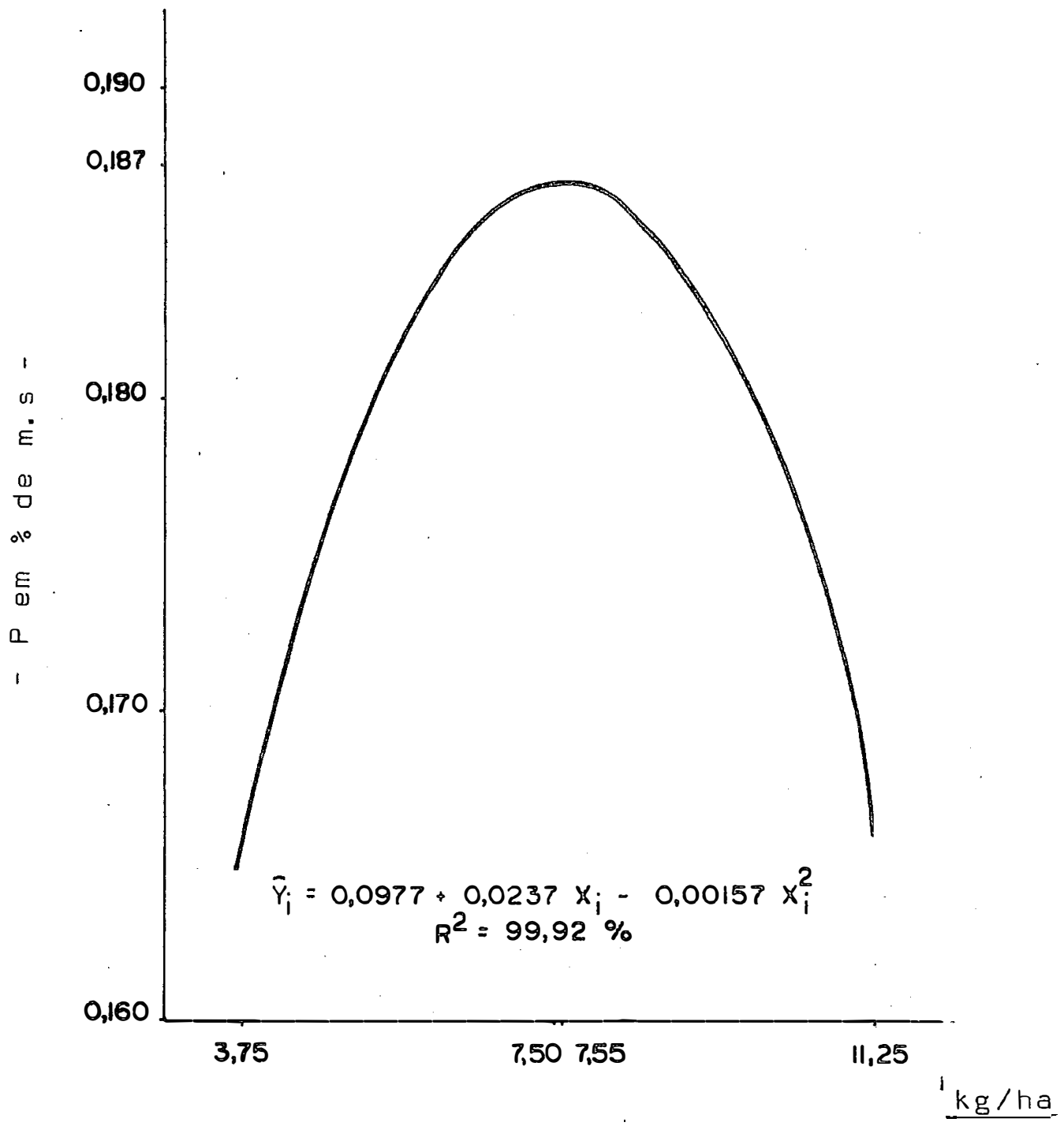

Figura 2. Representação gráfica dos teores de $P$ em folhas de Eucalyptus saligna $\mathrm{Sm}_{0}$, em função de três dosagens $\left(p_{0} a_{0}\right)$ do herbicida DCPA aos 120 dias após plantio. 
Na Tabela 15 são apresentadas as médias dos teores minerais encontrados em folhas de Eucalyptus saligna $\mathrm{Sm}$ 。 aos 180 dias de idade, para todas as dosagens e para as testemunhas. São apresentados ainda nesta tabe la, os DMS a 5\% de probabilidade para comparação entre os tratamentos.

A Figura 3 mostra as alterações no teor de $K$ nas folhas de E. saligna $\mathrm{Sm}$ 。 em função das dosagens do DCPA.

Na Figura 4 estão representadas as alterações no teor de $\mathrm{Mg}$ nas folhas de $E$. saligna $\mathrm{Sm}$. em função de dosagens do herbicida oryzalin, bem assim, a equação de regressão linear obtida para teores de Mg para os níveis de dosagens aplicados. O coeficiente de determinação encontrado foi elevado $\left(R^{2}=99,83\right)$ 。

\subsection{Fitotoxidade dos herbicidas ao Eucalyptus saligna Smith}

A ação fitotóxica dos herbicidas oryzalin e DCPA sobre a cul tura de Eucalyptus saligna Smith, foi estudada pela medição de diāmetro de copa, altura de planta e avaliação visual de injúria.

As médias das notas de injúria, encontradas aos $30,60,90$ e 120 dias após plantio estão apresentadas nas Tabelas 22, 24,26 e 28 .

O resumo das análises de variância para as notas de injúria. obtidas aos 60, 90 e 120 dias, está contido nas Tabelas 23, 25 e 27 respectivamente. Ocorreu diferença significativa apenas para as notas atribuidas aos 120 dias após plantio. Observou-se respostas linear e quadrática para os níveis de dosagens de oryzalin e apenas quadrática para níveis de DCPA (Tabela 27).

Os parâmetros altura de planta e diàmetro de copa de Eucalyp tus saligna Smith, tomados aos 180 dias após plantio, serviram para avaliar o efeito fitotóxico dos herbicidas oryzalin e DCPA sobre o crescimento inicial das plantas de Eucalipto. O resumo da análise de variância para os dois parâmetros encontra-se na Tabela 16. Somente houve efeito significati vo a nivel de $5 \%$ de probabilidade, entre as doses do herbicida DCPA, com re 
lação ao diâmetro da copa das plantas. A Tabela 17, mostra as médias para altura de planta e diámetro de copa, bem como, o DMS a $5 \%$ de probabilidade para comparação entre os tratamentos. Na Figura 5, esta a representação da equação de regressão quadrática obtida para o diāmetro da copa, com relação as doses de DCPA utilizadas.

Tabela 14. Resumo da anälise de variância para teores minerais em folhas de Eucalyptus saligna Sm., aos 180 dias após plantio. Mogi-Guaçu. $\mathrm{SP}-1975 / 76$ 。

\begin{tabular}{|c|c|c|c|c|c|}
\hline \multirow{2}{*}{ F.V. } & \multicolumn{5}{|c|}{ Quadrados médios } \\
\hline & $N$ & $\mathrm{P}$ & K & $\mathrm{Ca}$ & $\mathrm{Mg}$ \\
\hline Herbicida & 0,010837 & 0,000001 & 0,004004 & 0,003504 & 0,000337 \\
\hline Dosagem/ $/ H_{1}$ & 0,001900 & 0,000067 & 0,006434 & 0.001759 & 0.000577 \\
\hline R.L. & 0,003200 & 0,000113 & 0,004050 & 0,002450 & $0,001152 *$ \\
\hline$R . Q$. & 0,000600 & 0,000020 & 0,008817 & 0,001067 & 0,000002 \\
\hline Dosagem/ $/ \mathrm{H}_{2}$ & 0,013825 & 0,000079 & $0,043234 * *$ & 0,006825 & 0,000127 \\
\hline R.L. & 0,023112 & 0,000018 & $0,076050 * *$ & 0,013614 & 0,000050 \\
\hline R.Q. & 0,004538 & 0,000140 & 0,010417 & 0,000037 & 0,000204 \\
\hline (Fatorial) (5) & 0,008457 & 0,000058 & $0,020667 *$ & 0,004134 & 0,000344 \\
\hline Fat. vs. Test. 1 & 0,002401 & 0,000088 & 0,003384 & 0,004816 & 0,000004 \\
\hline Cap. vs. s/cap. 1 & 0,002112 & 0.000050 & 0,001800 & 0,002812 & 0,000000 \\
\hline (Tratamentos) (7) & 0,006685 & 0,000061 & $0,015503^{*}$ & 0,004042 & 0,000246 \\
\hline Blocos & 0,000225 & 0,000127 & 0,008136 & 0,004491 & 0,000302 \\
\hline Resíduo & 0,007889 & 0,000096 & 0,006007 & 0,006553 & 0,000216 \\
\hline C.V. & 3,41 & 6,88 & 9,80 & 10,24 & 7,38 \\
\hline
\end{tabular}

* Efeito significativo ao nível de $5 \%$ de probabilidade

** Efeito significativo ao nível de $1 \%$ de probabilidade

$H_{1}=$ Oryzalin

$\mathrm{H}_{2}=\mathrm{DCPA}$ 


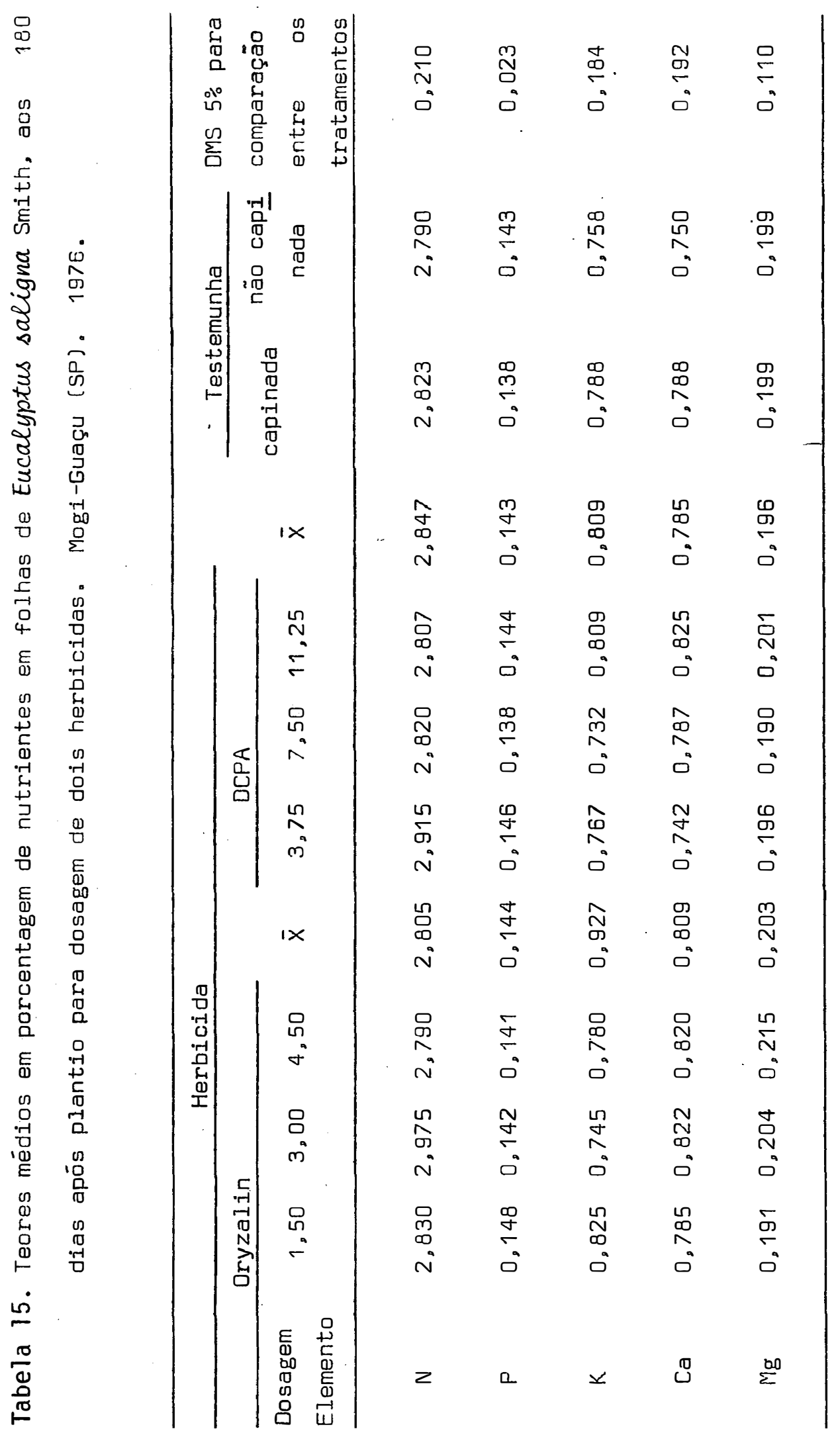




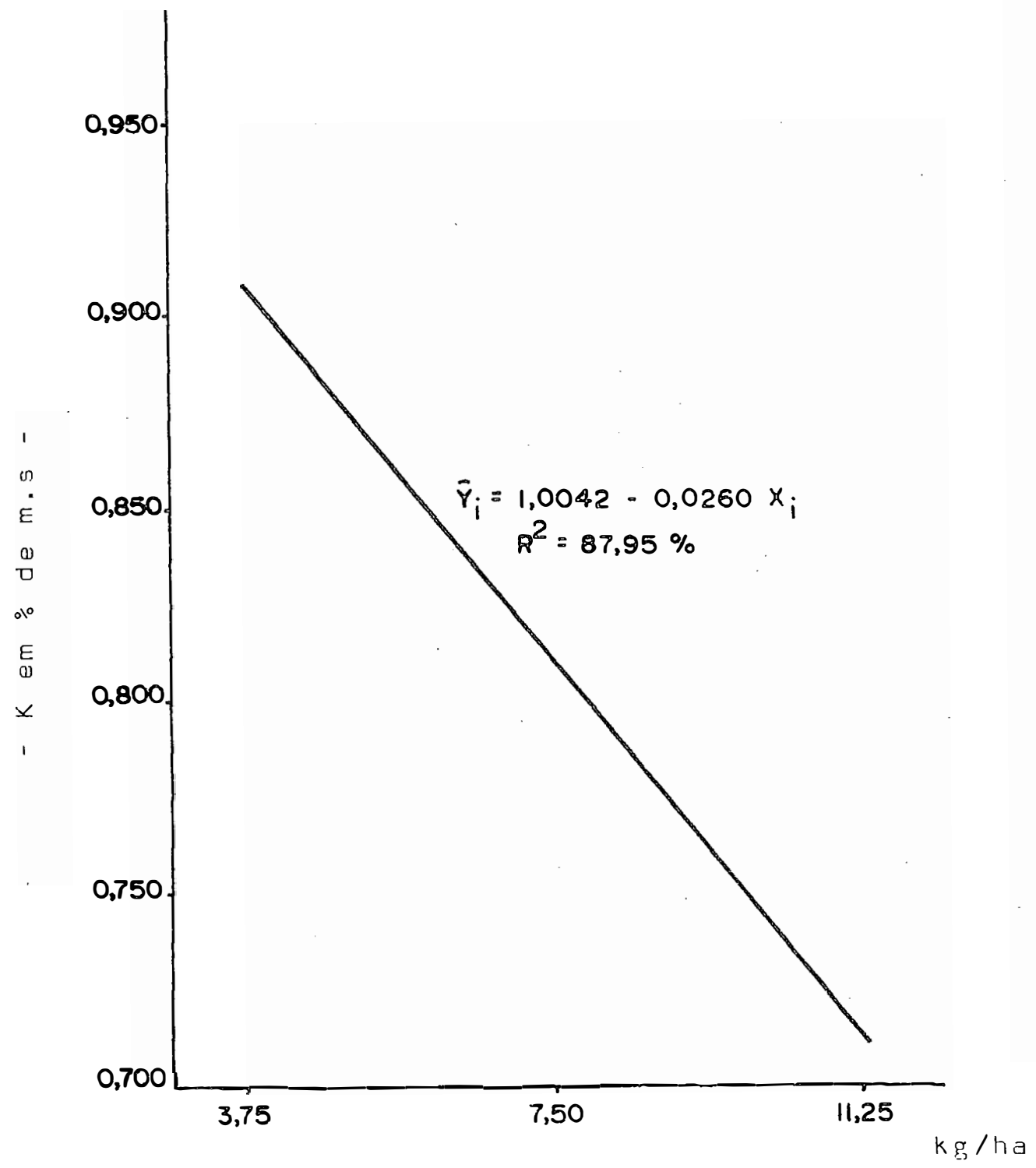

Figura 3. Representação gráfica dos teores de $K$ em folhas de Eucalyptus saligna $\mathrm{Sm}$. em função de três dosagens (p.a.) do herbicida DCPA aos 180 dias após plantio. 


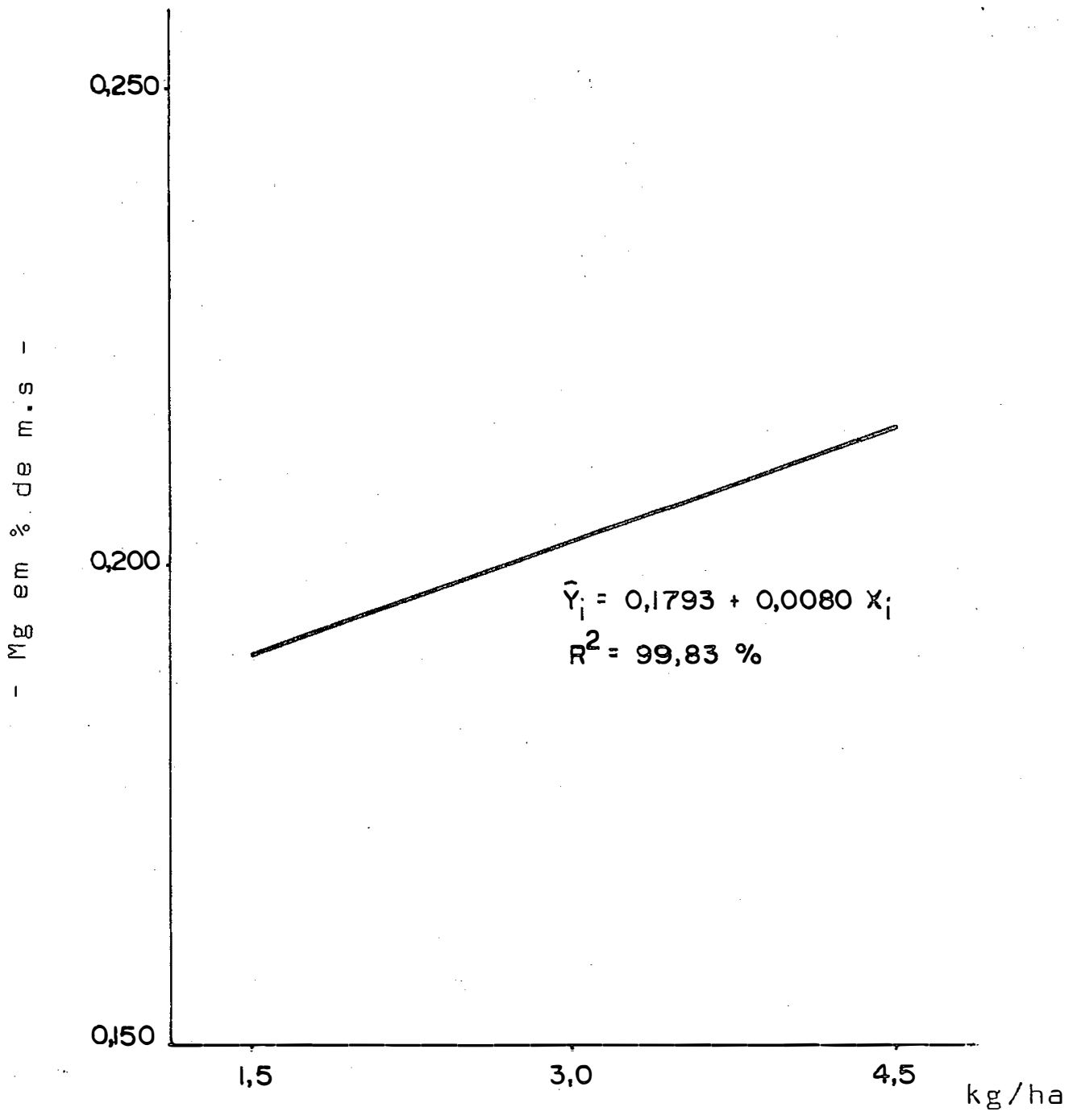

Figura 4, Representação gräfica dos teores de Mg em folhas de Eucalyptus sa ligna Sm. em função de três dosagens $\left(p . a_{\bullet}\right)$ do herbicida oryzalin aos 180 dias após plantio. 
Tabela 16. Resumo da análise de variância para altura e diâmetro de copa de Eucalyptus saligna Sm., aos 180 dias após plantio. Mogi-Guaçu, SP. $1975 / 76$.

\begin{tabular}{|c|c|c|c|}
\hline \multirow{2}{*}{ F.V. } & \multirow{2}{*}{$\mathrm{GL}$} & \multicolumn{2}{|c|}{ Quadrados Médios } \\
\hline & & Diâmetro de Copa & Altura de plantas \\
\hline Herbicida & 1 & 0,006667 & 0,0164808 \\
\hline Dosagem/ $/ \mathrm{H}_{1}$ & 2 & 0,080833 & 0,164808 \\
\hline R.L. & 1 & 0,011250 & 0,234613 \\
\hline R.Q.' & 1 & 0,150417 & 0,234613 \\
\hline Dosagem $/ H_{2}$ & 2 & $0,263333^{*}$ & 0,095004 \\
\hline R.L. & 1 & 0,245000 & 0,121058 \\
\hline R.Q. & 1 & $0,281667 *$ & 0,177013 \\
\hline (Fatorial) & $(5)$ & $(0,139000)$ & $(0,124247)$ \\
\hline Fat. vs. test. & 1 & 0,028359 & 0,000151 \\
\hline Cap. vs. s/cap. & 1 . & 0,227812 & 0,262812 \\
\hline (Tratamentos) & $(7)$ & $(0,135881)$ & $(0,126314)$ \\
\hline Blocos & 3 & 0,315494 & 0,212609 \\
\hline Resíduo & 21 & 0,058590 & 0,075265 \\
\hline c.v. & & 14,96 & 9,78 \\
\hline
\end{tabular}

\footnotetext{
* Efeito significativo ao nível de $5 \%$ de probabilidade ** Efeito significativo ao nível de $1 \%$ de probabilidade

$H_{1}=$ Oryzalin

$\mathrm{H}_{2}=\mathrm{DCPA}$
} 


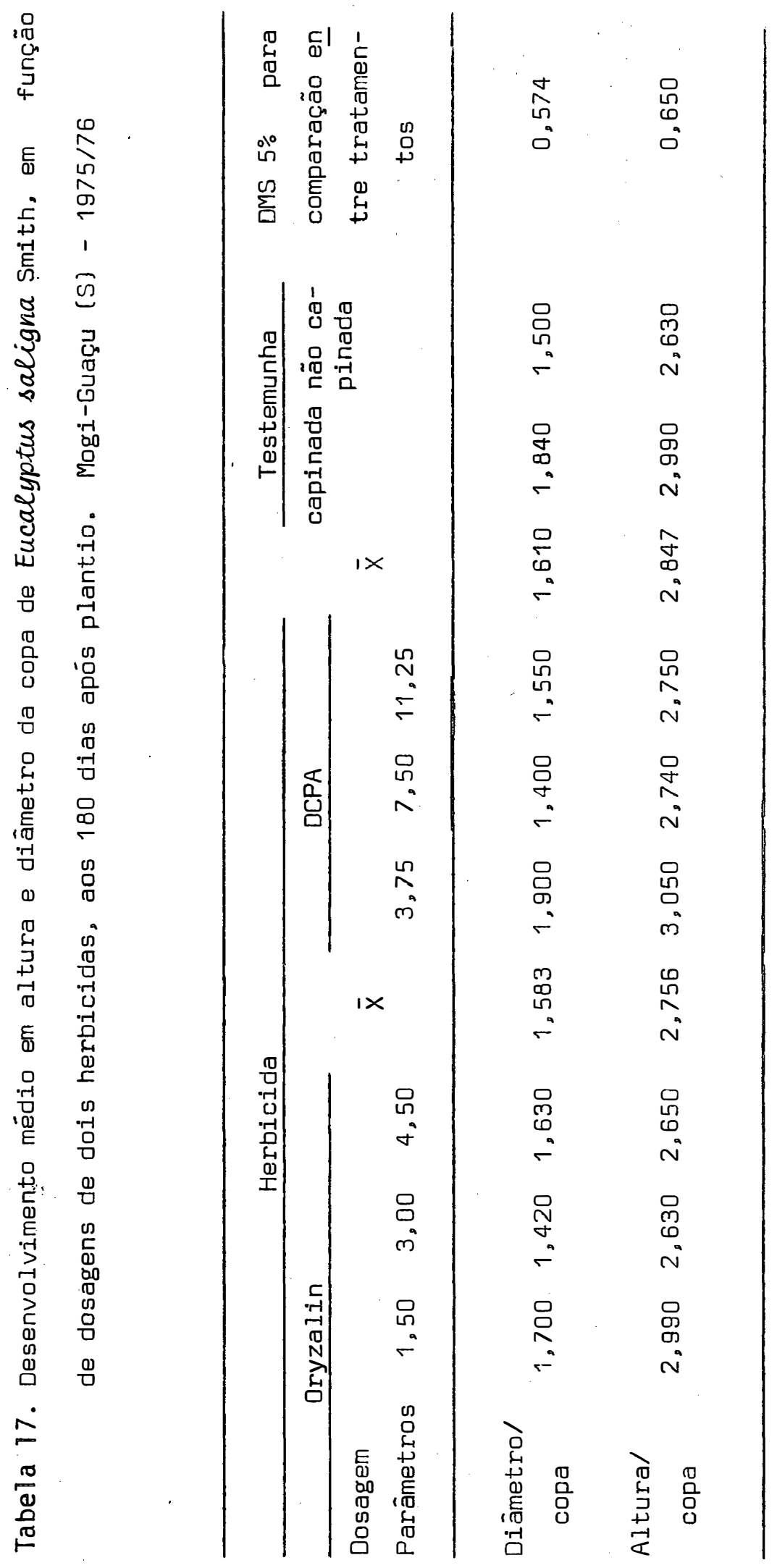




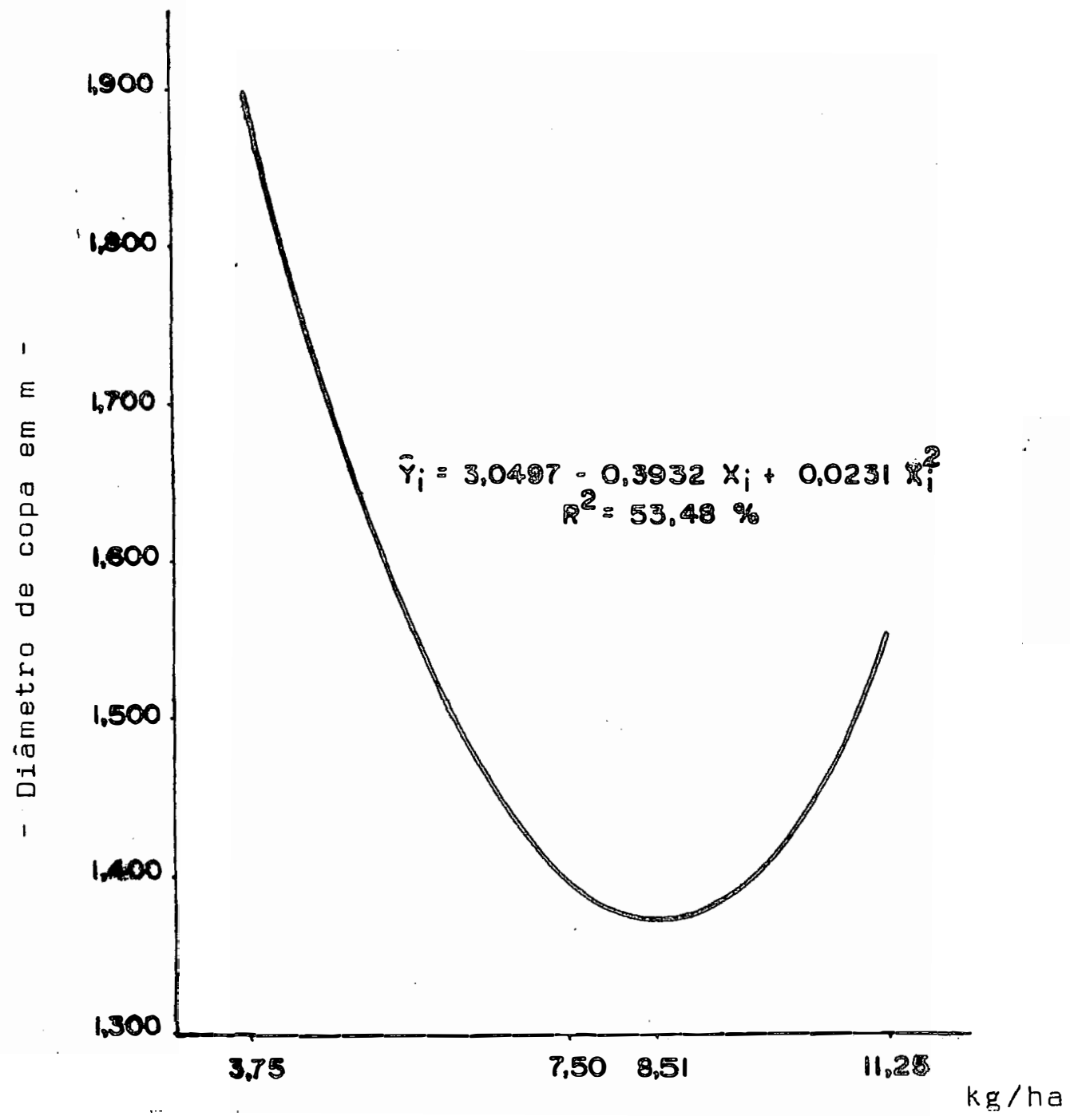

Figura 5. Representação gräfica do desenvolvimento do diâmetro de copa de Eucalyptus saligna $\mathrm{Sm}$. em função de três dosagens do herbicida DCPA, aos 180 dias após plantio. 


\subsection{Plantas invasoras}

As invasoras mais comuns encontradas na ärea experimental es tão na Tabela 18.

Tabela 18. Espécies invasoras encontradas em cultura de Eucalyptus saligna Smith. Mogi-Guaçu (SP) - 1975/76。

\begin{tabular}{lll}
\hline Nome Cientifico & Nome Comum & Familia \\
\hline Amaranthus hybridus L. & Caruru & Amasanthaceae \\
Marmodica charantia L. & Melãozinho & Curcubitaceae \\
Bracharia plantaginea (Link) Hitch & Marmelada & Gramineae \\
Sida spp. & Guanxuma & Malvaceae \\
Portulaca oleraceae L. & Beldroega & Portulaceae \\
Bidens pilosa L. & Picão Preto & Compositae \\
Digitaria sanguinalis (L) Scop. & Capim-Colchão & Gramineae \\
Ipomea spp. & Corda-de-Viola & Convolvulaceae \\
Cyperus spp. & Tiririca & Cyperaceae \\
Commelina spp. & Trapueraba & Commelinaceae
\end{tabular}

\subsubsection{Contagem individual de plantas invasoras aos 30 dias apōs plantio}

Realizada a contagem individual de plantas invasoras aos 30 dias de idade, com uso de um retângulo de $50 \mathrm{~cm}$ de comprimento e 20 fe largura, obteve-se os resultados em porcentagem contidos nas Tabelas 19 e 20 . Estes resultados foram comparados com as testemunhas capinadas e não capina das.: Na Tabela 19, encontram-se os números absolutos de plantas invasorás obtidas nos diversos tratamentos e na testemunha não capinada. As espécies mais frequentes na áréa, foram baseadas na contagem de plantas invasoras existentes na testemunha não capinada, foram Commelina spp, Sida spp, Cyperus spp e Amaranthus hybridus.

$\mathrm{Na}$ Tabela 20 estão as porcentagens de controle de plantas in vasoras calculadas em relação a testemunha capinada. 


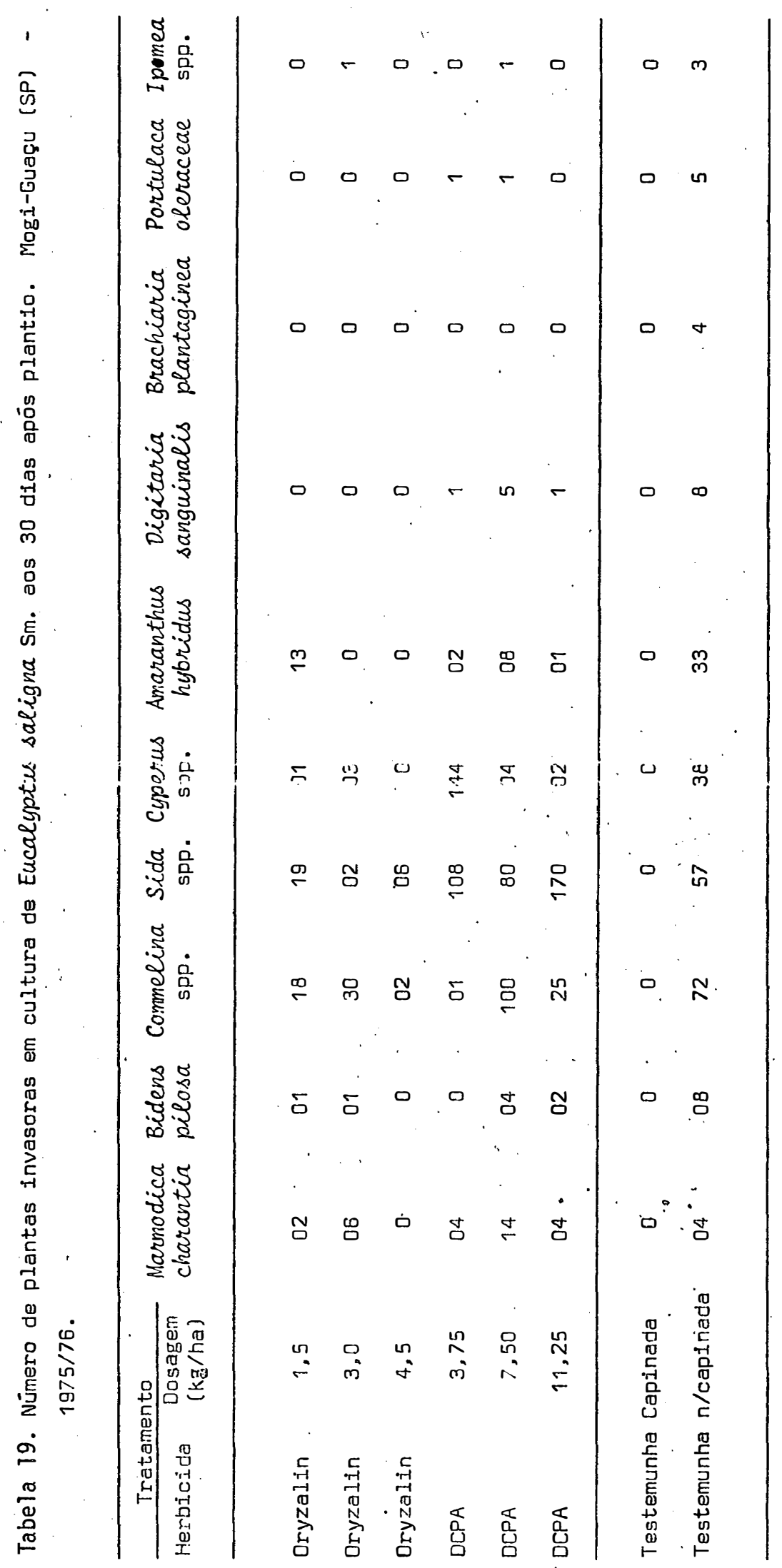




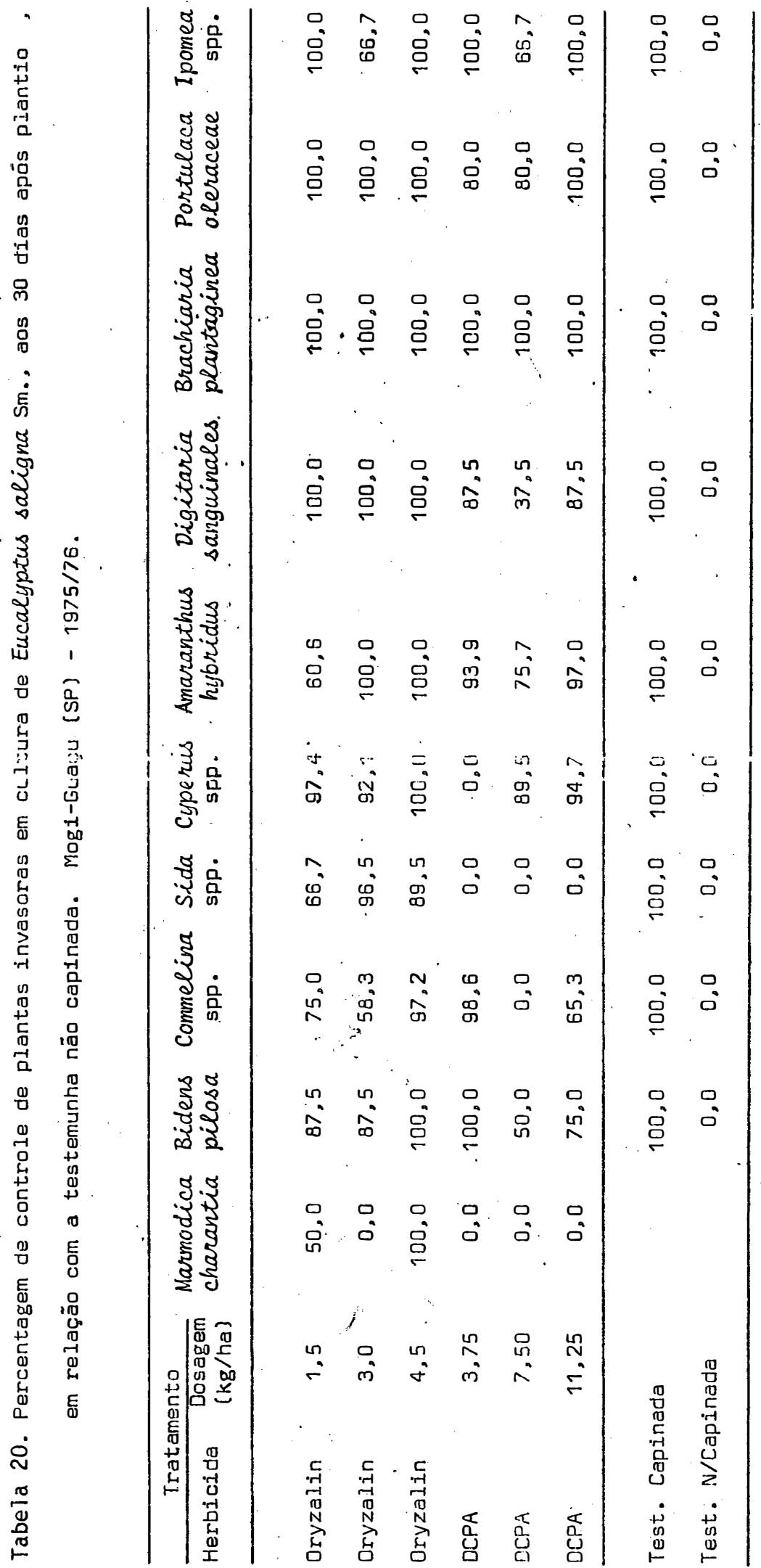


5.3.2. Avaliação visual de plantas invasoras aos 30 dias apos plantio

A avaliação visual procedida aos 30 dias após a instalação do experimento foi baseada no sistema EWRC, citado por ALVES (1974)。

Após análise dos dados, cujo resumo da análise de variância encontra-se na Tabela 21, verificou-se regressões significativas para todas as espécies de plantas invasoras estudadas, exceto para Commelina spp e Ama ranthus hybridus L.. Na mesma tabela são encontrados os coeficientes de va riação os quais, não foram elevados.

As médias das notas atribuídas a cada espécie, para todas do sagens e testemunhas estão contindas na Tabela 22, bem como, os DMS a $5 \%$ de probabilidade correspondentes, que poderão ser utilizados para comparação entre os tratamentos. Na mesma tabela encontram-se as notas atribuidas a injüria causada a cultura de Eucalyptus saligna Smith, aos 30 dias de idade.

Nas Figuras 6 a 9 são encontradas as representações gráficas co controle de várias plantạ invasoras e as equações de regressão linear ou quadrática correspondentes as variações do controle em função das dosa gens dentro de cada herbicida. Os coeficietes de determinação de cada curva, estão contidos nas figuras 6 a 9. Com excessão do coeficiente de deter minação para a curva da Sida spp. nas dosagens do herbicida DCPA que foi $25,56 \%$ e do de Marmodica charantia L. para dosagens do herbicida oryzalin todos os demais foram elevados. 


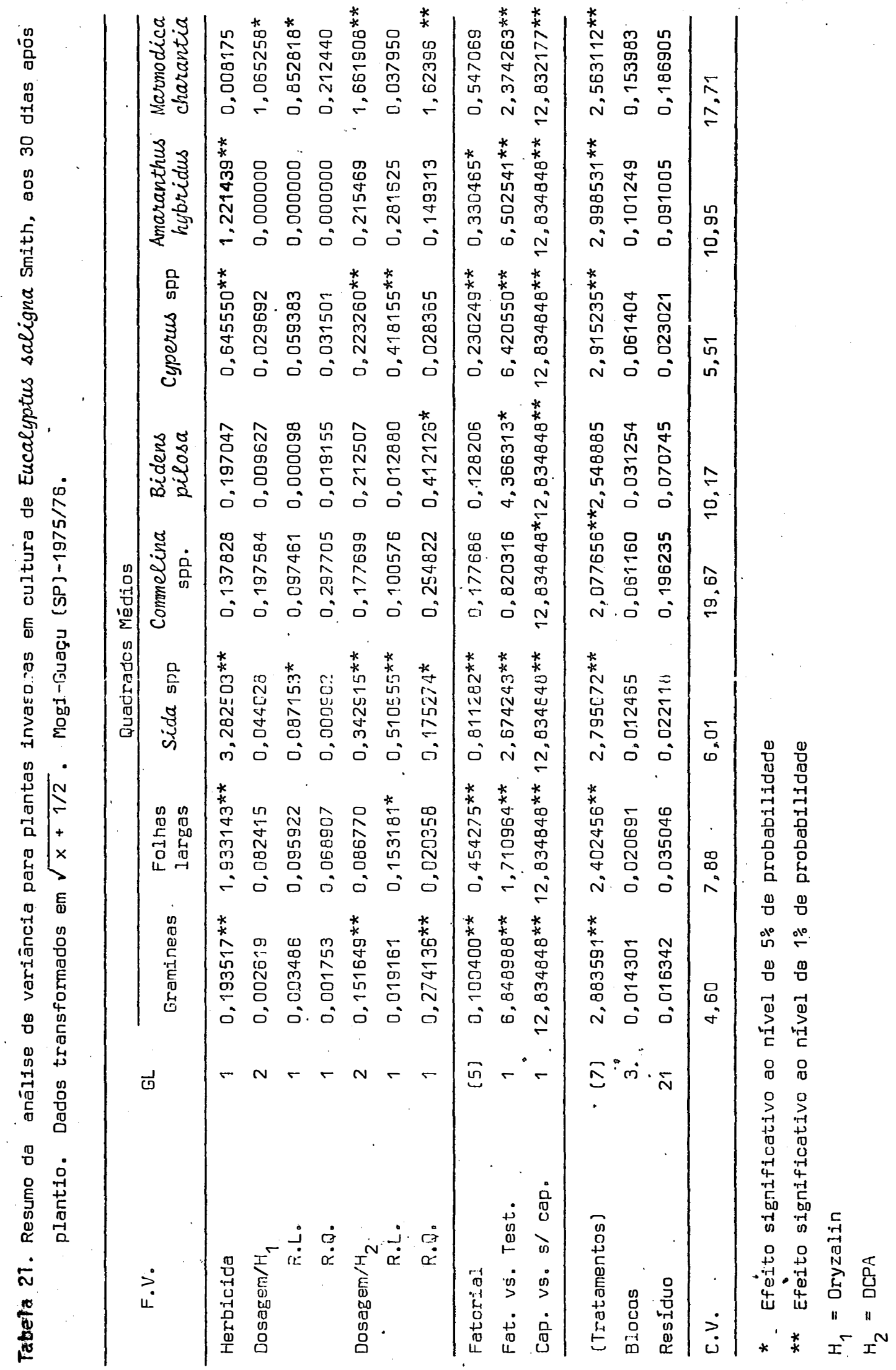




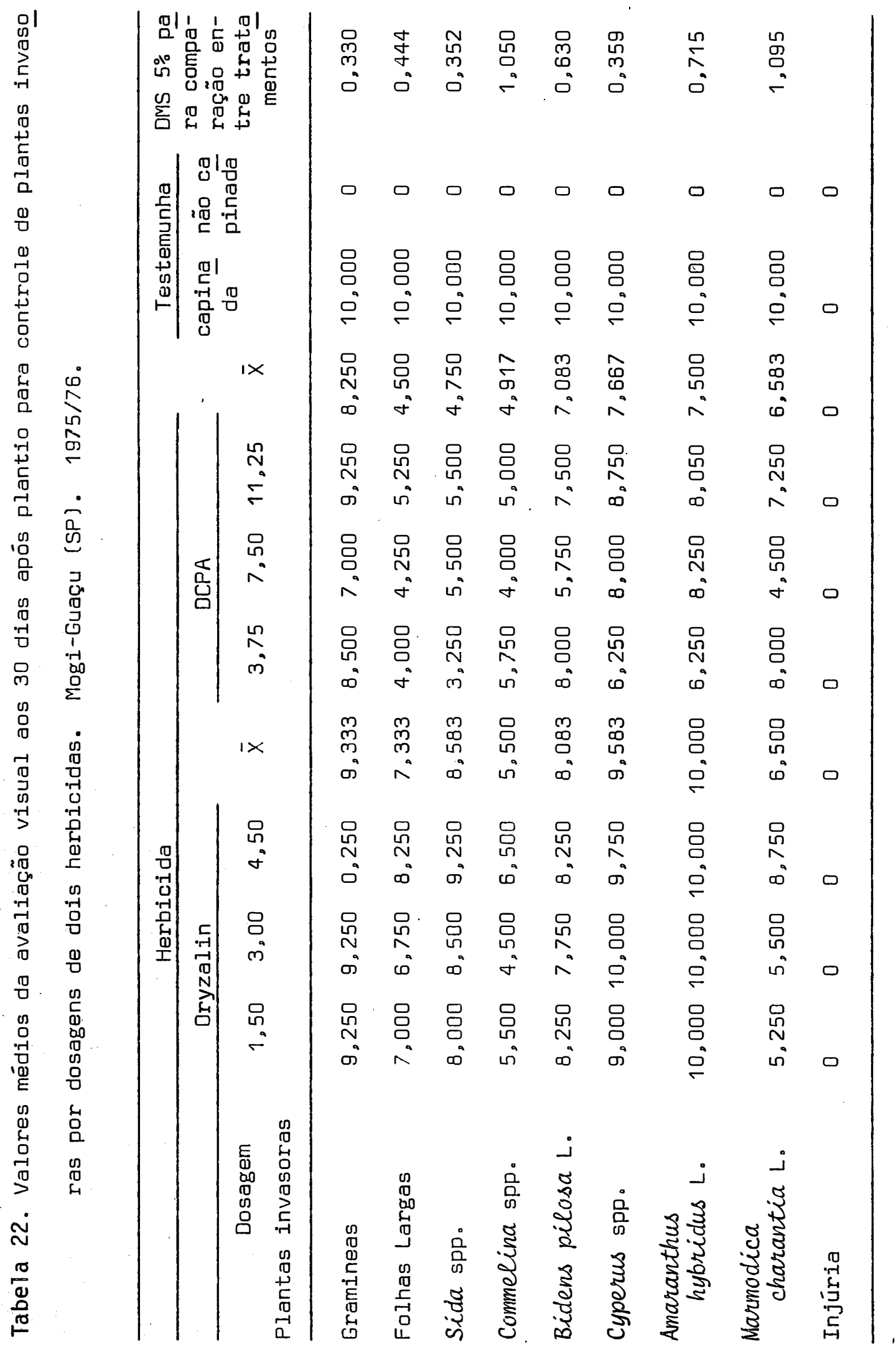




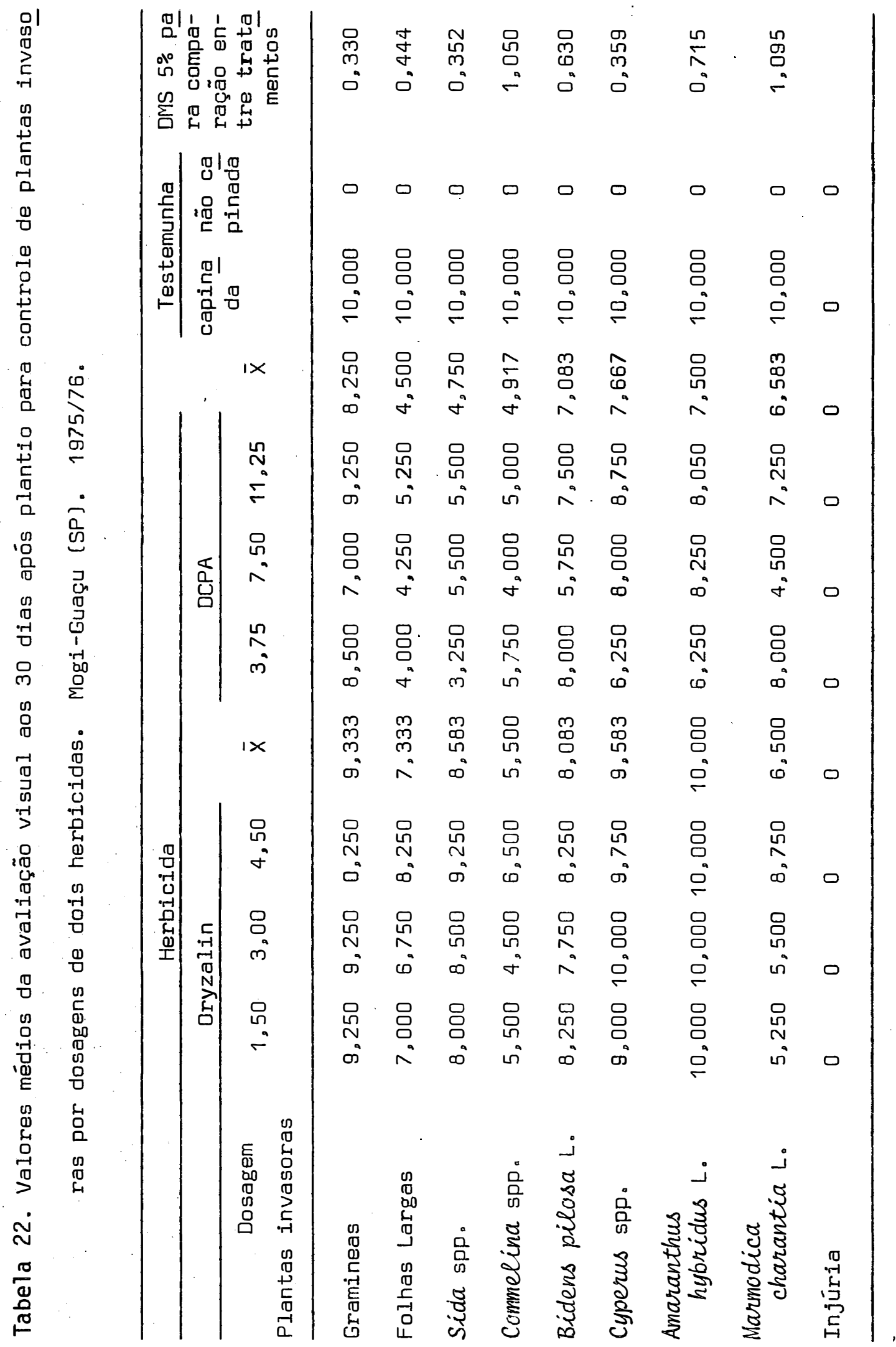



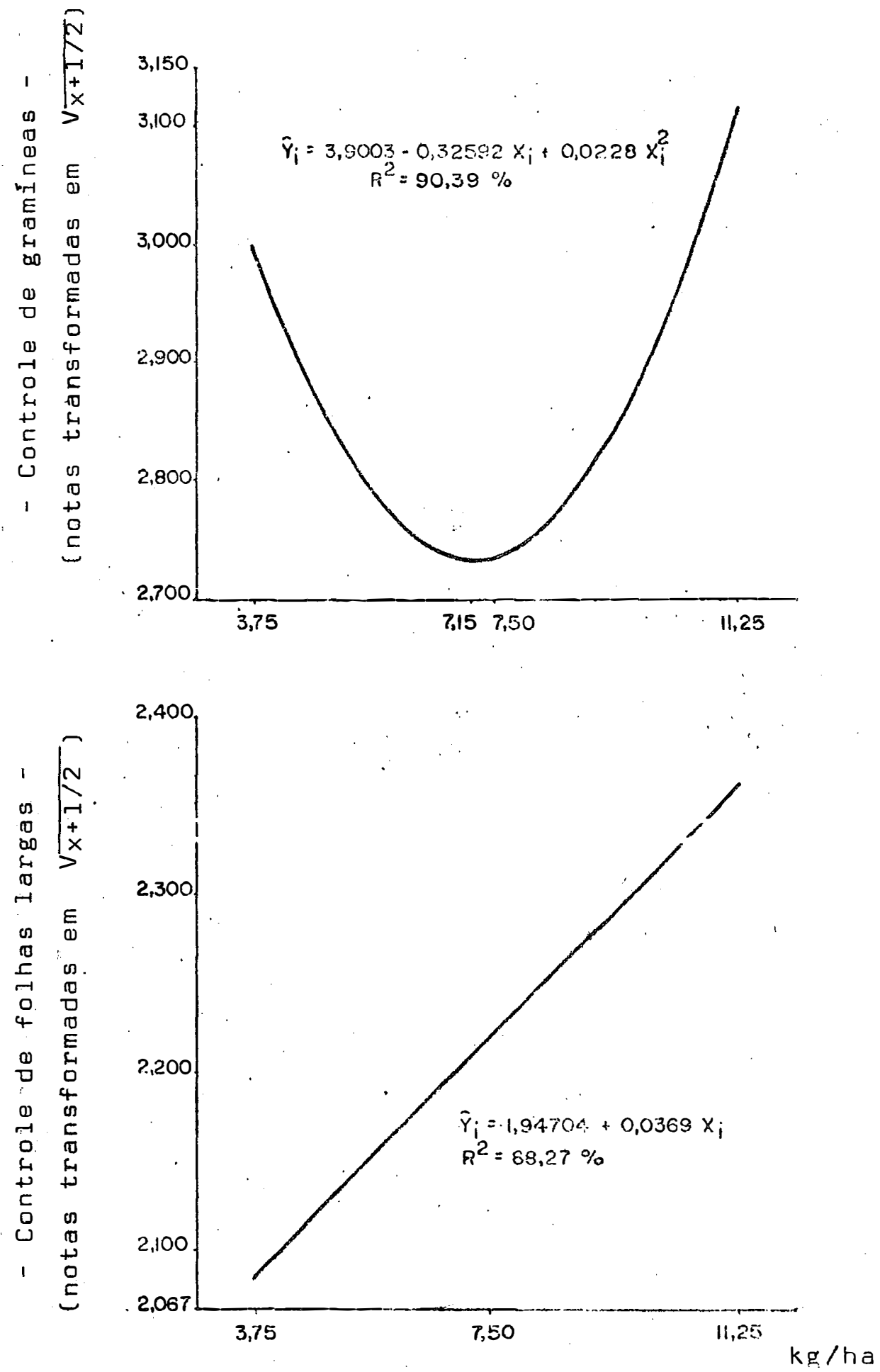

Figura 6. Representações gráficas do controle de gramineas e folhas largas em função de três dosagens $\left(p_{\circ} a_{\circ}\right)$ do herbicida DCPA, aos 30 dias apös plantio. 

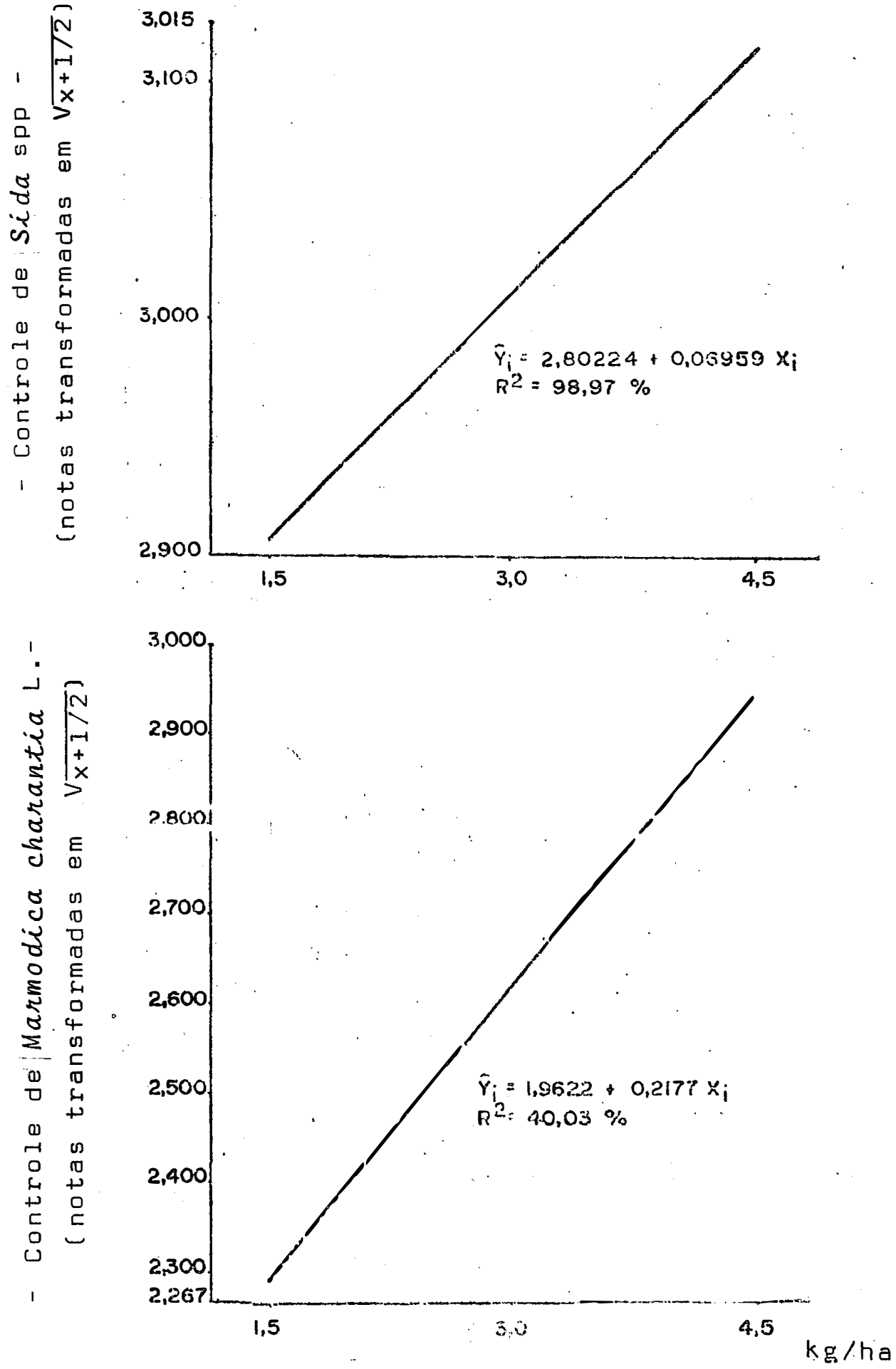

Figura 7. Representação gráfica do controle de Sida spp e Marmodica charantia L. em função de três dosagens (p.a.) do herbicida oryzalin aos 30 dias após plantio. 

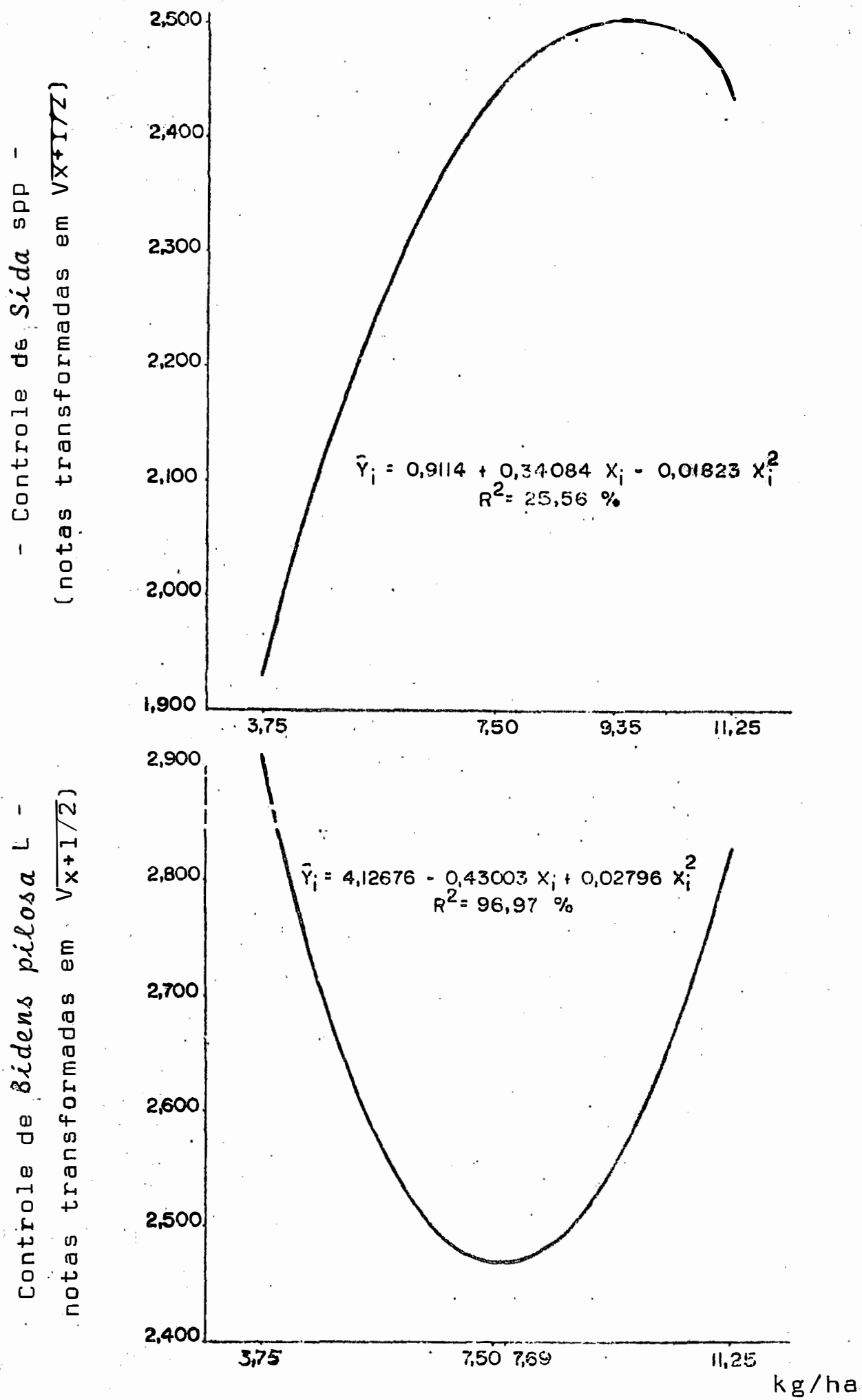

Figura 8. Representações gráficas do controle de Sida spp e Bidens pilosa L. em função de três dosagens do herbicida DCPA, aos 30 dias após plantio. 
.56.
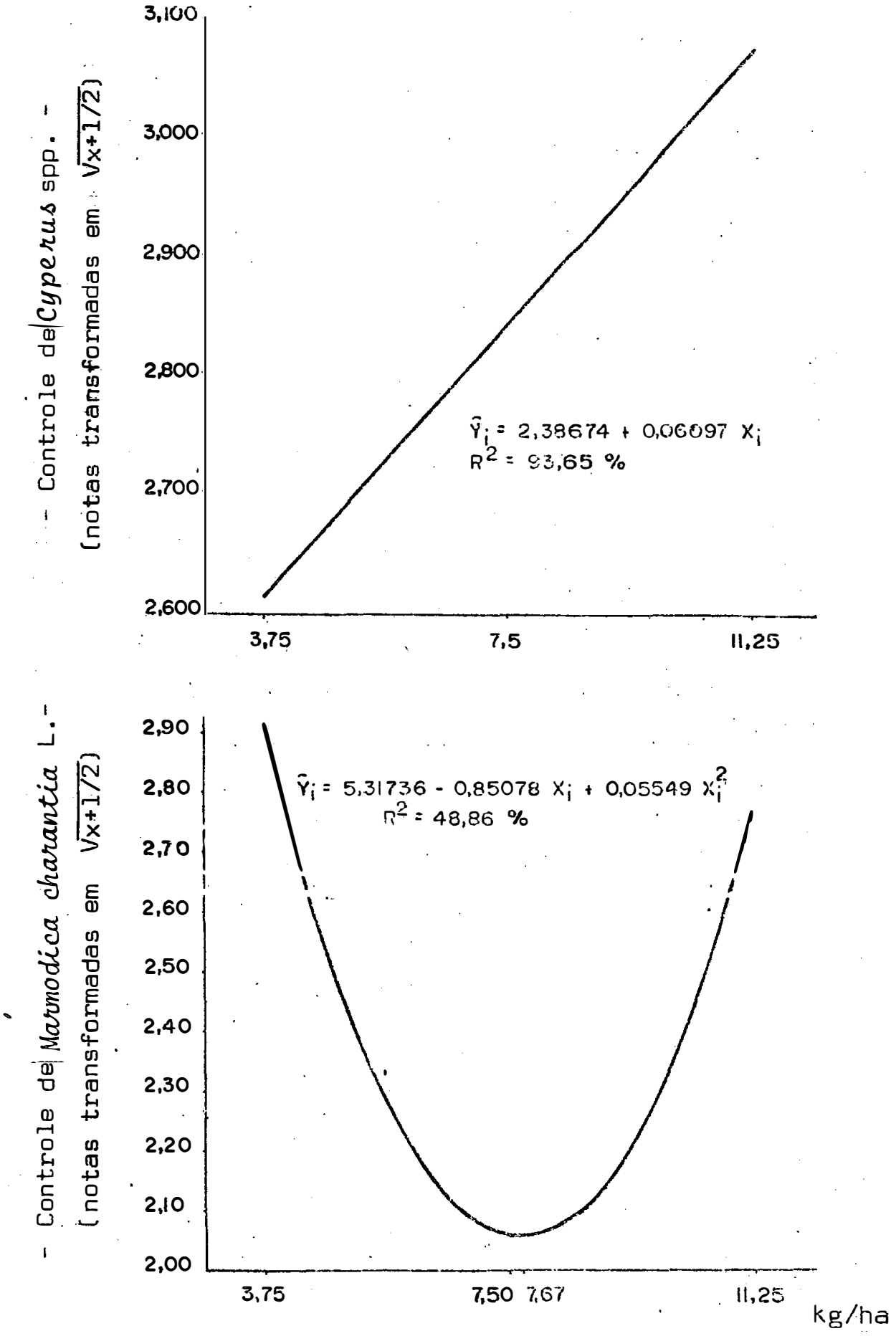

Figura 9. Representações gráficas do controle de Cyperus spp e Marmodica charantia $L$. em função de três dosagens (p.a.) do herbicida DCPA, aos 30 dias após plantio. 
5.3.3. Avaliação visual de plantas invasoras e injūrias aos 60 dias apōs plantio

A análise de variância dos dados obtidos através da avaliação visual de plantas invasoras aos 60 dias após plantio e transformados em $\sqrt{x+1 / 2}$, estão apresentados na Tabela 23 , cujo resumo mostra efeito significativo para regressão para dosagens de todas espécies encontradas na ärea.

A Tabela 23 apresenta ainda os coeficientes de variação cujas magnitudes variaram de 29,26 a 6,10. Embora alguns estudos indiquem que coeficiente de variação de 29,26 seja alto, para os estudos de plantas inva soras, onde a distribuição das mesmas é irregular este valor é considerado aceitável.

Enquanto as espécies de folhas largas, apresentam regressão significativa a nível de $5 \%$ para ambos os herbicidas usados, as demais espécies de plantas invasoras mostram significância para dosagens de um her bicida apenas, como se observa na Tabela 23.

A comparação entre todos os tratamentos, inclusive entre os tratamentos e as testemunhas, realizada através do teste Tuckey, está conti da na Tabela 24.

0 desdobramento dos graus de liberdade permite o traçado das curvas de regressão que refletem o controle de plantas invasoras e as dosagens dos herbicidas oryzalin e DCPA. Os gráficos 10, 11, 12 e 13 mostram a tendência do controle de plantas invasoras em função das dosagens dos her bicidas aos 60 dias após plantio.

Nos gráficos 10,11, 12 e 13 encontram-se também os coeficientes de determinação para cada curva estudada. 


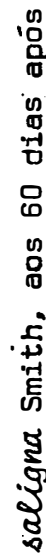

కี

焉

的

总

ஸ

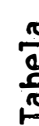




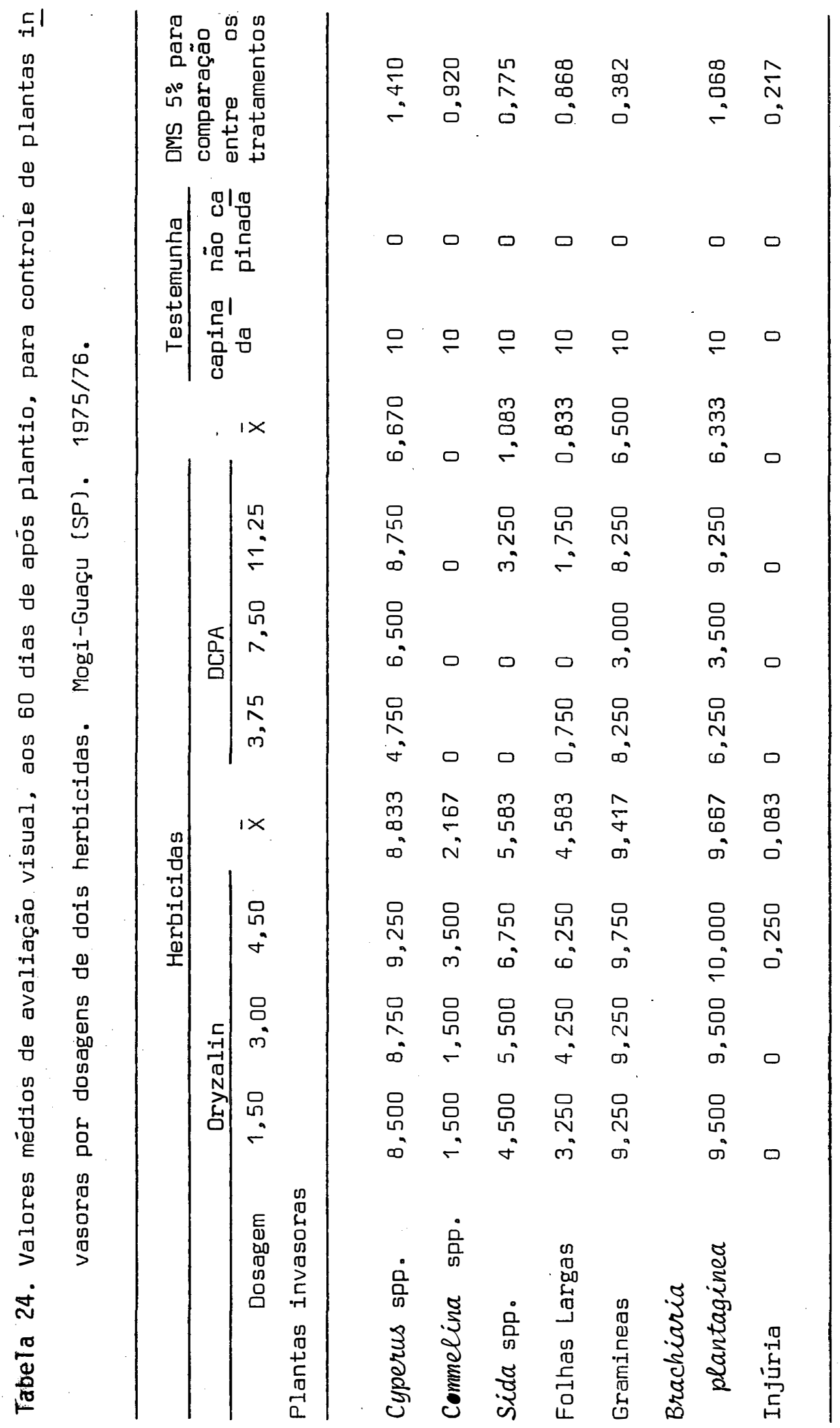




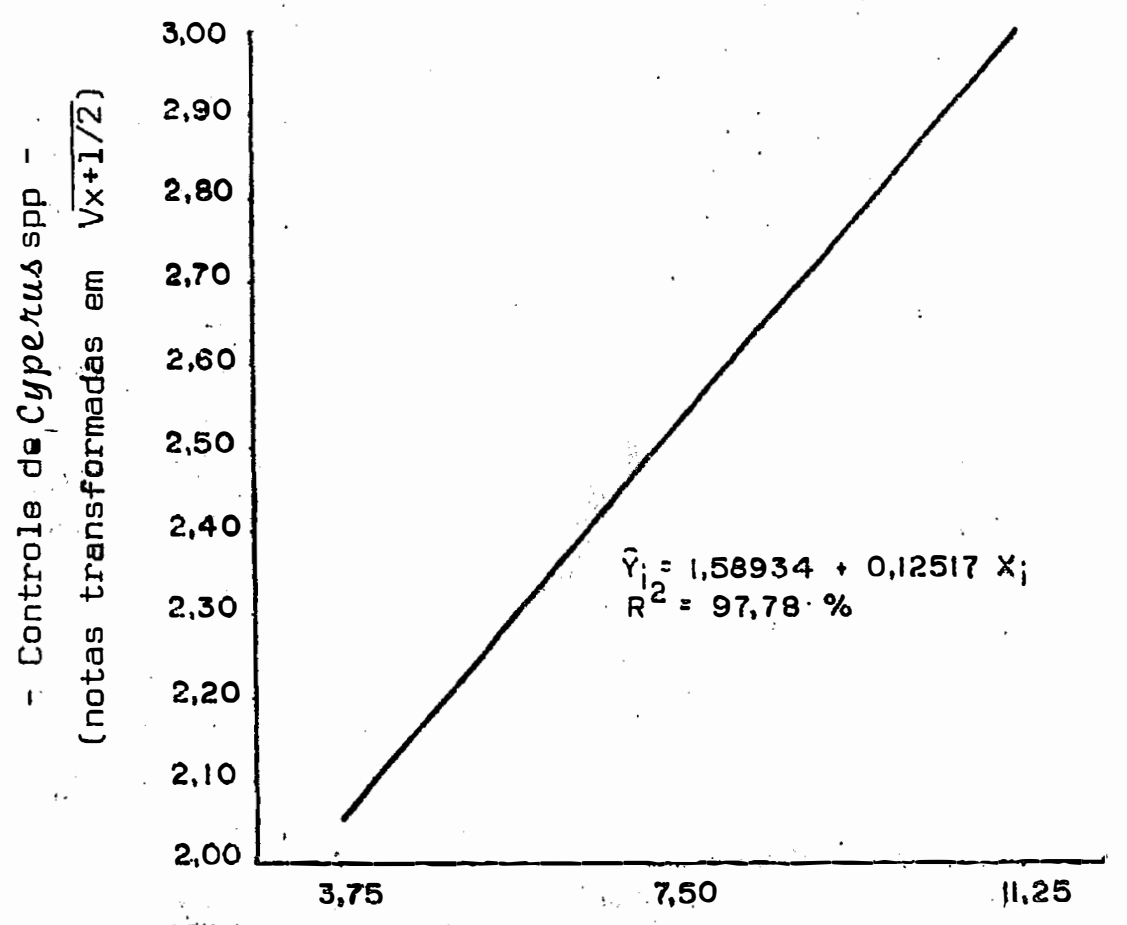

.60.

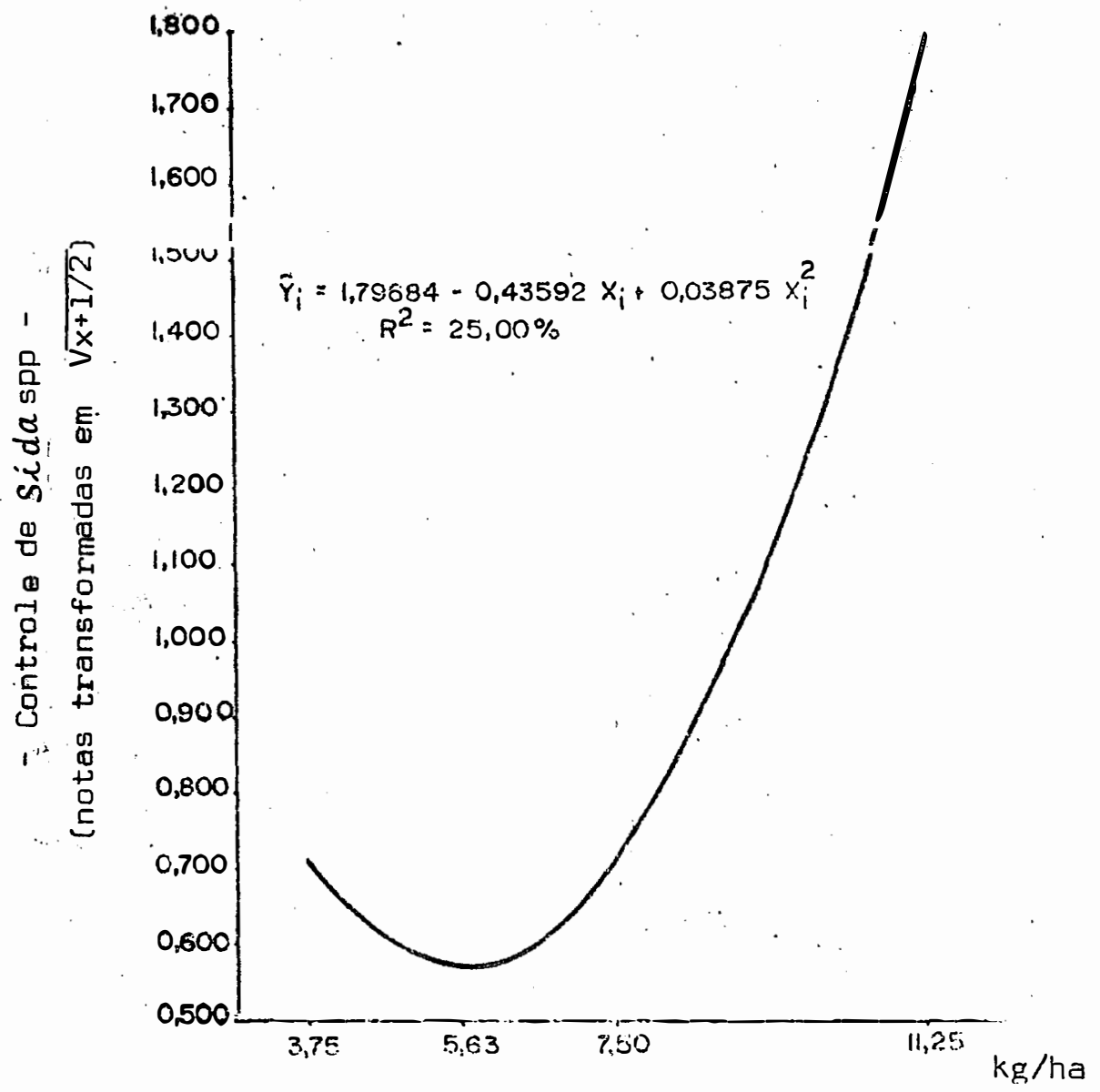

Fịgura 10. Representaçães gräficas do controle de Cyperus spp e Sida spp,em função de trés dasagens (p.a.) do herbicida DCPA, aos 60 dias após plantio. 


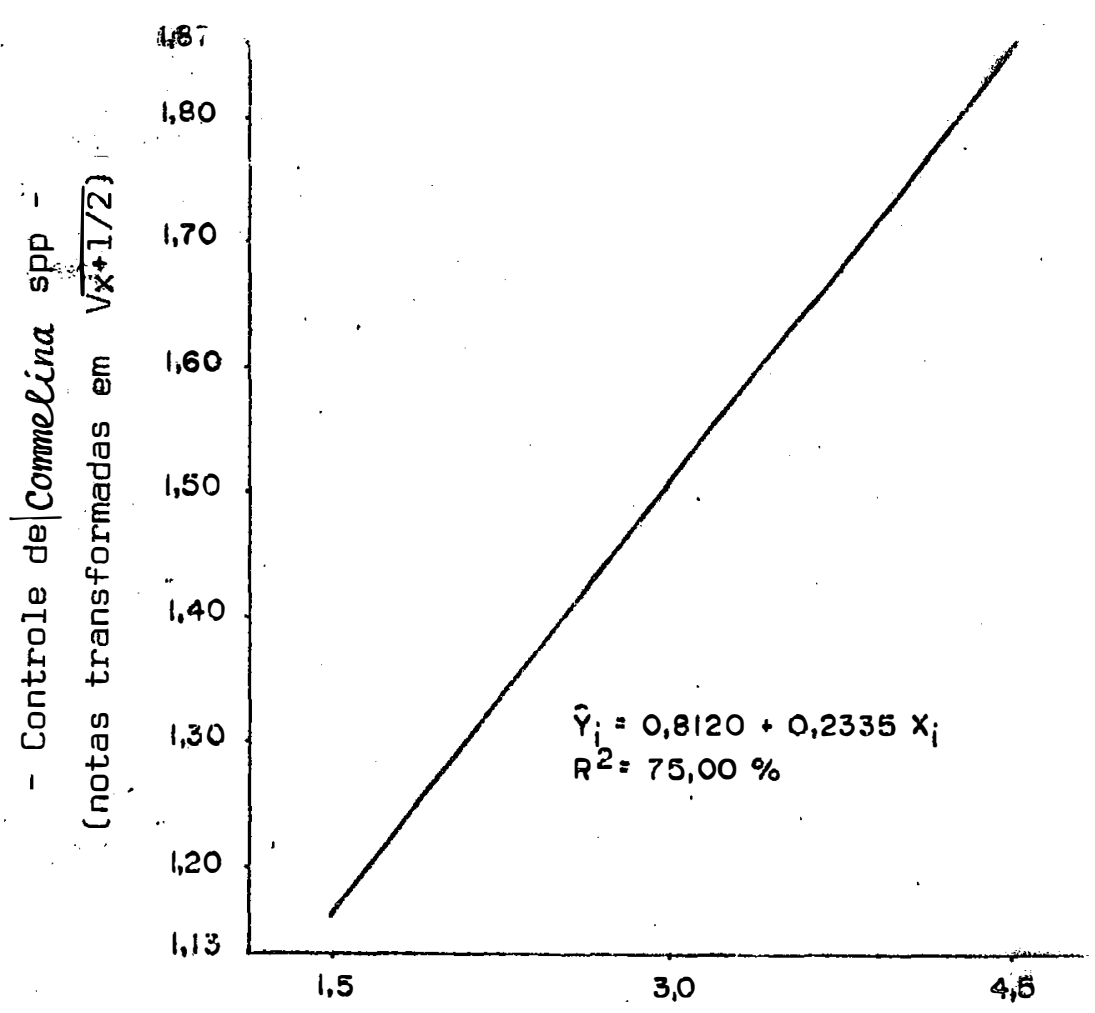

.61.

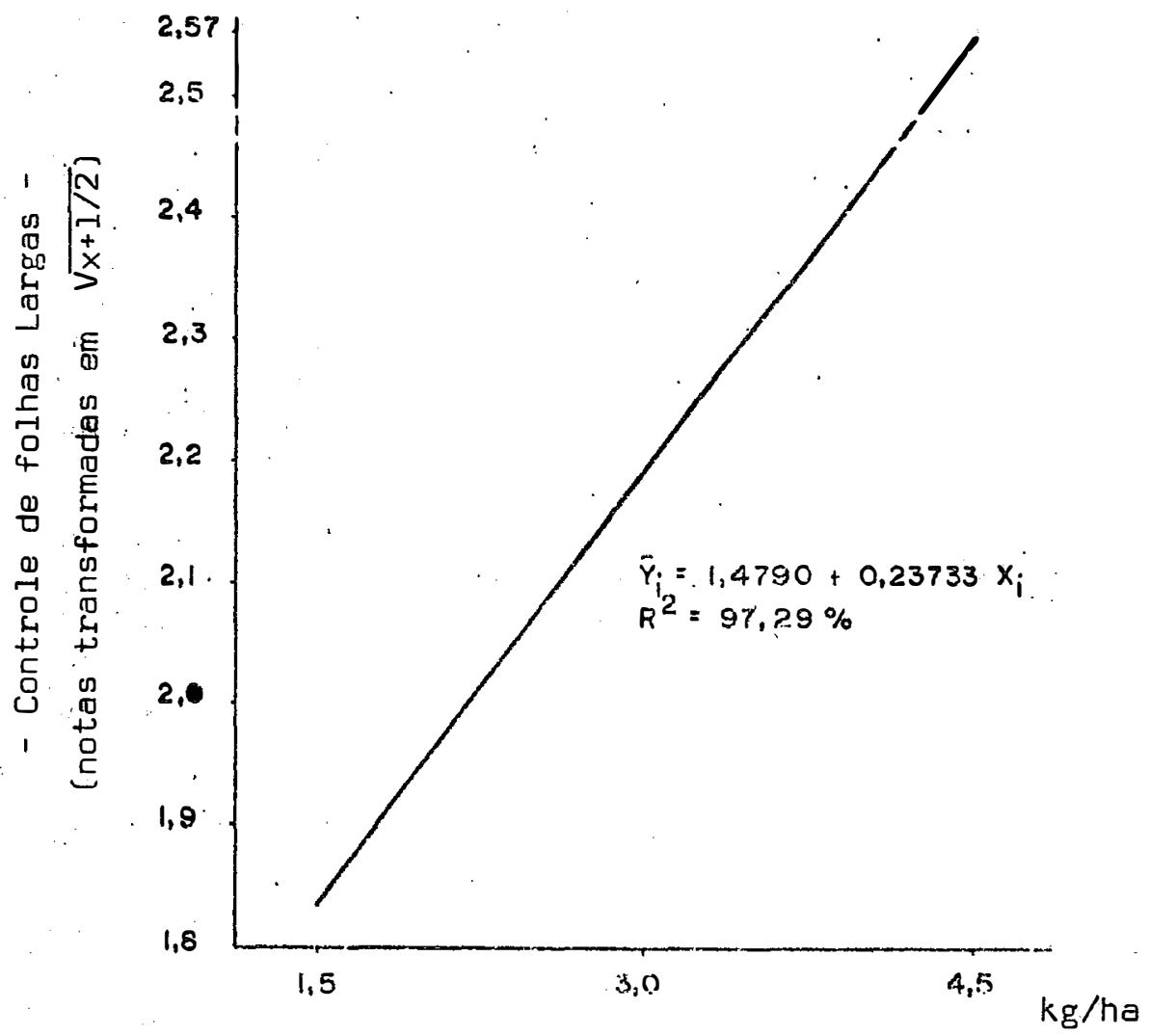

Figura 11. Representações gráficas do controle de folhas largas e Commelina spp. em função de três dosagens (p.a.) do herbicida oryzalin,aos 60 dias após plantio. 


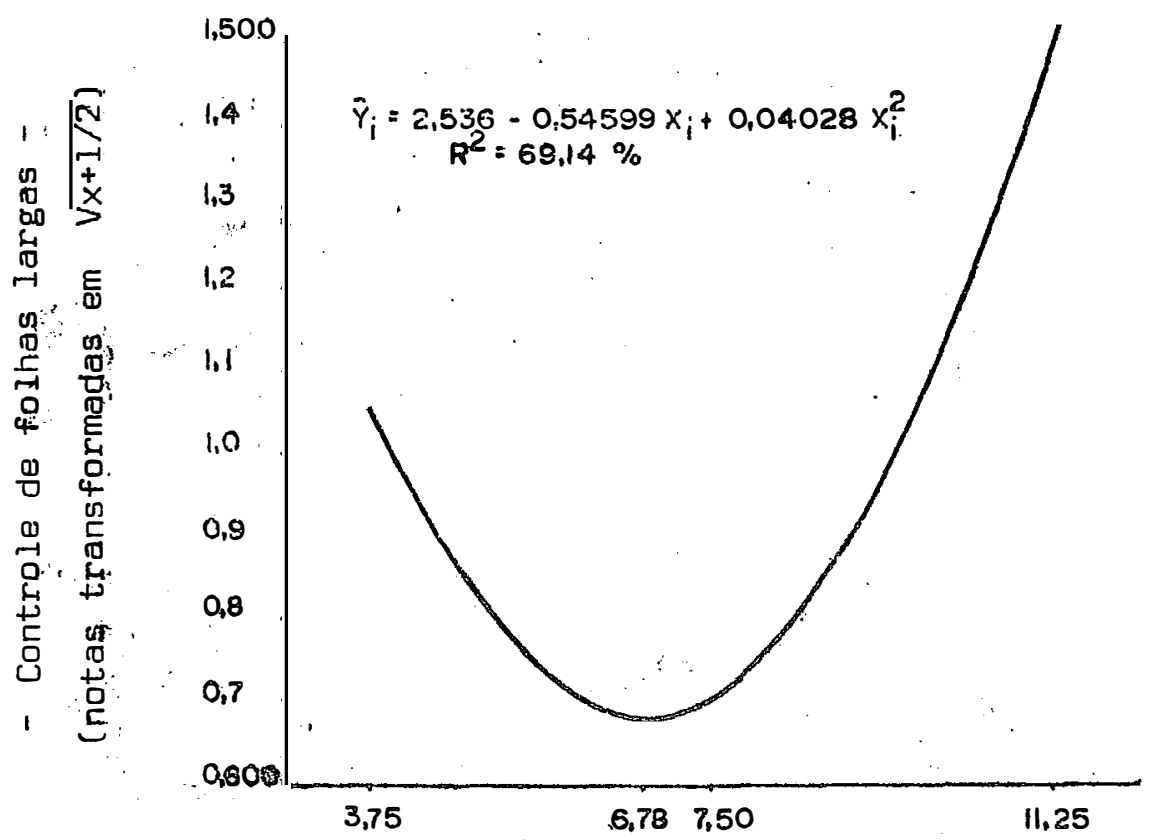

.62.

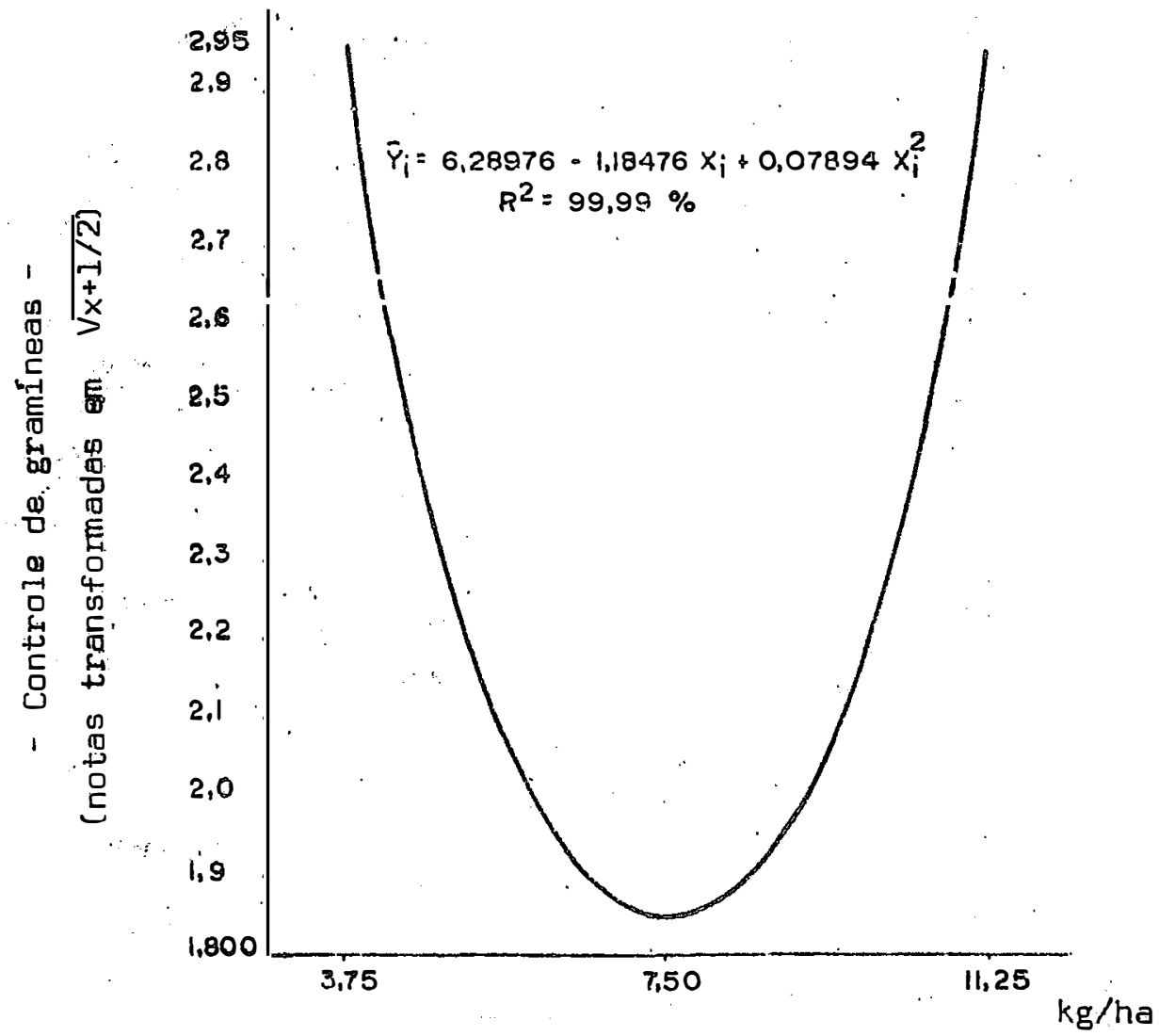

Figura 12, Representações grâficas do controle de Folhas largas e Gramineas em função de três dosagens $\left[p_{0} a_{0}\right]$ do herbicida DCPA, aos 60 dias após: plantıo。 


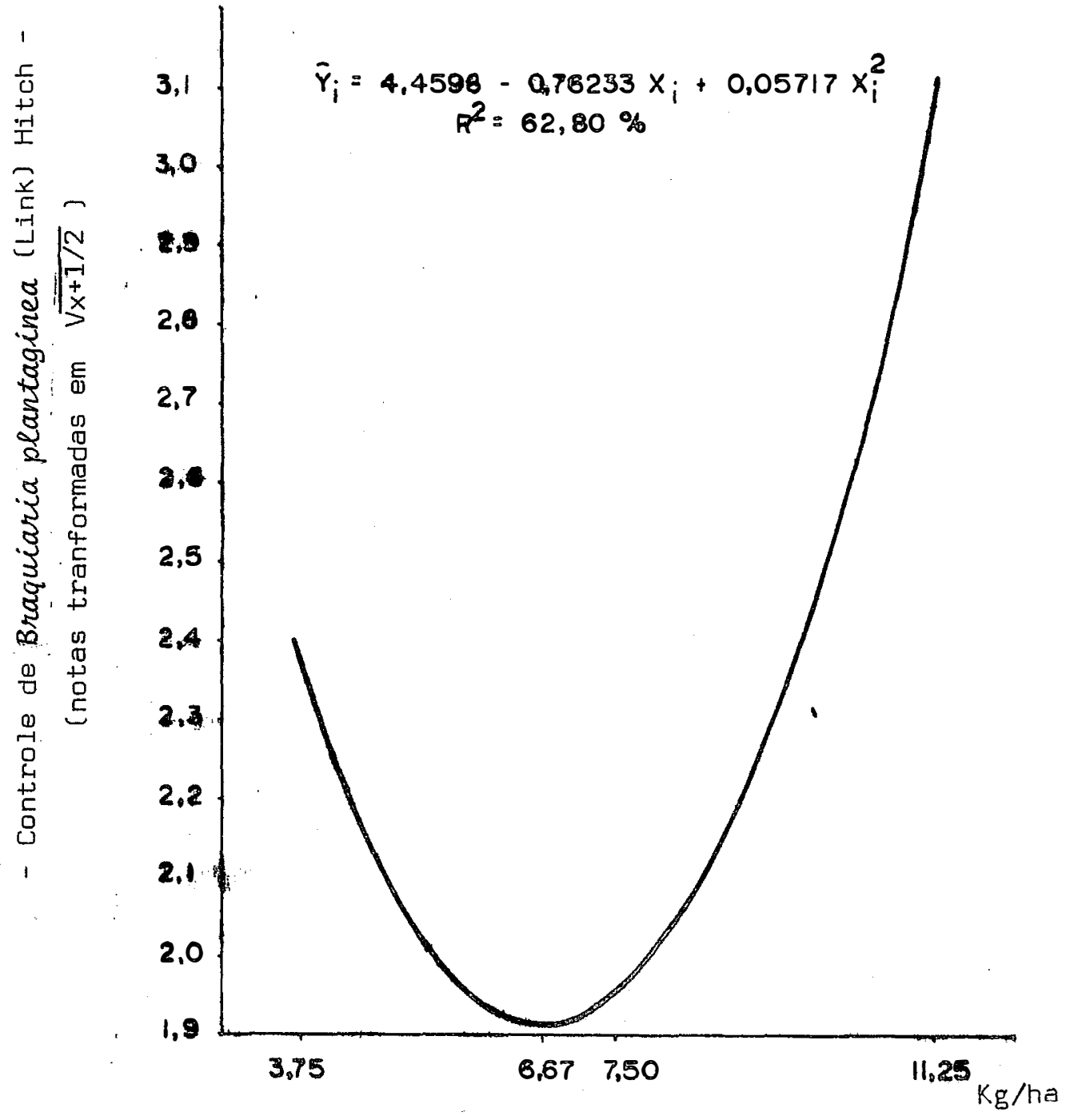

Figura 13. Representação gräfica do controle de Brachiaria plantaginea (Lìnk) Hìtch em função de três dosagens $\left(p . a_{\text {. }}\right)$ do herbicida DCPA, aos 60 dias após plantio. 


\subsubsection{Reinfestação}

0 estudo da reinfestação de plantas invasoras, foi realizada aos 90 e 120 dias após a instalação do experimento ou, a 30 e 60 dias após a capina geral efetuada na área experimental.

A Tabela 25 apresenta o resumo da análise de variância para injúria dos herbicidas oryzalin e DCPA à cultura do Eucalyptus saligna $\mathrm{Sm}$. bem como, para folhas largas em geral. Apresenta-se também nesta tabela os coeficientes de variação relativos aos dados de injúria e folhas largas.

Na Tatela 26 estão as médias das notas atribuídas aos tratamentos, assim como os DMS a $5 \%$ de probabilidade para comparação entre os mesmos.

0 resumo da análise de variância para a reinfestação de plantas invasoras da cultura aos 120 dias de idade, encontra-se na Tabela 27, bem como os coeficientes de variação para os dados relativos a gramineas, folhas largas e injúria. Os valores médios da reinfestação por grupos de plantas invasoras e os de injúria aos 120 dias após plantio são apre sentados na Tabela 28. Os DMS a 5\% calculado pelo teste TUCKEY, utilizados para comparação entre os tratamentos são constantes da Tabela 28.

As Figuras 14 e 15 mostram alterações no controle de gramineas e de grau de injüria das dosagens do herbicida DCPA e do oryzalin respectivamente, aos 120 dias após plantio. 
Tabela 25. Resumo da análise de variância para reinfestação de plantas inva soras em cultura de Eucalyptus saligna Sm. aos 90 dias após plan tio. Dados transformados em $\sqrt{x+1 / 2}$. Mogi-Guaçu (SP). 1975/ 176.
F.V.
G.L.

Quadrados Médios

Injüria Folhas Largas

Dosagens/H

$$
2
$$

0,303684

0.212047

R.L.
R.Q.

1

0,381938

0,384565

R.Q.
Dosagens/ $/ H_{2}$

R.L.

2

0,225429

0,039528

R.Q.

1

0,167986

0,341652

1

0,288800

0,011628

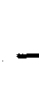

\section{(Fatorial)}

0,047171

0,671675

Fat. vs. Test.

Cap. vs. s/Cap.

1

0,196559

0,444685

(Tratamentos)

(7)

2,375442 **

$2,335453^{\star \star}$

Blocos

3

0,143322

0,014871

Resíduo

21

0.128094

0,245222

1,289903

12,834848 **

C.V.

24,50

21,33
* Efeito significativo ao nível de $5 \%$ de probabilidade
* Efeito significativo ao nível de $1 \%$ de probabilidade
$H_{1}=$ Oryzalin
$\mathrm{H}_{2}=\mathrm{DCPA}$




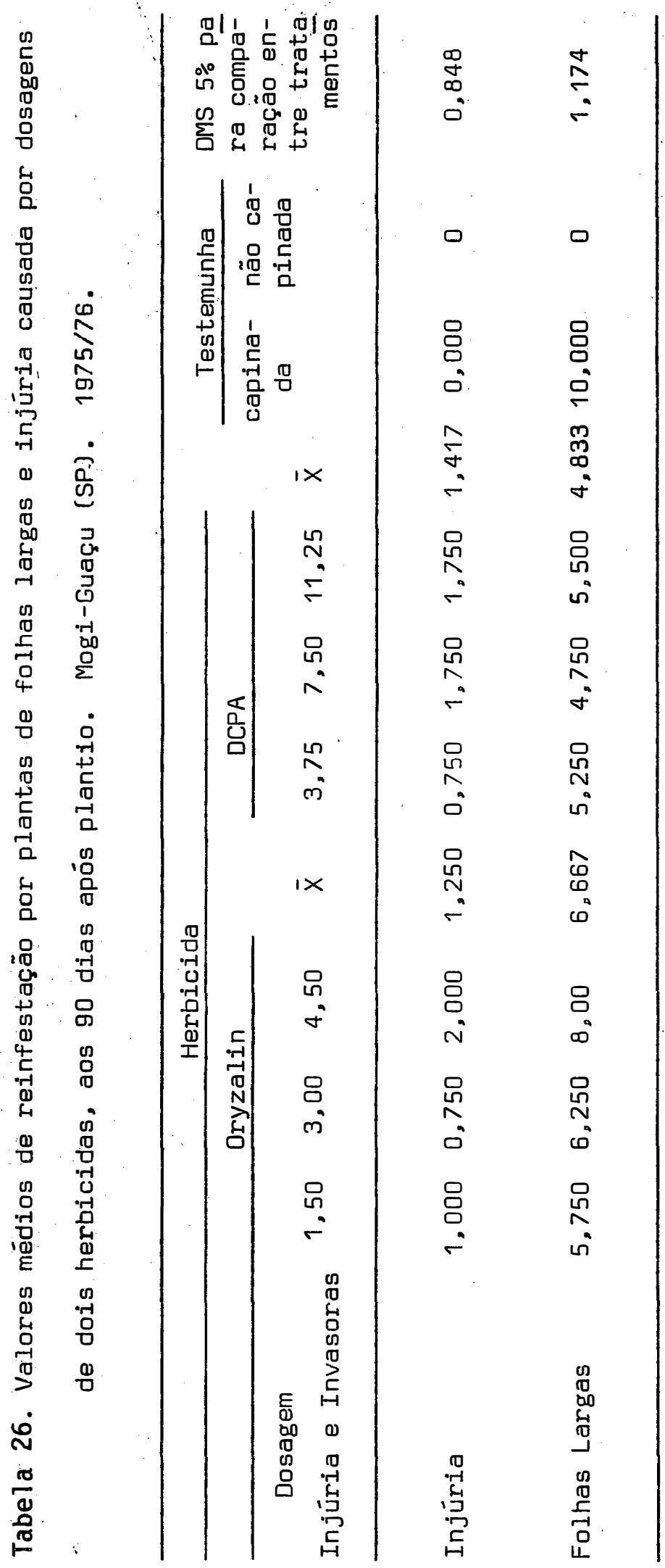


Tabela 27. Resumo da análise de variáncia para reinfestação de plantas inva soras em cultura de Eucalyptus saligna Smith, aos 120 dias após plantio. Dados transformados em $\sqrt{x+1 / 2}$. Mogi-Gaaçu, $1975 /$ 76.

\begin{tabular}{|c|c|c|c|c|}
\hline \multirow{2}{*}{$F \cdot V$. } & \multirow{2}{*}{ G.L. } & \multicolumn{3}{|c|}{ Quadrados Médios } \\
\hline & & Gramíneas & Folhas Largas & Injüria \\
\hline Dosagens $/ H_{1}$ & 2 & 0,014631 & 0,165224 & $0,490861 * *$ \\
\hline R.L. & 1 & 0,003121 & 0,320400 & $0,736291 * *$ \\
\hline R.Q. & 1 & 0,026140 & 0,010047 & $0.245431 * *$ \\
\hline Dosagens $/ \mathrm{H}_{2}$ & 2 & $1,574829 *$ & 0,374575 & $0,089269 * 2$ \\
\hline R.L. & 1 & 0,012561 & 0,424581 & 0,000000 \\
\hline R.Q. & 1 & $3,137096 * *$ & 0,324569 & $0,178538^{* *}$ \\
\hline (Fatorial) & (5) & $1,028424 *$ & $0,672092^{*}$ & $0,248201 * *$ \\
\hline Fat. $\times$ Test. & 1 & $4,734576 * *$ & 0,797978 & $7,558320^{* *}$ \\
\hline Cap. vs. s/Cap. & 1 & $12,834848 * *$ & $12,834848 * \star$ & $12,834848^{* *}$ \\
\hline (Tratamentos) & (7) & $3,244506 * *$ & $2,429046 * *$ & 3,090596 \\
\hline Blocos & 3 & 0,112323 & 0,102319 & 0,022820 \\
\hline Resíduo & 21 & 0,282337 & 0,242142 & 0,014035 \\
\hline C.V. & $(\%)$ & 20,12 & 21,89 & 10,46 \\
\hline
\end{tabular}

* Efeito significativo ao nível de $5 \%$ de probabilidade

** Efeito significativo ao nível de $1 \%$ de probabilidade

$H_{1}=$ Oryzalin

$\mathrm{H}_{2}=\mathrm{DCPA}$ 


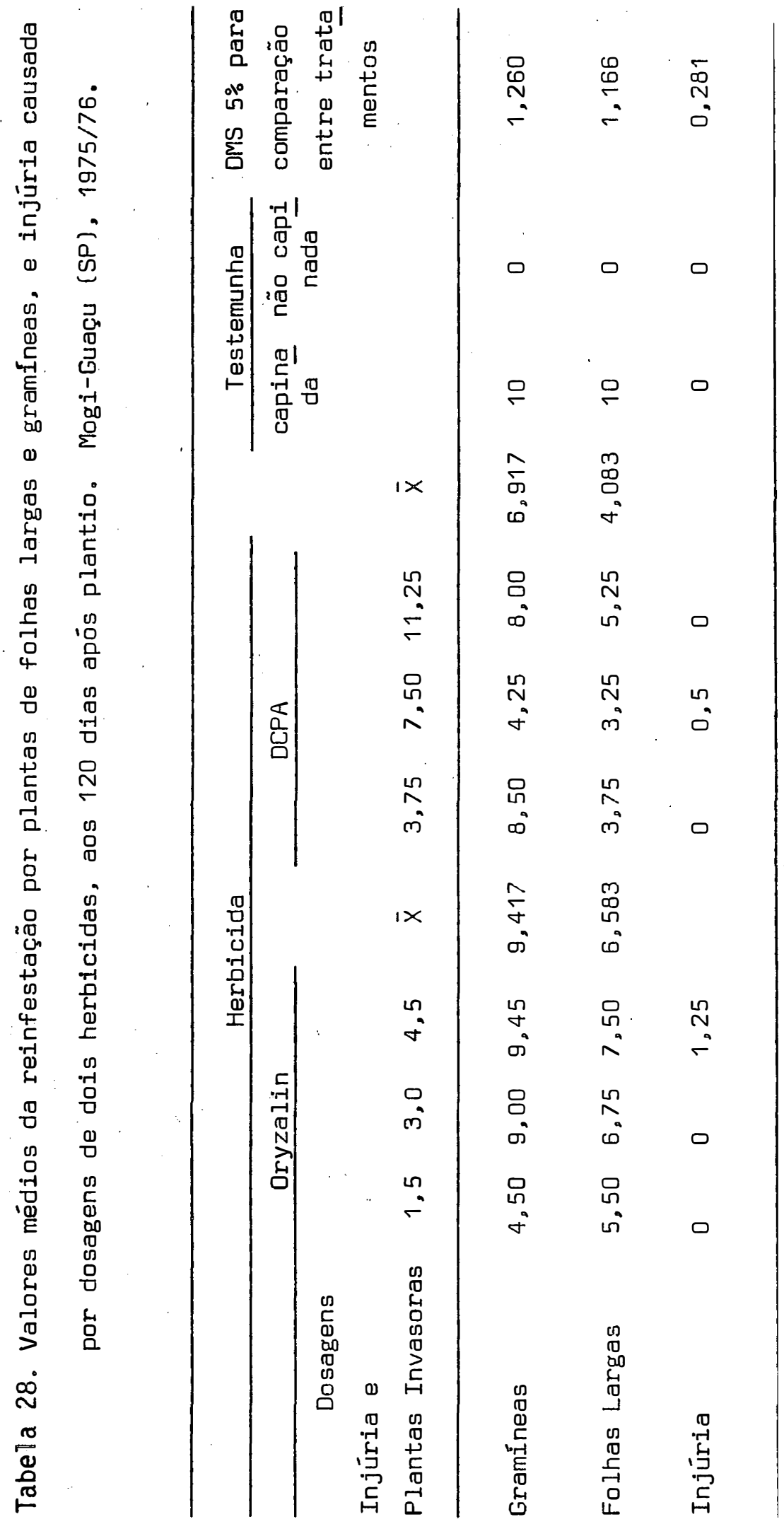




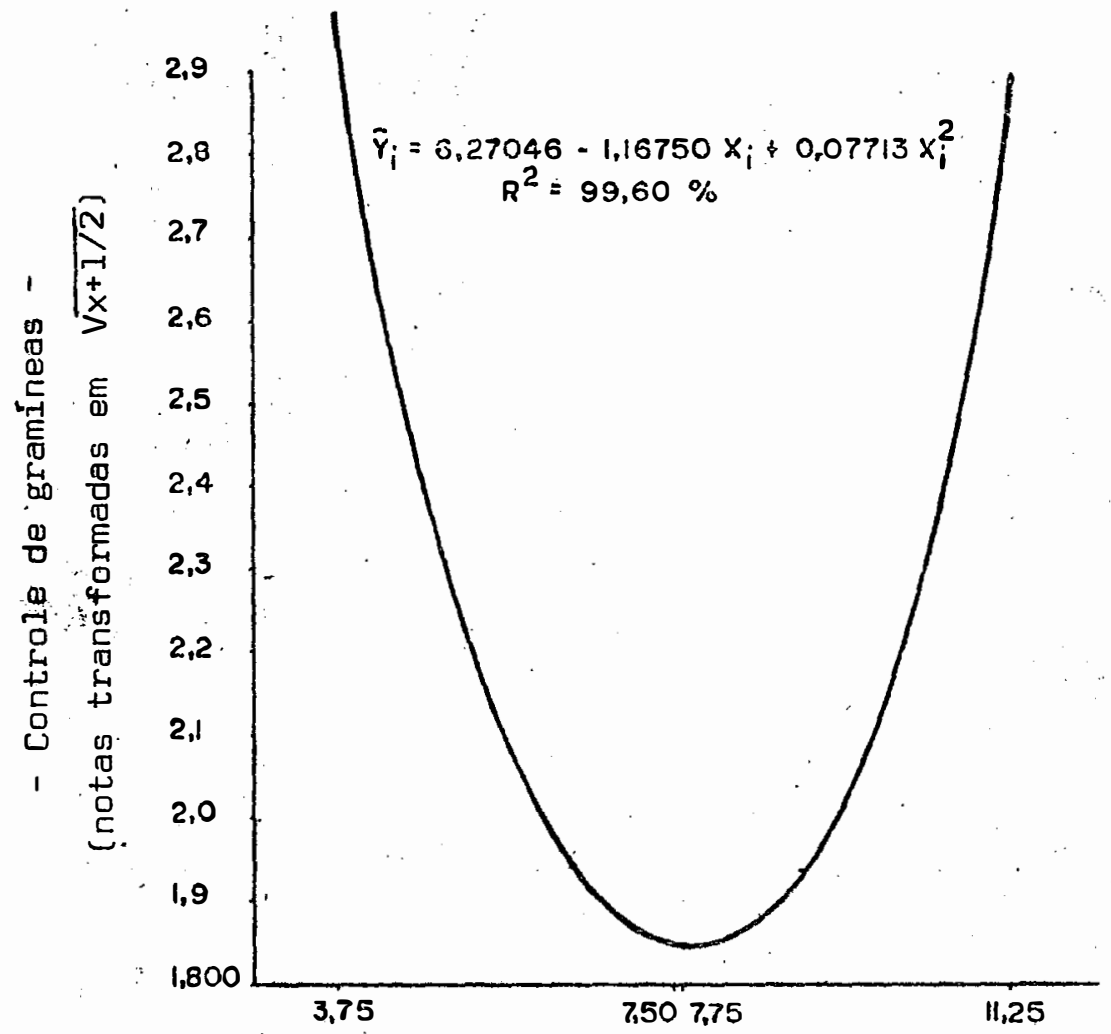

.69.

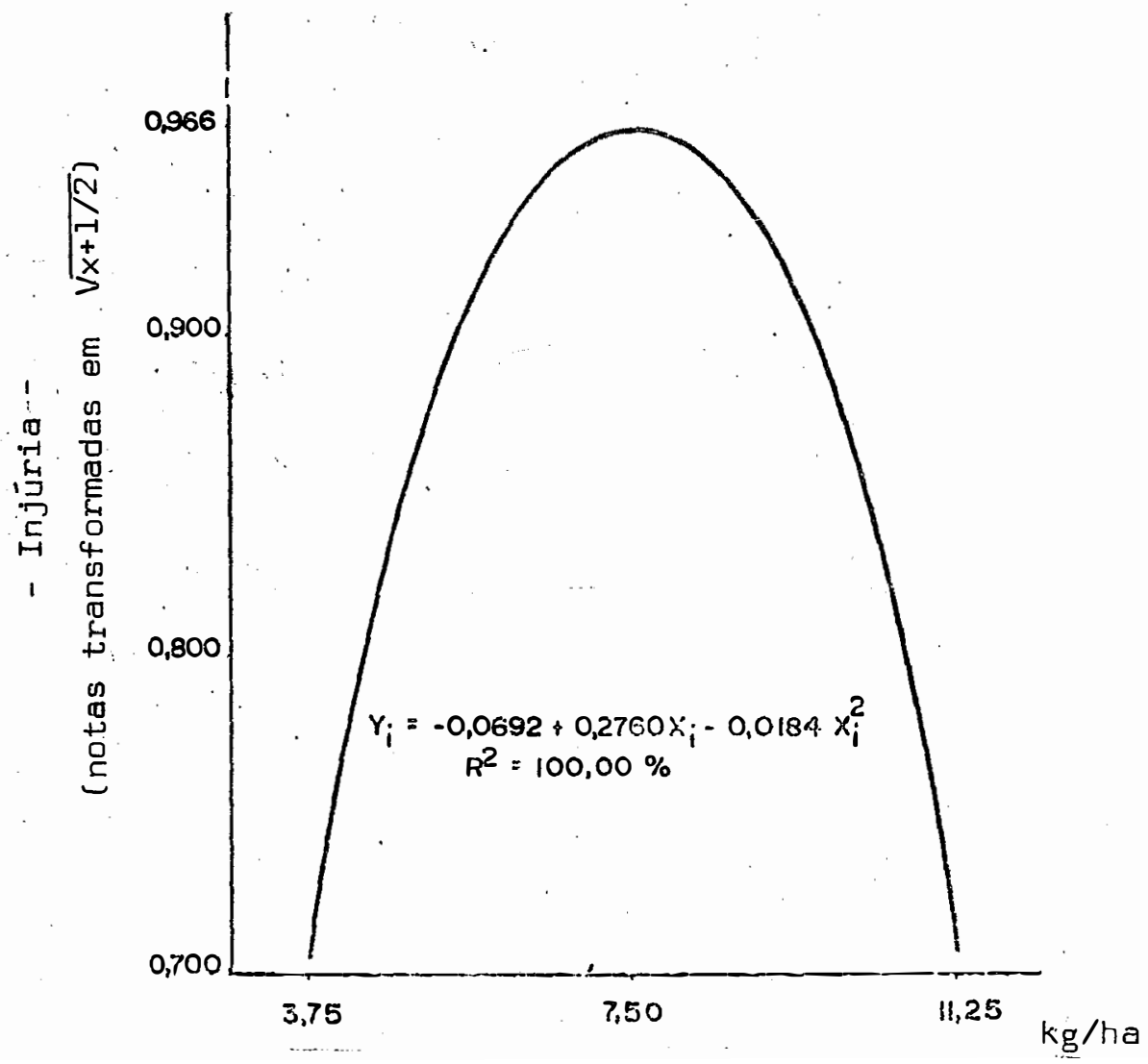

Figura 14. Representações gräficas do controle de gramíneas e injüria, em função de três dosagens (p.a.) do herbicida DCPA, aos 120 dias após plantio. 


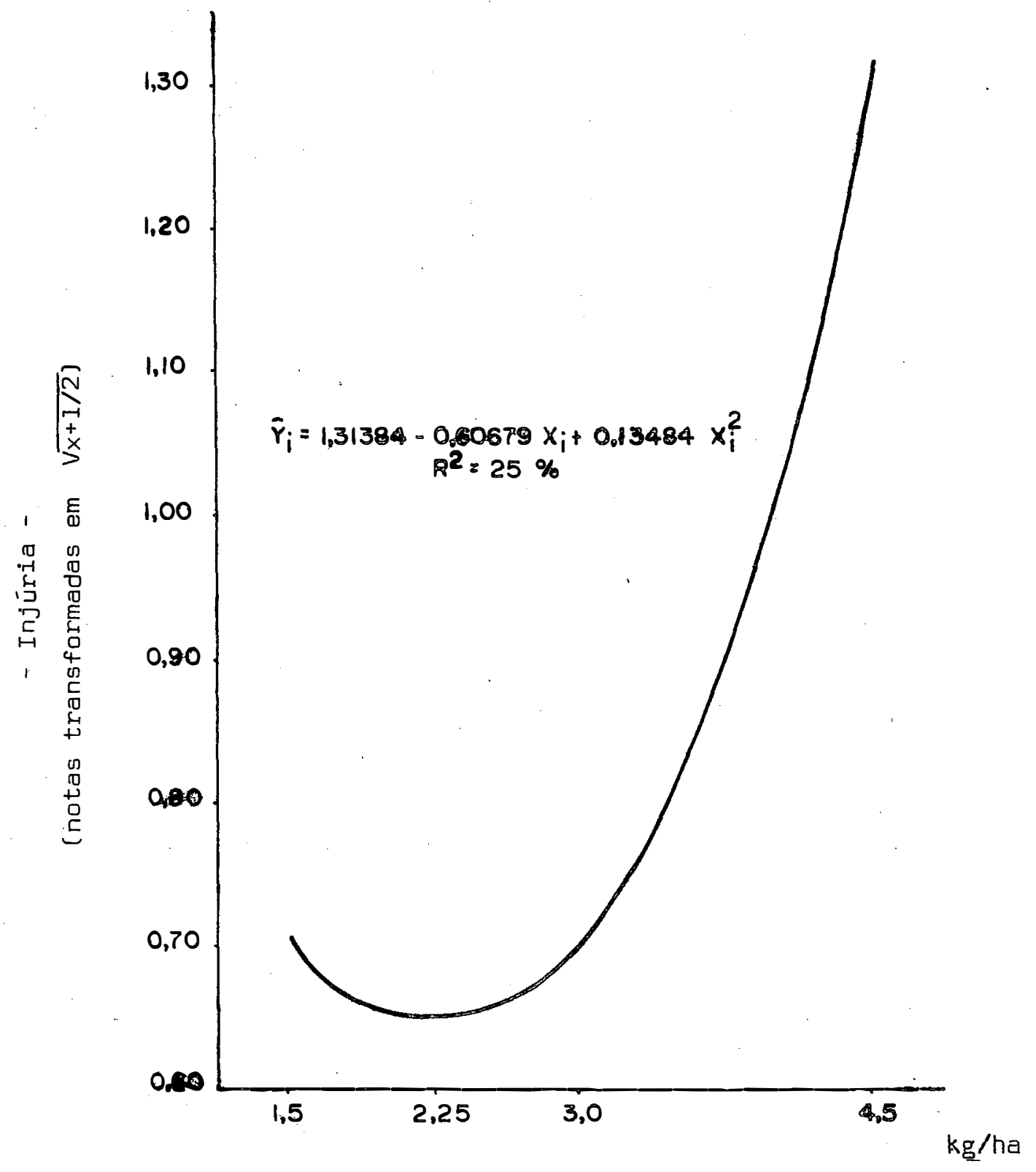

Fígura 15. Representação gråfica da injūria em função de três dosagens ( $p$. a.) do herbicicida Oryzalin, aos 120 dias após plantio. 


\section{DISCUSSAO}

\subsection{Teores de nutrientes}

A carência de pesquisas que demonstram a influência da absor ção de nutrientes em função da aplicação de herbicidas, estimulou o presente trabalho. Apenas alguns estudos realizados na Universidade de Wisconsin, DUAL PURPOSE WEED KILLER TESTED IN FOREST NURSERIES (1966), outFO pOF FULLER TON (1969) e ainda pela IRLANDA, MINISTRY OF AGRICUTTURE FOR NORTHERN IRELAND (1970), dão conta de que a aplicação de herbicidas aumentam de algum modo a absorção de mutrientes pelas plantas. No presente estudo, os teores minerais encontrados em folhas de Eucalyptus saligna Smith, foram determinados em três épocas diferentes, ou seja: aos 60, 90 e 120 dias após plantio.

\subsubsection{Teores : de nutrientes aos 60 dias apōs plantio}

Analisando as Tabelas 10 e 11 , verifica-se que não houve mo dificaçōes dos teores de nutrientes em folhas de Eucalyptus saligna. "Smith. quando aplicados os herbicidas oryzalin e DCPA.

Tais resultados estão em desacordo com os obtidos na Universidade de Wisconsin, DUAL PURPOSE WEED KILLER TESTED IN FOREST NURSERIES (2966), onde a aplicação do produto DCPA em plantas de Pinus de vārias es pécies com aproximadamente dois anos, quando comparados com plan- 
tas não tratadas com herbicidas. A inexistência de diferenças nos teores minerais aos 60 dias, pode ser resultado da abundância de nutrientes ainda existente no solo, nesta ocasião. Por outro lado, as plantas não teriam desenvolvido satisfatóriamente seu sistema radicular, a ponto de apresentar diferenciação na absorção.

Considerando os conceitos de PIMENTEL GOMES (2970), com :excessão do coeficiente de variação para nitrogênio e potássio que foram baixos, os demais foram altos. Contudo, em estudo de campo, onde a distribuição de plantas invasoras é irregular, os coeficientes de variação para fósforo, cálcio e magnésio são aceitáveis, não demonstrando nenhuma imprecisão ex perimental.

\subsubsection{Teores de nutrientes aos 120 dias apōs plantio}

Decorridos 120 dias após a instalação da cultura, verificou-se que o efeito herbicida foi significativo apenas para nitrogênio. maior teor de nitrogênio encontrado em folhas de Eucalyptus saligna Smith, quando tratado com oryzalin pode ser resultado do grande número de moléculas deste elemento na composição deste produto (ELANCO INTERNATIONAL, 1968).

0 efeito de dosagem dentro do.herbicida oryzalin, mostrou-se significativo para regressão linear com relação ao fósforo e significativo para regressão quadrática. Para o cálcio o efeito de dosagem dentro do her bicida oryzalin, mostrou-se significativo para regressão quadrática, a nível de $5 \%$ de probabilidade.

Os teores médios dos herbicidas oryzalin e DCPA, comparados pelo teste TUCKEY, na Tabela 13, apresentou diferença entre as dosagens, pa ra o fôsforo em relação ao herbicida oryzalin. O teor de fósforo encontrado em folhas de Eucalyptus saligna Smith na dosagem de 4,5 kg/ha foi 15,60\% inferior ao teor encontrado na dosagem de $1,5 \mathrm{~kg} / \mathrm{ha}$. Não houve, entretanto, diferenças entre as testemunhas entre si e entre estas com as dosagens de qualquer dos herbicidas. Tais resultados estão em desacordo com os obtidos por FULLERTON (1969). 
A tendência das curvas da Figura 1 , indica que tanto

para fósforo como para o cálcio, a medida que se aumentam as dosagens do herbici da oryzalin, há um acréscimo nos teores destes elementos até certo ponto, passando a decrescer quando se eleva a dosagem do herbicida. 0 aumento de dosagens de herbicida DCPA, provocou um aumento no teor de $P$ nas folhas de Eucalyptus saligna Smith, aos 120 dias após plantio, até a dosagem de 7,55 kg/ha, passando a decrescer em dosagens superiores. Tais tendências apresentadas nas três curvas mencionadas podem ser explicadas pela injúria causada às plantas de $E$. saligna Smith quando se aumenta a dosagem dos herbici das. De acordo com KOGAN et alii (1970) a debilidade causada a cultura pela injpuria, desacelera a absorção dos nutrientes.

A considerar os coeficientes de variação da Tabela 12, infere-se que a obtenção dos dados para análise dos elementos minerais foi procedido por critérios rigorosos. Tais coeficientes demonstram boa precisão experimental.

Os teores médios de nutrientes, contidos na Tabela 13, subme tidos ao teste TUCKEY, não demonstraram haver diferença entre os mesmos . Tais resultados estão em desacordo com os publicados na IRLANDA, MINISTRY OF AGRICULTURE FOR NORTHEM IRELAND (1970), que apresentam aumento na absorÇão de elementos minerais por Picea sitchesis. No entanto, no presente tra balho, com espécies diferentes os resultados divergentes, eram esperados.

Observando as Figuras 1 e 2, verifica-se que o ponto de maior absorção para $P$ se deu na dosagem de $2,41 \mathrm{~kg}$ por hectare do herbicida oryzalin, ao passo que para o $\mathrm{Ca}$, a maior absorção ocorreu em $3,4 \mathrm{~kg} / \mathrm{ha}$ para o.mesmo herbicida. Com relação ao DCPA, a maior absorção de P ocorreu com a dosagem de $7,5 \mathrm{~kg} / \mathrm{ha}$.

Os coeficientes de determinação da Figura 1 mostram que $34,74 \%$ da variação dos teores de $P$ e $54,74 \%$ dos teores de Ca encontrados nas folhas de Eucalyptus saligna Sm. foram devidos as alterações nas dosagens do herbicida oryzalin. As alterações nos teores de $P$ foram causados por 99,92\% de possibilidade devidas ao herbicida DCPA aos 120 dias após plantio. 


\subsubsection{Teores de nutrientes aos 180 dias após plantio}

A análise da Tabela 14, permite observar que não houve diferenças entre os herbicidas, para nenhum nutriente aos 180 dịas após plantio. Para dosagem dentro do herbicida DCPA, observou-se que houve alta sig nificância para regressão linear com relação ao potássio. Os teores de $K$ observados na Tabela 15 para o herbicida OCPA demonstram a tendência linear para as diversas dosagens. A medida que se aumentou a dosagem do herbicida DCPA de $3,75 \mathrm{~kg} / \mathrm{ha}$ para $11,25 \mathrm{~kg} / \mathrm{ha}$ do p.a., os teores de $\mathrm{K}$ em foThas de Eucalyptus saligna Smith foram reduzidos de 0,927\% para 0,732\%, numa redução de $21,25 \%$. Na Figura 3, encontra-se a representação grāfica da redução dos teores minerais em folhas de $E$. saligna $\mathrm{Sm}$., em função do aumen to das dosagens do DCPA. Os dados sugerem que dosagens altas do DCPA, provocam uma diminuição na absorção de $K$ pela cultura. 0 coeficiente de deter minação da Figura 3 mostra que $87,95 \%$ da variação nos teores de $K$ nas folhas de Eucalyptus saligna $\mathrm{Sm}$. foi devida as alterações nos níveis de DCPA aplicados. 0 teste TUCKEY, aplicado entre as médias dos tratamentos, comprova a significància discutida. Não houve entretanto, diferenças entre os teores de minerais e as testemunhas, bem como entre dos os tratamentos. Es tes resultados estão em desacordo com os obtidos na IRLANDA, MINISTRY OF AGRICULTURE FOR NORTHEN IRELAND (1970), para Picea spo.

0 desdobramento dos graus de liberdade permitiram observar significância a 5\% de probabilidade para regressão linear das dosagens dentro do herbicida oryzalin. Os teores médios de magnésio, apresentados na Tabela 15, para o herbicida oryzalin, embora não tenha causado significância pelo teste TUCKEY, mostra que a cada aumento das dosagens do herbicida, há um aumento nos teores de nutrientes contidos nas folhas de Eucalyptus sa ligna Sm., inversamente ao que ocorreu com o potássio. 0 teor de Mg corres pondente a dosagem $4,5 \mathrm{~kg} / \mathrm{ha}$ do $\mathrm{p.a}$. foi $0,215 \%$, enquanto que o teor corres pondente a dosagem $1,5 \mathrm{~kg} / \mathrm{ha}$ foi $0,191 \%$ ou seja, $11,16 \%$ inferior ao teor da dosagem de $4,5 \mathrm{~kg} / \mathrm{ha}$.

A Figura 4 mostra a tendéncia observada nos dados correspondentes as médias de Mg contidas em folhas de Eucalyptus saligna Smith. Aumentando-se a dosagem do herbicida oryzalin aumenta o teor de Mg em folhas 
da cultura. Pelo coeficiente de determinação observá-se que $99,83 \%$ do teor de Mg encontrado nas folhas foi devido aos níveis de oryzalin aplicados.

A Tabela 15 mostra os OMS $5 \%$ que comparadas com as médias não revelam signficância entre os tratamentos.

\subsection{Fitotoxidade dos herbicidas}

\subsubsection{Diâmetro de copa e altura de plantas}

A análise da Tabela 16 demonstra que não houve diferenças en tre herbicidas no desenvolvimento da altura e diàmetro da copa de Eucalyptus saligna Smiht. O teste Tuckey, comprova, na Tabela 17, a inexistência de diferenças entre os tratamentos, ou seja, a altura de plantas e diâmetro de copa não foram afetados pela aplicação de diferentes dosagens dos herbicidas oryzalin e DCPA.

0 desdobramento dos graus de liberdade para dosagens dos dois herbicidas não revelou diferença significativa para regressão linear ou quadrática com relação a dosagem dentro do herbicida oryzalin nem para diāmetro de copa ou para altura de planta. O resultado demonstra que o aumento das dosagens do herbicida oryzalin não influenciou o crescimento inicial do diâmetro de copa ou altura de planta.

Dosagens do herbicida DCPA, embora não tenha modificado o de senvolvimento em altura das plantas, afetaram o diâmetro de copa, conforme mostram os resultados da Tabela 16. A análise de regressão, mostrou significância a nível de 5\% para regressão linear com relação a dosagem do herbi cida DCPA e para diaâmetro de copa de Eucalyptus saligna Smith. A Figura 5 indica a tendência de modificação do diâmetro de copa em função das dosagens do herbicida DCPA. A medida que se aumentam as dosagens do herbicida DCPA, há uma sensivel redução nos diâmetros da copa de Eucalyptus saligna Smith, até a dosagem de $8,51 \mathrm{~kg} /$ ha do p.a.. A partir desta dosagem, os diāa metros voltaram a crescer. O resultado aparentemente inesperado não pode 
ser explicado por leis biológicas. Provavelmente, fenômenos aleatọriós tenham contribuído para o resultado. o coeficiente de determinação $\left(R^{2}\right)$ mostra que somente $53,48 \%$ da variação do crescimento em diâmetro de copa ffoi devịda as alterações nos níveis de DCPA aplicado.

O coeficiente de variação para diâmetro de copa, igual a a 15,96 classificado como médio por PIMENTEL GOMES (1970), pode ser considera do bom para as presentes condições experimentais. 0 coeficiente de variação para altura de plantas, 9,78, revela ótimas condições experimentais.

\subsubsection{Injüria visual}

A injúria visual foi verificada por avaliações visuais do grau de injúria entre todos os tratamentos. Embora o método possa parecer subjetivo, os padrões seguidos pelo URWC, citado por ALVES (1974), permitiram razoável segurança na avaliação de injúria dos herbicidas oryzalin e DCPA na cultura de Eucalyptus saligna Smith.

Na Tabela 21, observa-se completa ausência de injúria para todos os tratamentos, inclusive para as dosagens maiores. As plantas de Eucalyptus saligna Smith, aos 30 dias não apresentaram nenhum sintoma de to xidez causado por dosagens dos herbicidas oryzalin e DCPA.

Até aos 60 dias após plantio, nenhuma injúria foi causada por qualquer das dosagens do herbicida DCPA aplicado em pós-emergência da cultü ra de Eucalyptus saligna Smith. Entretanto, na dosagem $4,5 \mathrm{~kg} / \mathrm{ha}$ para oryzalin, observou-se pequeno sintoma de injúria que foi atribuído ao efeito fitotóxico de alta dosagem do herbicida. Os principais sintomas observados foram amarelecimento das folhas e redução do crescimento vegetativo. Não obstante, nas dosagens de 1,5 e $3,0 \mathrm{~kg} / \mathrm{ha}$ não foi constatado nenhum sinal aparente de injúria.

Pela avaliação visual realizada aos 90 dias após plantio, ob servou-se ligeiros sintomas de injúria para todos os tratamentos do herbici da oryzalin como para o herbicida DCPA. Os sinais de injüria entretanto fo ram confundidos com intensa concorrência que havia sido estabelecida com a 
cultura, em razão do desenvolvimento intenso de muitas espécies não controladas pelos herbicidas.

Aos 120 dias após plantio, observou-se injúria à cultura de Eucalyptus saligna Smith causada pelo herbicida oryzalin, apenas para a dosagem de 4,5 kg/ha. Para o herbicida OCPA, foi observado pequeno grau de injüria na dosagem média de $7,5 \mathrm{~kg} / \mathrm{ha}$. O fato de não ser observada injūria na dosagem aos 120 dias após plantio sugere que a aparente injúria observada aos 90 dias era consequência da concorrência estabelecida com a cultura de Eucalyptus saligna Smith. As Figuras 14 e 15, mostram que o grau de injüria em função de dosagens dos herbicidas oryzalin e DCPA aos 120 dias após plantio.' A medida que se aumenta a dosagem de DCPA, a injúria aumenta até certo ponto para decrescer em seguida. Para o oryzalin, a medida que se aumenta a dosagem, há aumento de injúria causada pelo herbicida.

\subsection{Plantas invasoras}

As principais plantas invasoras encontradas na área experi mental, coincide em parte com levantamentos realizados por VEIGA (1968) na região de Piracicaba (SP). Das espécies contidas na Tabela 18, Comelina spp. (trapueraba), Sida spp (guanxuma), Amaranthus hybridus L. (picão preto) e Cyperus spp. (tiririca), foram as mais frequentes.

0 controle das plantas invasoras foi analisado com dados de contagem individual e avaliação visual aos 30 dias, avaliação visual aos 60 dias e avaliação visual da reinfestação aos 90 e 120 dias após a instalação do experimento.

6.3.1. Contagem individual de plantas invasoras aos 30 dias apōs plantio

Pela análise da Tabela 19 verifica-se a distribuição das espécies de plantas invasoras na área ocupada pelos tratamentos. A Tabela 20 mostra a porcentagem de controle das plantas invasoras na área de cada tratamento, para cada espécie, em relação com a testemunha não capinada. 
Na Tabela 19, verifica-se que o DCPA não fol eficiente no controle de Marmodica charantia L. A espécie foi bem controlada pelo oryza lin, nas dosagens de $4,5 \mathrm{~kg} / \mathrm{ha}$.

Bidens pilosa L. foi controlada tanto pelo DCPA como pelo oryzalin e em todas as dosagens. O herbicida oryzalin controlou satisfato riamente espécies de Commelina spp., contudo o DCPA não foi tão eficaz quan to ao oryzalin, no controle da espécie.

Enquanto o oryzalin foi eficiente no controle de Síla spp.o DCPA foi completamente ineficaz no seu controle.

Pequenas doses de DCPA não controlaram Cyperes spp, mas a elevação das mesmas apresentaram-se eficientes. Para o oryzalin, em todos os níveis do produto, ouve controle acima de $90 \%$ em relação a testemunha não capinada.

Oryzalin na menor dosagem de $2 \mathrm{~kg} / \mathrm{ha}$ do produto formulado/ha foi pouco eficiente no controle de Amaranthus hybridus L.. Doses maiores do produto aumentaram a sua eficiência. O DCPA, mostrou-se eficiente no controle de Digitaria sanguinalis Scop.. Brachiaria plantagine (Link) Hitch. Portulacca oleracea L. e Ipomea spp. embora estas espécies tenham sido menos frequentes na área do ensaio.

Na Tabela 20, a mesma tendência da Tabela 19 é observada.

6.3.2. A avaliação visual de plantas invasoras aos 30 dias apõs plantio

A observação do resumo da nálise de variància da Tabela 21. indicam haver diferenças na eficiência dos herbicidas para espécies de gramíneas, folhas largas, Sida spp, Cyperus spp. e Amaranthus hybridus L.。 Não houve entretanto, influência dos herbicidas para Commelina spp.. Bidens pilosa L. e Marmodica charantia L.

0 efeito de dosagem dentro do herbicida oryzalin mostrou-se 
significativo para todas as espécies estudadas, exceto para folhas largas Commelina spp., Bidens pilosa L. e Amaranthus hybridus L.. Efetuado o desdobramento dos graus de liberdade, para dosagem do herbicida oryzalin verificou-se efeito significativo para regressão linear, para as espécies de fo lhas largas em geral e Cyperus spp.. Para as espécies de gramíneas, Sida spp., Bidens pilosa L. e Marmodica charantia L. houve efeito de regressão quadrática para dosagens de oryzalin. As dosagens de oryzalin não afetaram a ocorrência das espécies de Commelina spp. e Amaranthus hybridus L.。

0 efeito de dosagens dentro do herbicida DCPA mostrou significāncia apenas para Marmodica charantia L.. O efeito de regressão linear foi verificado apenas para Sida spp. e para Marmodica charantia L. para dosagens de DCPA. Não se verificou efeito de regressão quadrätica para nenhu ma espécie de plantas invasoras. A Tabela 22 mostra os DMS a 5\% para compa ração entre os tratamentos. Verificando-se os DMS desta tabela, observa-se diferenças entre os tratamentos e as testemunhas e também muitas diferenças estatísticas entre os tratamentos. As notas conferidas as testemunhas capi nadas, igual a 10, serve para dar posição do controle quantificado pelas no tas atribuídas ao tratamento na ocasião da avaliação. Assim, um tratamento que recebeu uma nota 9,5 controlou eficientemente a espécie em questão. A testemunha não capinada recebeu nota zero e representa o outro extremo da eficiência controle. A colocação da posição exata da espécie entre os extremos 0 a 10, respectivamente, testemunhas não capinada e capinada, foi realizada com todo critério possível.

A Figura 6, mostra a curva de controle de gramíneas e folhas largas, em função das dosagens do herbicida DCPA. Para gramíneas, a curva indica que o controle de plantas decresceu até a dosagem de $7,15 \mathrm{~kg} / \mathrm{ha}$, vol tando a aumentar em dosagens superiores. Tais resultados estão em desacordo com os apresentados por KURTH e DORSSER (1969).

0 resultado inesperado pode ser justificado pela distribuição imperfeita de gramíneas na área que mascara a amostragem。 0 pequeno $n^{2}$ de amostras não permitiu uma distribuição normal da curva de controle pa ra as gramíneas invasoras. 
A medida que a dosagem aumentou o controle das plantas de fo Ihas largas aumentou linearmente. Resultados idênticos foram encontrados por WISE et alii (1969) E AHRENS (1975). A tendência sugerida pela Figura 6 indica que maiores dosagens poderiam ser usadas até o limite em que as mesmas atingissem o ponto de controle total das folhas largas.

A curva que descreve o comportamento do controle de Sida spp, em função das dosagens do herbicida oryzalin. Figura 7, mostra que um aumen to dos niveis destas dosagens provocou uma resposta linear em controle, isto é, a medida que se aumenta a dosagem do produto, o controle da Sida spp. também aumenta.

A representação gräfica do controle Marmodica charantia L. em função de dosagens do oryzalin, mostra a mesma tendência da apresentado para Sida pp, isto é, aumenta linearmente com o aumento das dosagens.

Na Figura 8, encontra-se o comportamento do controle de Sida spp. e Bidens pilosa L., em função das dosagens de DCPA. Para Sida spp. o controle cresceu até a dosagem de $9,35 \mathrm{~kg} / \mathrm{ha}$ e decresceu a partir desta dosagem: enquanto que para Biden pilosa L., o controle decresceu até a dosagem de $7,5 \mathrm{~kg} / \mathrm{ha}$ e cresceu a partir desta dosagem. Tais resultados inesperados podem ser explicados por distribuição irregular de plantas invasoras na área, não permitindo amostragem representativa da população de plantas invasoras.

O controle de Cyperus spp., demonstrado pela Figura 9, foi mais eficiente a medida que se aumentavam as doses do herbicida DCPA. Estes resultados são condizentes com princípios biológicos, isto é, maiores doses de herbicidas provocam maiores índices de controle das plantas de $\mathrm{Cy}$ perus spp.

A representação gráfica do controle de Marmodica charantia L. em função de aplicação de dosagens dos herbicidas DCPA aos 30 dias de idade, mostrou uma tendência de controle decrescente até certo ponto, voltando a crescer em seguida. O ponto mais baixo de controle se deu na dosagem de $7,5 \mathrm{~kg} / \mathrm{ha}$, conforme mostra a Figura 9. 
Os coeficientes de determinação $\left(R^{2}\right)$, expressos em porcentagens encontrados nos gráficos descritos, revelam que a maior parte da varia ção do controle de Cyperus spp. deve se ao aumento das dosagens do herbicida DCPA. Mas o comportamento do controle Marmodica charantia L. é explicado em apenas $48,86 \%$ pelas variações das dosagens do DCPA aos 30 dias apōs plantio.

A comparação entre as testemunhas com o fatorial, expressa, no resumo da análise de variáncia, mostra que houve diferença estatística en tre as testemunhas e o fatorial, para todas as espécies de plantas 1nvasoras, exceto para Commelina spp..

Com excessão do coeficiente de variação apresentado por Marmodica charantia que foi médio, todos os demais foram baixos, demonstrando boa precisão experimental.

\subsubsection{Avaliação visual de plantas invasoras aos 60 dias apōs plan- tio}

Para todas as espécies de plantas invasoras analisadas aos 60 dias, observou-se diferenças entre os herbicidas no controle das plantas. Em geral, o controle de invasoras pelo oryzalin foi mais eficiente que o controle pelo DCPA.

Pelo exame da Tabela 23, verifica-se que apenas para Commeli na spp. e para plantas de folhas largas em geral, houve efeito de dosagens dentro do herbicida oryzalin. Dosagens do herbicida DCPA, entretanto, reve laram efeito significativo para Sida spp., espécies de folhas largas, gramí neas e Brachiaria plantaginea; não mostrando efeito significativo para Cupe rus spp. e para Commelina spp..

0 desdobramento dos graus de liberdade para dosagens dentro do herbicida oryzalin mostrou efeito de regressão linear para Commelina spp. e para espécies de folhas largas, não havendo efeito de regressão quadrática para nanhuma espécie de plantas invasoras. 
Dosagens dentro do herbicida DCPA, mostraram efeito de regressão linear apenas para Cyperus spp.. Houve entretanto, efeito de regressão quadrática para Sida spp., espécies de folhas largas, gramíneas e Brachiaria plantaginea.

As representações gräficas do controle de Cyperus spp. e Sida spp., para dosagens de DCPA, contidas na Figura 10, mostram efeito linear para a primeira e quadrática para a segunda. Dosagens crescentes de DCPA, proporcionaram crescentes aumentos no controle de Cyperus spp., enquanto que dosagens crescentes de DCPA proporcionaram decrescente controle de Sida spp. até a dosagem de $5,63 \mathrm{~kg} / \mathrm{ha}$, voltando a aumentar a partir desta dosagem. Pára a primeira curva, o coeficiente de determinação igual a $97,78 \%$, indica que a maior parte do controle de Cyperus spp. é função das dosagens do DCPA. Contudo, para a segunda, o coeficiente de determinação $\underline{i}$ gual a 25,00\% mostra que apenas $25 \%$ da probabilidade de crescimento é devida a variação das dosagens do DCPA.

A Figura 11, mostra a representação gräfica do controle de Commelina spp. e de espécies de folhas largas, em função das dosagens de oryzalin. Para ambos, observa-se tendência linear no controle, em função das dosagens. Maiores dosagens, maior controle. Ambos os coeficientes de determinação demonstram que a variação de controle é em grande. parte explicada pelas variações nos teores de oryzalin, ou seja, 75,00\% e 97,29\%, respectivamente.

0 controle de folhas largas, gramíneas e Brachiaria plantagi nea (Link) Hitch, por dosagens de DCPA, expressas nas Figuras 12 e 13, mostram tendência irregular de distribuição das plantas invasoras na área experimental. Provavelmente, por deficiência de amostragem a curva apresenta tendência quadrática. 0 controle, para as três espécies ou grupos estudados, diminui até aproximadamente à dosagem de 6,5 a 7,5 kg/ha do DCPA, para depois aumentar. Os coeficientes de determinação para as três curvas, foram superiores a $60 \%$, demonstrando que as variaçōes no controle das espécies de folhas largas, gramíneas e Brachiaria plantaginea (Link) Hitch, foram devidas as variações nas dosagens do herbicida DCPA. 
As médias das notas que originaram as curvas de controle, con tidas na Tabela 24, confirmaram os resultados obtidos. Os DMS comparativos a nível de 5\%, revelam significâncias entre testemunhas e tratamentos e tra tamentos entre si.

\subsubsection{Reinfestação}

Após a avaliação aos 60 dias, realizou-se uma capina geral na área, em todos os tratamentos e testemunhas. Aos 90 dias, poucas espécies invasoras foram encontradas na área experimental. A avaliação nesta ocasião foi feita somente para espécies de folhas largas. Na Tabela 25, en contra-se o resumo da anālise de variância, não se verificando nenhuma significância para herbicidas ou para dosagem dentro de herbicida ou ainda para testemunhas com fatorial. Contudo, no quadro geral das médias na Tabela 26, O DMS a 5\% de probabilidade, mostra diferenças signficativas para alguns tratamentos em relação as testemunhas capinada e não capinada.

A reinfestação aos 120 dias apōs a instalação do experimento ou aos 60 dias após a capina total foi avaliada pelos grupos de espécies in vasoras de folhas largas e por espécies de gramíneas, conforme se evidencia na Tabela 27. Não se observa significância para dosagem dentro do herbicida oryzalin para gramíneas ou folhas largas. Com relação a dosagem do DCPA, houve significância a nível de 5\% para gramíneas.

0 desdobramento dos graus de liberdade mostrou efeito de regressão quadrática para dosagens do herbicida DCPA, para espécies de gramí neas. Os valores para gramíneas contidos na Tabela 28, mostram tendēncia quadrática e na Figura 14, encontra-se a curva do controle de plantas invasoras em função das dosagens do DCPA. A Figura 14 sugere que a medida que aumenta a dosagem do herbicida, o controle de gramíneas diminui até a dosagem de $7,5 \mathrm{~kg} / \mathrm{ha}$, voltando a aumentar em dosagens maiores. Também este resultado teo̊rico não é comumm de ser observado na prática. Justifica-se o mesmo pela distribuição irregular de gramíneas na ärea, a qual não foi uni formemente coberta pela amostragem. A análise da Tabela 28 , mostra que o oryzalin foi mais eficiente no controle de gramíneas que o DCPA, O, mesmo 
.84.

ocorrendo para espécies de folhas largas.

A comparação entre fatoríal com as testemunhas, apresentou significância a nível de $1 \%$ de probabilidade para gramíneas, não sendo significante para folhas largas. 


\section{CONCLUSÕES}

Para as condições experimentais descritas, a aplicação de di. ferentes dosagens dos herbicidas oryzalin e DCPA na cultura de Eucalyptus saligna Smith em solo franco argilo arenoso permite as seguịtes conclusões:

1. Os teores de $\mathrm{N}, \mathrm{P}, \mathrm{K}, \mathrm{Ca}$ e $\mathrm{Mg}$ em folhas de Eucalyptus saligna Smith, não foram modificados pelos herbicidas oryzalin ou pelo DCPA, quando comparados com teores encontrados em folhas de plantas das testemunhas.

2. Os teores de $\mathrm{N}, \mathrm{P}, \mathrm{K}, \mathrm{Ca}$ e Mg em filhas de Eucalyptus saligna Smith, não foram afetados por níveis de dosagens dos herbicidas oryza lin e DCPA, aos 60 dias de idade. Contudo, aos 120 dias, 0 teor de $P$ aumen tou com o aumento da dosagem do DCPA; e o teor de $\mathrm{P}$ diminuiu e o de Ca aumentou com o aumento das dosagens de oryzalin. O teor de $K$, aos 180 dias após plantio, diminuiu com o aumento das dosagens do herbicida DCPA.

3. Aplicações de dosagens médias dos herbicidas oryzalin e DCPA não afetaram o desenvolvimento em altura e diàmetro de copa de plantas de Eucalyptus saligna Smith; no entanto, um aumento das dosagens do herbici da DCPA provocou redução apenas do diāmetro da copa da cultura.

4. Avaliações visuais para determinação do grau de injüria 
durante os primeiros 120 dias após plantio, permitiram afirmar que dosagens médias dos herbicidas oryzalin e DCPA não apresentaram toxidez para a cultura de Eucalyptus saligna Smith. Entretanto, as dosagens de $4,5 \mathrm{~kg} / \mathrm{ha} e$ $11,25 \mathrm{~kg} / \mathrm{ha}$ dos herbicidas oryzalin e DCPA, respectivamente, provocaram pequeno grau de injúria às plantas aos 90 e 120 dias após a instalação da cul tura.

5. No controle da maioria das plantas invasoras, independentemente das dosagens, o oryzalin foi mais eficiente que o DCPA, em todas as épocas estudadas, ou seja, aos 30,60, 90 e 120 dias após plantio. 


\section{SUMMARY}

Since 1966 with the advent of fiscal incentives and a national paper and cellulose program in Brazil, a significant contingency of the labor force has been mobilized for facilitate the implantation of extensive forest areas.

Attracted by better wages in urban enterprises, the rural exodus has created serious problems in maintaining reforestation efforts.

The use of herbicides is one valid alternative for substituting rural labor in clearing projects of forest areas.

The objectives of the experiment were (a) to determine the effect of DCPA and Oryzalin in content of N, P, K, Ca and Mg in Eucalyptus saligna Smith leaves; (b) to observe the efficiency of dosage levels of cited herbicide products in the control of vegetation harmful to the Eucalyptus saligna Sm: and (c) to verify degrees of toxidity in the dosage of the herbicide products in the initial growth of Eucalyptus saligna Smith.

The experiment was installed on the "Santa Terezinha" Farm, Mogi Guaçu municipality, state of São Paulo. The experimental scheme was a $2 \times 3$ factorial with two experimental test groups and four repetitions. The treatments consisted of $1.50,3.00$ and $4.50 \mathrm{~kg} / \mathrm{ha}$ of Oryzalin and 3.75, 7.50 and $11.25 \mathrm{~kg} / \mathrm{ha}$ of DCPA. Each treated parcel contained ten plants, arranged 
in rows. One experimental plot was weeded, while the second was not. The commercial product Surflan containing 75\% Oryzalin and Dacthal containing 75\% DCPA, were the sources of the herbicides Dryzalin and DCPA.

Application of the herbicides was at post-emergence for the Eucalyptus plant, and at pre-emergence for invading plants.

Collection of Eucalyptus saligna Smith leaves for foliage analysis were realized 60, 120 and 180 days after seeding. Visual evaluations in controlling invading plants and injury to the Eucalyptus saligna Sm. were undertaken 30, 60, 90 and 180 days following the initial planting. Invading plants were counted 30 days after planting.

It was concluded according to the condition of the experiment, that the levels of NPK, Ca and Mg in the leanes of Eucalyptus saligna Smith were not modified the herbicids oryzalins and DCPA when compared with the check. On the other hand, different levels of the herbicid DCPA, caused modification in the $P$ content and different dosage of oryzalin caused modifications in $P$ and $C a$ content 120 after planting. The levels used of the herbicid DCPA also caused change in the $K$ content 180 days after planting.

The height and diameter of the tree tops of Eucalyptus saligna Smith were not modified the average levels of the herbicids oryzalin and OCPA however, the herbicid DCPA at $4.5 \mathrm{~kg} / \mathrm{ha}$ caused reductions on the diameter of the top of the trees.

Visual evaluation to determine the degree of damage, showed that 30 and 60 days after planting, the treatments did not extribit any kind of damage. Ninety and 120 days after planting, the $4.5 \mathrm{~kg} / \mathrm{ha}$ of oryzalin and the $11.25 \mathrm{~kg} / \mathrm{ha}$ of DCPA caused slightly degrees of damage to the plants.

To control most of the weed and in all period of study disregarding the levels oryzalin was more efficient than, DCPA, that is, 30, 60, 90 and 120 days after planting. 


\section{LITERATURA CITADA}

ALLEN, M.G. e D.F. REID, 1973. Further experiments with 2,6 chlorothiobenzamide (chlorothiamid) in planted areas of softwoods. In: Proceeding of the 11th British Weed Control Conference, London. Apud Weed Abstracts, $22(8): 179$.

AHRENS, J.F., 1974. Weed control in field-grown chrysantemus. In:

Proceedings of the Northeastern Weed Science Society of Philadelfia, 28 : 86-94. Apud Weed Abstracts, 24:654, 1975.

ALTHEN, F.W., 1970. Methods for successful afforestation of a weed-infested day soil. Forestry Chronicle, Toronto, 46(2): 139-43.

ALVES, A., 1974. O efeito herbicida em ervas daninhas. Atualidades Agronô micas, São Paulo, 2(8):34-36.

AREND, J.L. e E.I. ROE, 1961. Releasing sonifers in the Lake States with chemicals. Washington, DC, Department of Agriculture, 22 p. (Agriculture Randbook, $n^{8}$ 185).

AUDUS, I.J., ed. 1964. The Physiology and Biochemistry of Herbicides. Lon don, Academic Press, 555p. 
AZZI, G.M. e J. FERNANDES, 1966. Métodos de julgamento do efeito herbicida. In: VI Seminário Brasileiro de Herbicidas e Ervas Daninhas, Sete Lagoas, p. $21-19$.

BACK, P.V., 1972. Danson gun control. Queensland Agricultural Journal, Brisbane, $98(11): 579-586$.

BAGAEV, V.B. e Y.P. ZHUKOV, 1974. Plant reaction to herbicides at different fertilizer levels. Dok Zady Tskha 203:153-167. Apud Weed Abstracts, 24: 1383, 1975.

BAGLEY, W.P., 1966. Herbicides for weed control in forest and windbreak tree plantations. In: 6: Congresso Florestal Mundial, Madrid, p. 1-9.

BAZAN, L.A.C. e K. MINAMI, 1974. Resultados preliminares sobre testes de herbicidas em eucalipto. IPEF, Piracicaba (8):47-48。

BRASIL, U.M.; P.S. FERNANDER; J.W. SIMÕES e J.E。F。FERREIRA, 1976。 Emprego de herbicidas na implantação de povoamentos de Eucalyptus saligna Smith. TPEF, Piracicaba (13): 123-134。

BINGHAN, S.W., 1968. Economic evaluation for weed control in field lined wood ornamental nursery crop. Proceedings of the American Society for Horticultural Science, Geneva, NY, 92:704-712.

BINGHAN, S.W. e J.R. JONES, 1967. Phytotoxicity of certain herbicides to several wood ornamentals. Proceedings of the American Society for Horticultural Science, Geneva, NY, 91:786-791.

BOULANGER, J.; Van ZUIJLEN; DINH-MGOCXUAN e E. GRAMAIN, 1973. Chemical reeding of fibre Hibiscus in West Africa. Coton et Fibres Tropicales, Paris, $28(4): 569-578$.

BRASIL. Servico Nacional de Pesquisas Agronômicas. Comissão de Solos, 1960. Levantamento de reconhecimento dos solos do Estado de São Paulo. Rio de Janeiro, $634 \mathrm{p}$. (Boletim 12). 
BROWN, R.M., 1972. Further trials with atrazine for controlling grass weed in British forestry. In: Proceedings of the 11th. British Weed Control Conference, London. Apud Weed Abstracts, $22(8): 179,1973$.

BURKHALTER, A. e M.C. CARTER, 1969. Ribonuclease levels and resistance of woody plants to 2-4,0. Weed Science Soc. America, n. 56. Apud Forestry Abstracts, 33: 906, 1972.

CAMARGO, P.M., Coord., 1971. Texto Bäsico de Controle Quỉmico de Plantas Daninhas. 3a. ed. Piracicaba, ESALQ, 432 p.

CHURCH, J.A. e.A. BOYER, 1971. Site preparation for forest planting. Proceedings of the 24th New Zealand Weed and Pest Control Conference, p. 17-20. Apud Weed Abstracts, 21(2):132, 1972.

COELHO, J.P. e A.A. VIANA, 1966. Controle de ervas daninhas em pré-plantio na cultura de couve-flor. In: Anais do VI Seminário Brasileiro de Herbi cidas e Ervas Daninhas, Sete Lagoas, p. 251-255.

CRAFTS, A.S., 1967. The Chemistry and Mode of Action of Herbicides. New York, Interscience, $268 \mathrm{p}$.

DETROUX, L. e J. GOSTINCHAR, 1967. Los Herbicidas y Su Empleo. Barcelona, Oikos-tan, $474 \mathrm{p}$.

DHILLON, $P_{.} ; W_{0}$. BYRNES e C. MERRITT, 1967. Simazine and phosphorus interactions in red pine seedling. Weeds, Ithaca, NY, 15(4): 339-343.

DORSSER, J.C., 1969. Nursery weed control. Dep. Forest Research Institute New Zealand: 35-36. Apud Weed Abstracts, 20(2): 102, 1971.

DOWLER, C.C., 1970. Effect of aerially-applied herbicides on Texas and Puerto Rico forests. Weed Science, Ithaca, 18(1):164-168.

DUAL purpose weed killer tested in forest nerseries, 1966. Crops and Soils, Madison, 18(7): 21 . 
ELANCO INTERNACIONAL, 1968. Ryzelan: An experimental herbicide for the control of weed in transplanted rice.3p. (Technical report)

FITZGERALD, C.M. e W.H. MCCOMB, 1970. Domage to pine released from herdwood competition by 2,4-D. Joumal of Forestry, Washington, 68(3): 164-165.

FLINTA, C:M., 1960. Practicas de Plantación Forestal en América Latina. Rome, FAO, 497 p. (Cuadernos de fomento forestal $n^{8} 15$ ).

FORSTER, R., 1974. Uso de Herbicidas na Agricultura: Notas de aulas. Picicaba, ESALQ/USP. (Curso de Matologia).

FORSTER, R。 e A. ALVES, 1975. Herbicidas: como controlar as ervas daninhas. Granja, Porto Alegre (329): 1-29.

FURLGERTON, T.M. 1969. The herbicide effect of DCPA on the establishment and winter hardness of bermuda grass. Ph.D. Tesis - Univ. of Arkansas, p. 65. Apud Weed Abstracts, 20(4): 248, 1971.

GOEBEL, N.B., 1970. Control of black Jack oak with Dybar in South Carolina Piemont. Clemson University, Forest Research Service, Clemson College, ก. 19. $11 \mathrm{p}$.

GODOY, H. e A.A. ORTOLANI, (s.d.). Carta Climätica do Estado de São Paulo. Campinas, Instituto Agronōmico.

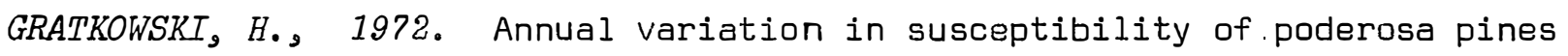
to phenoxy herbicides. Research Progress Report Western Society of Weed Sciences: 20-21. Apud Weed Abstracts, 20(10): 246, 1973.

GROVER, R., 1967. Effects of chemical weed control on the growth patterns of conifer transplants. Weed Research, oxford, 2(2): 155-163.

HARRINGTON, G.M., 1970. The effect of picloran on Acacia hookil: A summary of experiments carried out in Ankole. Uganda. 4th East African Herbicide Conference, Arusha, p. 11. Apud Weed Abstracts, 20(3): 160, 1971. 
HARVEY, R.G., 1973a. Relative phytotoxicities of dinitroaniline herbicides. Weed Science, Ithaca, NY, 21(6): 517-520.

HARVEY, R.G., 1973b. Comparision of twelve dinitroaniline herbicides. Weed Science, Ithaca, NY, 21(6): 512-516.

IRLANDA. Ministry of Agriculture for Northerm Ireland, 1970. Effect of herbicide and fertilizers on growth and nutrient uptake of Sitka spruce (Picea sitchensis). Annual Report on Research and Technical Work, p. 37. Apud Weed Abstracts, 21(5): 381, 1972.

IYER, J.G.; G. CHERSTER e S.A. WILDES, 1969. Chlorthal degradation in soil and its uptake by pine seedlings. Weede Research, Oxford, 9(1): 53-61.

JOHNSON, C.M. e A. ULRICH, 1959. Analitical methods. Bulletin of the Califormia Agricultural Experimental Station, Berkeley, $n^{8} 766$.

JOHNSON, B.J., 1973. Herbicides, springging rates ant nitrogen treatments for stablishment of Tifwoay bermuda grass. Agronomy Jourmal, Madison, $65(6)$ : 969-972.

KLINGMAN, G.C., 1961. Weed Control: As a Science. New York, Wiley. 421 p. KLINGMAN, G.C.; F.M. ASHTON e C.J. NOORDHOFF, 1975. Weed Science: Principles and Pratices. New York, Wiley. $431 \mathrm{p}$.

KOGAN, M.A.; T. MURAOKA; V.F. NASCIMENTO FILHO e A.M.L. NEPTUNE, 1973. Influence of 2,4-D on the absorption of phosphorus by barley roots using ${ }^{32} P$ as tracer. Agricultura Técnica, Santiago de Chile, 33(4):173-175. Apud Fertilizer Abstracts, 8(4): 100, 1975.

KOZLOWSKI, T.T., 1966. Consecuencias en la repoblción forestal. In: $6^{8}$ Congreso Forestal Mundial, Madrid, 38p.

KOZLOWSKI, T.T.; S. SASAKI e J.H. TORRIE, 1967. Effects of temperature on phytotoxicity of monuron, picloram, CDEC, EPTC, CDAA and sesone to young pine seedlings. Silva Fennica, Helsinki, 1(3):13-28. Apud Forestry Abstracts, 29: 107, 1968. 
KUO, P.C. e Y.N. YAD, 1971. Test of 2,4-D and atrazine on China - fir transplants. Memoirs of the College of Agriculture National Taiwan University, Taipei, 12(2):125-131. Apud Weed Abstracts, 22(6):118,1973.

KURTH, I.R. e J.C. DORSSER, 1969. Tolerance of ten tree species to propazine, dacthal and linuron pre-emergence sprays on seedbeds. Research Leaflets, Forest Research Institute, New Zealand Forest Service, $n^{8} 26, p .4$. Apud Weed Abstracts, 21(1): 32, 1972.

LOAIZA, G.; V.H.G., 1967. El Efecto del Uso de Herbicidas y Fertilizantes en el Crescimiento Inicial de Pinus caribaea. Morelet var. hondurensis (Sénéclause) Barret et Golfari y Eucalyptus saligna n Plantaciones. Turrialba, Costa Rica, IICA/OEA, 104 p. (Tesis M.Sc.)

LUND-HOIE, J.A., 1969. Uptake, translocation and metabolism of simazine in Norway (Picea abies). Weed Research, Oxford, 9(2): 142-147.

MELLO, H.A.; J. MASCARENHAS SOBRINHO; J.W. SIMÕES E H.T.Z. do COUTO, 1970 . Resultados da aplicação de fertilizantes minerais na produção de madeira de Eucalyptus saligna $\mathrm{Sm}$. em solos de cerrado do Estado de São Paulo. IPEF, Piracicaba, 1: 7-26.

MENEGHEL, D.; F.M. PEREIRA; P.R. MACHADO e R.M. POMPEU, 1976. Oryzalin: HeI bicida para controle das ervas daninhas em cultura de cebola transplantada. In: $16^{8}$ Congresso da Sociedade de Olericultura do Brasil, Lavras, MG, 3p.

MONTOYA, L.A., 1961. Las malas hierbas y su control. In: HARDY, F. ed. Manual de Cacao. Turrialba, Costa Rica, Instituto Interamericano de Ciências Agrícolas. p. 193-205.

NAIR, P.N., 1973. The effects of Gramoxone application on Eupatorium odoratum. Indian Forester, Calcuttá, 99(1): 43-48.

PEEVY, F.A., 1973. Bromacil and picloran under southern upland harwoods. Weed Science, Ithaca, NY, 21(1): 54-56. 
PIMENTEL GOMES, F., 1970. Curso de Estatistica Experimental. 4a. ed. Piracicaba, 429 p.

PRIMO, Y.E., 1958. Herbicidas y Fitorreguladores. Madrid, Aguilar. 241 p. ROBINS, W.W.; A.S. GRAFTS e R.N. RAINOR, 1955. Destmucción de las Malas Hierbas. México, Unión Tipográfica Editorial Hispano Americana. 351 p. RUSS, O.G., 1974. Effects of aplication data on crop responses to herbicide solution combinations. Fertile Solutions, Manhattan, Kansas, $18(4): 24-26$.

SAMPSON, A.W. e A.M. SACHULTZ, 1956. La lucha contra el matoral y los árboles inútle. Unasyzva, Rome, $9(14):$ 5-36.

SCHMIDT, G., 1973. Investigations to determine the most favourable period fọr applying herbicides vased on or containing triazine for weed control in Pinus silvestris plantations on fertile or moderatelu fertile sites without graondwater influence. Sozialistische Forstwirtschaft, 23:119128. Apud Forestry Abstracts, 35: 465, 1974.

SMITH, D.T.; A.F. WIESE e P.W. SANTELMANN, 1973. Weed control research in guar in Texas and Oklahoma 1961-72. Bulletin. Texas Agricultural Experiment Station, College Station, n. 1138, $12 \mathrm{p.}$

VEIGA, R.A.A., 1968. Efeitos de alguns herbicidas sobre desenvolvimento de mudas de Eucalyptus saligna Smith em viveiros, em plantações novas e con trole de ervas daninhas. In: Anais do $1^{8}$ Congresso Florestal Brasileiro, Curitiva, PR, P. 255-267.

VEIGA, R.A.A., 1969. Fitotoxidade em plantações novas de eucalipto pelo uso de herbicidas. O Solo, Piracicaba, 61(2): 33-38.

WILD, S.A., B.H. SHOW e A.V. FEDKENHEWER, 1968. Weeds as a factor depressing forest growth. Weed Research, Oxford, 8(3): 196-204.

WINGET, C.H.; T.T. KOZLOWSKI e J.E. KUNTZ, 1961. Effect of herbicides on red pine seedlings and transplants. Forest Research Note. Wiscosin College of Agriculture, n.69, 5p. Apud Forestry Abstracts, 23: 632, 1962. 
WISE, A.F.; E.W. CHENAUT e E.B. HUDSPETH, 1969. Incorporation of pre-plant herbicides for cotton. Weed Science, Ithaca, NY, 17(4): 481-483.

WOOD, I.M.W., 1970. Herbicides for weed control in grain sorghum crops in the Northern Territory. Australian Journal of Experimental Agriculture and Animal Husbandry, 10(46): 588-591. Apud Weed Abstracts, 20(3): 150 , 1971.

WOODFORD, E.K. e S.A. EVANS, 1965. Weed Control Handbook. 4th ed. Oxford, Blackwell Scientific Publications. $434 \mathrm{p}$. 